\title{
FRAPCON-3: A Computer Code for the Calculation of Steady-State, Thermal-Mechanical Behavior of Oxide Fuel Rods for High Burnup
}

Manuscript Completed: November 1997

Date Published: December 1997

Prepared by

G. A. Berna/GABC

C. E. Beyer/PNNL

K. L. Davis/INEEL

D. D. Lanning/PNNL

Pacific Northwest National Laboratory

Richland, WA 99352

Idaho National Engineering and Environmental Laboratory

Idaho Falls, ID 83415

Subcontractor:

Gary A. Berna Consulting

2060 Sequoia Drive

Idaho Falls, ID 83404-6131

DETRIOITON OF THS DOCUMENT IS VUHATED

H. Scott, NRC Project Manager

Prepared for

Division of Systems Technology

Office of Nuclear Regulatory Research

U.S. Nuclear Regulatory Commission

Washington, DC 20555-0001

NRC Job Code W6200 


\section{DISCLAIMER}

Portions of this document may be illegible electronic image products. Images are produced from the best available original document. 


\section{DISCLAIMER}

This report was prepared as an account of work sponsored by an agency of the United States Government. Neither the United States Government nor any agency thereof, nor any of their employees, makes any warranty, express or implied, or assumes any legal liability or responsibility for the accuracy, completeness, or usefulness of any information, apparatus, product, or process disclosed, or represents that its use would not infringe privately owned rights. Reference herein to any specific commercial product, process, or service by trade name, trademark, manufacturer, or otherwise does not necessarily constitute or imply its endorsement, recommendation, or favoring by the United States Government or any agency thereof. The views and opinions of authors expressed herein do not necessarily state or reflect those of the United States Government or any agency thereof. 


\begin{abstract}
FRAPCON-3 is a FORTRAN IV computer code that calculates the steady-state response of light water reactor fuel rods during long-term burnup. The code calculates the temperature, pressure, and deformation of a fuel rod as functions of time-dependent fuel rod power and coolant boundary conditions. The phenomena modeled by the code include 1) heat conduction through the fuel and cladding, 2) cladding elastic and plastic deformation, 3) fuel-cladding mechanical interaction, 4) fission gas release, 5) fuel rod internal gas pressure, 6) heat transfer between fuel and cladding, 7) cladding oxidation, and 8) heat transfer from cladding to coolant. The code contains necessary material properties, water properties, and heat-transfer correlations. The codes' integral predictions of mechanical behavior have not been assessed against a data base, e.g., cladding strain or failure data. Therefore, it is recommended that the code not be used for analyses of cladding stress or strain. FRAPCON-3 is programmed for use on both mainframe computers and UNIX-based workstations such as DEC 5000 or SUN Sparcstation 10. It is also programmed for personal computers with FORTRAN compiler software and at least 8 to 10 megabytes of random access memory (RAM).
\end{abstract}

The FRAPCON-3 code is designed to generate initial conditions for transient fuel rod analysis by the FRAPTRAN computer code (formerly named FRAP-T6). 



\section{Contents}

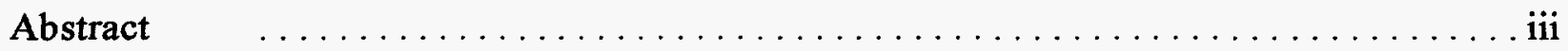

Executive Summary $\ldots \ldots \ldots \ldots \ldots \ldots \ldots \ldots \ldots \ldots \ldots \ldots \ldots \ldots \ldots \ldots \ldots$

Acknowledgments $\ldots \ldots \ldots \ldots \ldots \ldots \ldots \ldots \ldots \ldots \ldots \ldots \ldots \ldots \ldots \ldots \ldots$

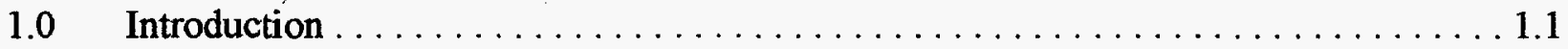

1.1 Objectives of the FRAPCON Series $\ldots \ldots \ldots \ldots \ldots \ldots \ldots \ldots \ldots \ldots$

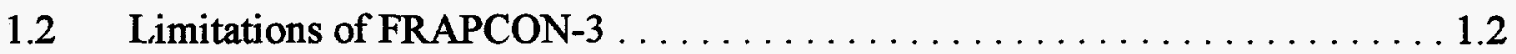

1.3 Report Outline and Relation to Other Reports . . . . . . . . . . . 1.3

2.0 General Modeling Descriptions $\ldots \ldots \ldots \ldots \ldots \ldots \ldots \ldots \ldots \ldots \ldots \ldots \ldots \ldots$

$2.1 \quad$ FRAPCON-3 Solution Scheme $\ldots \ldots \ldots \ldots \ldots \ldots \ldots \ldots \ldots \ldots \ldots \ldots \ldots$

2.2 Coupling of Thermal and Mechanical Models $\ldots \ldots \ldots \ldots \ldots \ldots \ldots$

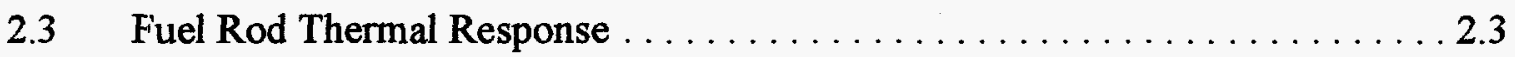

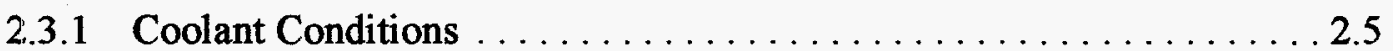

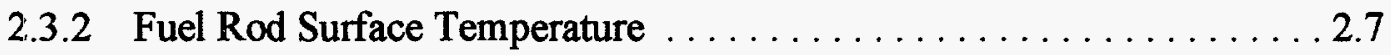

2.3.3 Cladding Temperature Drop . . . . . . . . . . . . . . . 2.9

2.3.4 Fuel-Cladding Gap Temperature Drop . . . . . . . . . . . . . 2.9

2.3.4.1 Radiation Heat Transfer . . . . . . . . . . . . . 2.10

2.3.4.2 Conduction Through the Interfacial Gas . . . . . . . . 2.11

2.3.4.3 Conductance Through Points of Contact . . . . . . . 2.12

2.3.5 Fuel Pellet Heat Conduction Model . . . . . . . . . . . . . . . 2.13

2.3.5.1 The Finite Difference Approach . . . . . . . . . . 2.14

2.3.5.2 Mesh Point Layout . . . . . . . . . . . . . . 2.15

2.3.5.3 Difference Approximation at Internal Mesh Points . . . . . 2.17

2.3.5.4 Difference Approximation at Boundaries . . . . . . . . 2.18

2.3.5.5 Thermal Conductivity and Iteration Procedures . . . . . . . . 2.19

2.3.5.6 The Finite Difference Temperature Calculation . . . . . . 2.22

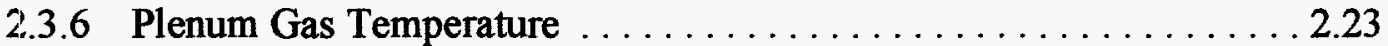

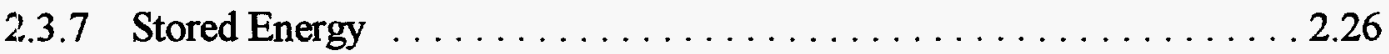

2.4 Fuel Rod Mechanical Response $\ldots \ldots \ldots \ldots \ldots \ldots \ldots \ldots \ldots \ldots \ldots \ldots \ldots \ldots \ldots .26$

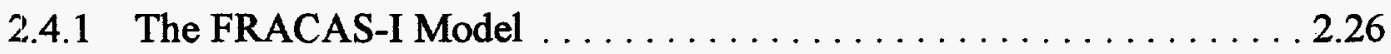

2.4.1.1 General Theory and Method of Solution . . . . . . . 2.27

2.4.1.1.1 General Considerations in Elastic-Plastic

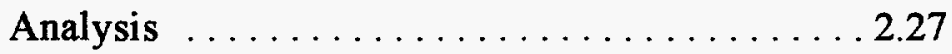

2.4.1.1.2 Extension to Creep ................ 2.33

2.4.1.2 Rigid Pellet Cladding Deformation Model $\ldots \ldots \ldots \ldots . . .2 .37$

2.4.1.2.1 Cladding Deformation Model . . . . . . . . . 2.38

2.4.1.2.2 Rigid Pellet Fuel Deformation in FRACAS-I . . . 2.52 
2.4.1.2.3 Radial Deformation. .............. 2.53

2.4.1.2.4 Axial Deformation ................. 2.53

2.4.1.2.5 Fuel Relocation.................. 2.54

2.5 Fuel Rod Internal Gas Pressure Response ................................................56

2.5.1 Fuel Rod Internal Gas Pressure.....................................................2.56

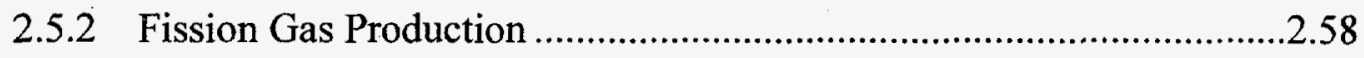

2.5.3 Fuel Rod Gas Release ................................................................2.58

2.5.3.1 ANS-5.4 Gas Release Model .............................................2.59

2.5.3.2 Modified Forsberg Massih Model.........................................2.59

2.5.3.3 Low Temperature Fission Gas Release Model at High

Burnup........................................................................2.60

2.5.3.3.1 Grain Boundary Accumulation and Re-Solution . 2.61

2.5.3.3.2 Diffusion Constant ................ 2.63

2.5.3.3.3 Gas Release.................. 2.63

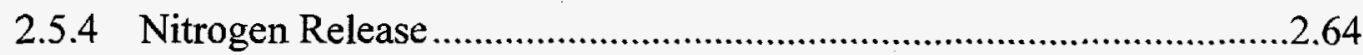

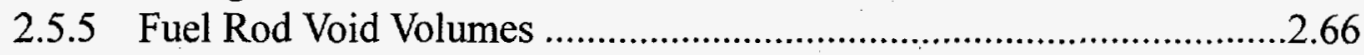

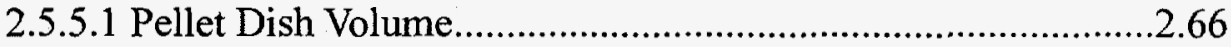

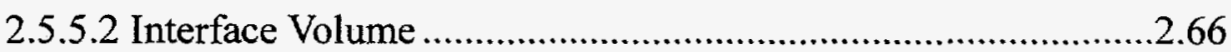

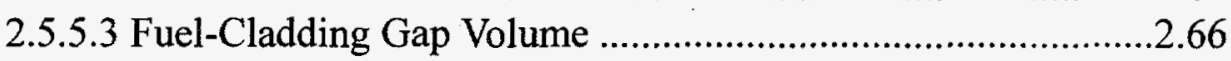

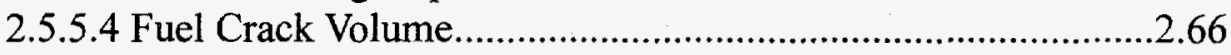

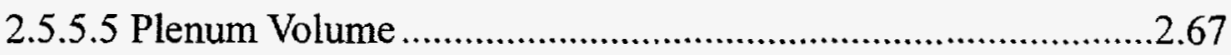

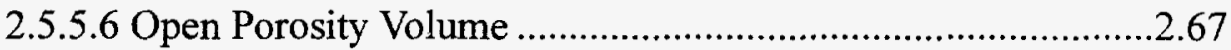

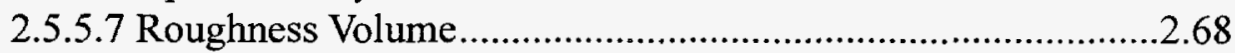

2.5.5.8 Central Hole Volume......................................................... 2.68

2.6 Waterside Corrosion and Hydrogen Pickup.................................................2.68

2.6.1 PWR and BWR Waterside Corrosion Models ..................................2.68

2.6.2 Hydrogen Pickup Fraction ........................................................2.69

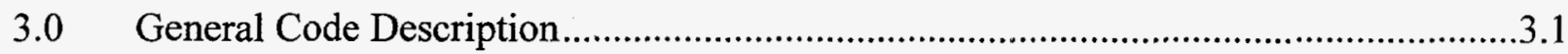

3.1 Code Structure and Solution Routine ........................................................

3.1.1 Code Structure ..........................................................................

3.1.2 Solution Scheme ........................................................................ 3.1

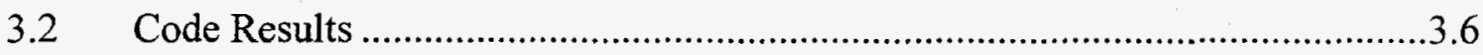

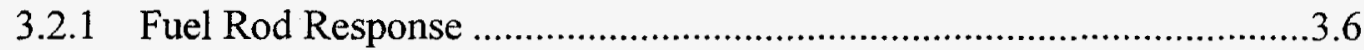

3.2.2 Plot Package ............................................................................... 3.7

3.2.3 FRAPTRAN Initialization ........................................................ 3.7

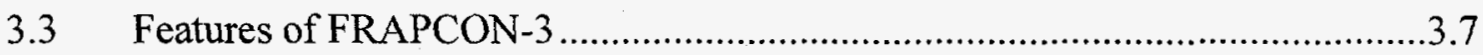


References

Appendix A:Input Instructions for the FRAPCON-3 Code A.1

Appendix B:List of Subroutines in FRAPCON-3

B.1

\section{Figures}

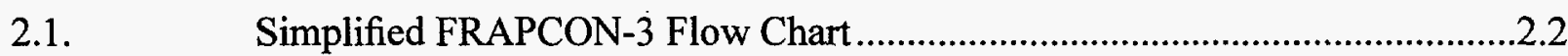

2.2. Flow Chart of the Fuel and Cladding Temperature Calculation ...........................

2.3. Schematic of the Fuel Rod Temperature Distribution ........................................

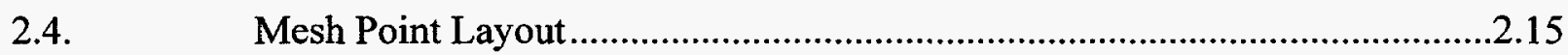

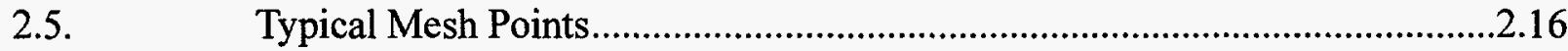

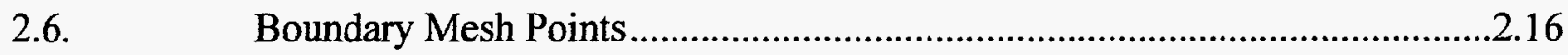

2.7. Typical Isothermal Stress-Strain Curve ......................................................2.29

2.8. Schematic of the Method of Successive Elastic Solutions ...............................2.33

2.9. Cladding Creep Strain as a Function of Time and Hoop Stress........................2.36

2.10. Fuel Rod Geometry and Coordinates.............................................................40

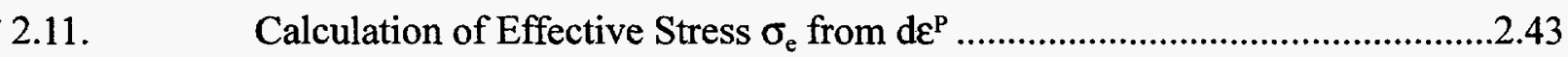

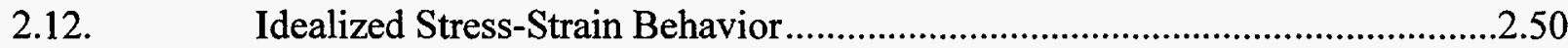

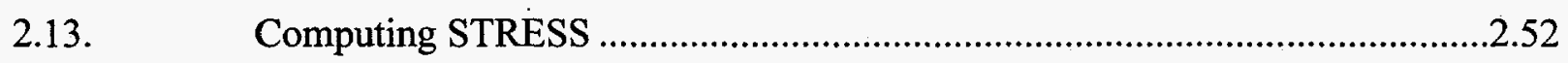

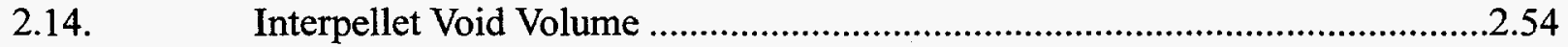

2.15. Power and Burnup Dependence of the FRAPCON-3 Relocation Model ........2.55

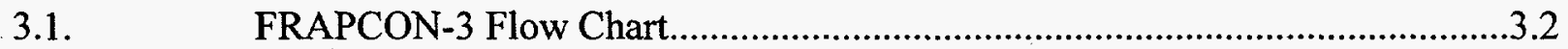

3.2. Calling Sequence for FRAPCON-3 Subroutines ..............................................3.3

\section{Tables}

2-1. Summary of FRACAS-I Governing Equations …........................................2.31

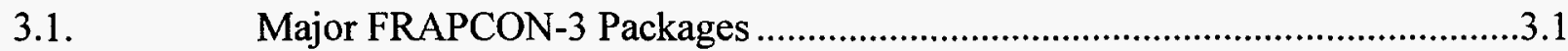

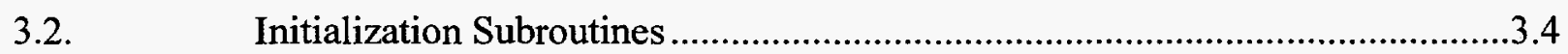

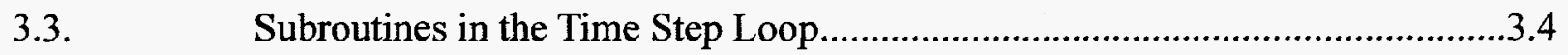

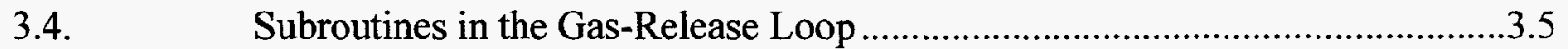

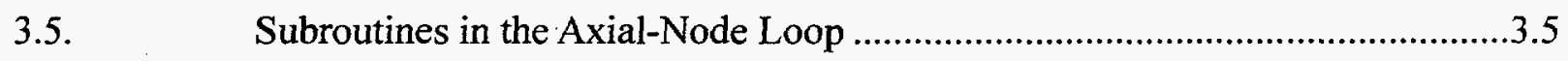

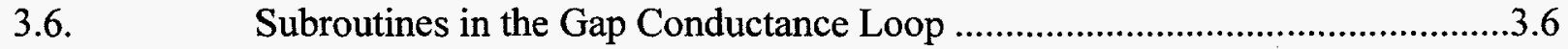

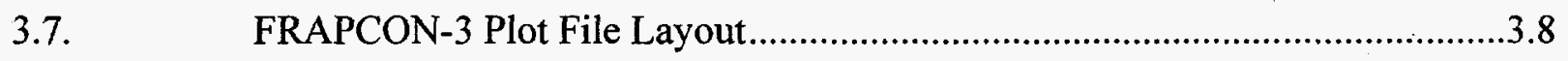




\section{Executive Summary}

A new fuel performance code, FRAPCON-3, has been developed for the Nuclear Regulatory Commission for calculating steady-state fuel behavior at high burnup (up to $65 \mathrm{GWd} / \mathrm{MTU}$, depending on application). The code was developed from Version 1, Modification 5, of the FRAPCON-2 code with two objectives: to simplify the code and extend its predictive abilities to high burnup. This report volume 1) describes the code limitations and structure, 2) summarizes the fuel performance models, and 3) provides the code input instructions and features to aid the user. There are two other volumes of this report: Volume 1 describes the properties and models updated for high burnup application, and Volume 3 provides a code assessment based on comparisons of code predictions to integral performance data up to high burnups. The updated FRAPCON-3 code is intended to replace the earlier codes FRAPCON-2 and GAPCONTHERMAL-2.

The code is designed to perform steady-state fuel rod calculations and generate initial input conditions for FRAPTRAN for transient analyses. The code uses a single channel coolant enthalpy rise model. The FRAPCON-2 fuel pellet heat conduction model was replaced with a finite difference heat conduction model, similar to RELAP5 and FRAPTRAN, that uses a variable mesh spacing to accommodate the power peaking at the pellet edge that occurs in high burnup fuel. The fuel-cladding contact gap conductance model was modified. A new model from the Institute for Tranuranium Elements is used to calculate the radial power peaking in high burnup fuel. A new model for fission gas release based on Booth type diffusion with grain boundary gas accumulation and resolution is used to calculate gas release during steady-state power and slow power ramp operation. In addition, new fuel behavior models for thermal conductivity (includes burnup degradation), swelling, cracking, and relocation have been introduced. New cladding behavior models for corrosion and hydriding, axial growth, and mechanical properties have been introduced. The code continues to use the MATPRO material properties package as did the earlier versions of FRAPCON. 


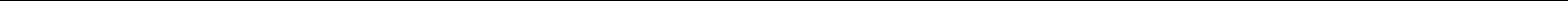




\section{Acknowledgments}

The authors acknowledge Mr. Harold Scott of the U.S. Nuclear Regulatory Commission for his technical guidance on the FRAPCON-3 code improvement project that resulted in this report. Also, we acknowledge Edna Johnsen of INEEL for work on the graphics, typing, and organizing of this report. 


\subsection{Introduction}

\subsection{Objectives of the FRAPCON Series}

The ability to accurately calculate the performance of light water reactor (LWR) fuel rods under long-term burnup conditions is a major objective of the reactor safety research program being conducted by the U.S. Nuclear Regulatory Commission (NRC). To achieve this objective, the NRC has sponsored an extensive program of analytical computer code development, as well as both in-pile and out-of-pile experiments to benchmark and assess the analytical code capabilities. The computer code developed to calculate the long-term burnup response of a single fuel rod is FRAPCON. This report describes FRAPCON-3, the third released code of the FRAPCON series.

FRAPCON-3 is an analytical tool that calculates LWR fuel rod behavior when power and boundary condition changes are sufficiently slow for the term "steady-state" to apply. This includes situations such as long periods at constant power and slow power ramps that are typical of normal power reactor operations. The code calculates the variation with time of all significant fuel rod variables, including fuel and cladding temperatures, cladding hoop strain, cladding oxidation, fuel irradiation swelling, fuel densification, fission gas release, and rod internal gas pressure. In addition, the code is designed to generate initial conditions for transient fuel rod analysis by FRAPTRAN, the successor to the FRAP-T6 ${ }^{1}$ code, the companion transient fuel rod analysis code.

FRAPCON-3 is linked with a MATPRO² materials properties package, modified to include high burnup properties. The MATPRO subcode is composed of modular subroutines that define materials properties for temperatures ranging from room temperatures to temperatures above melting. Each subroutine defines only a single material property. For example, MATPRO contains subroutines defining fuel thermal conductivity as a function of fuel temperature, fuel density, and burnup; fuel thermal expansion as a function of fuel temperature; and the cladding stress-strain relation as a function of cladding temperature, strain rate, cold work, hydride content, and fast neutron fluence.

The development of the FRAPCON series was a joint effort of Idaho National Engineering and Environmental Laboratory (INEEL) and Pacific Northwest National Laboratory (PNNL). ${ }^{a}$ FRAPCON-1 was developed first. ${ }^{3}$ The basis of the FRAPCON-1 code is the FRAP-S $3{ }^{4}$ code developed at INEEL, but with two major changes. First, the code was modified for dynamic dimensioning to increase the number of computer facilities on which the code could be installed. Second, the FRAP-S3 temperature subcode was replaced by a more efficient subcode developed at PNNL. The next version, FRAPCON-2,5 involved improvements that added much complexity

a. INEEL and PNNL are operated for the U.S. Department of Energy by Lockheed Martin Idaho Technologies and Battelle Memorial Institute, respectively. 
to the code. The major improvements in FRAPCON-2 with respect to FRAPCON-1 include three advanced mechanics options, four additional fission gas release options, and an uncertainty analysis option. ${ }^{6}$

FRAPCON-3 takes a major step toward code simplification by removing unneeded capabilities and incorporating some code enhancements. Simplifications include removing all but the FRACAS-I mechanical model, removing all but the ANS $5.4^{7}$ fission gas release model, removing the automated uncertainty model, removing the FRAIL model, and simplifying both the code input and output. Enhancements include 1) incorporating a finite difference heat conduction model required for enhanced spatial definition of heat generation and conduction, 2) adding a two-stage fission gas release model, 3) adding high burnup fission gas release and thermal conduction models to allow the code to model fuel rod behavior to burnups of 65 to $75 \mathrm{GWd} /$ MTU (depending on code application), and 4) incorporating a UNIX-based graphics package. The code retains the FRAPCON-2 capability to perform evaluation model analyses using inputs described in Appendix Section A. This option has not been tested.

\subsection{Limitations of FRAPCON-3}

The code has inherent limitations. The major limitations are

1. The thermal models of the code are based on steady-state conditions and equations, and calculate only radial heat flow. Similarly, the gas release models are based on steady-state and slow power ramp data and do not reflect release rates expected for rapid power changes. Therefore, changes in linear heat generation rate should not exceed $1.5 \mathrm{~kW} / \mathrm{ft}$ between time steps, and time steps should be $\geq 0.1$ day, but $\leq 50$ days. (Analysis for thermal response alone can involve time steps as low as 0.001 day.) The FRAPTRAN code is recommended for modeling of transients or power ramping on the order of a few minutes or less.

2. Only small cladding deformations ( $<5 \%$ strain) are meaningful. All of the thermal and mechanics modeling assumes an axisymmetric fuel rod. The fuel rod is assumed to have no axial constraints. No assessment has been performed for cladding temperature $>700 \mathrm{~K}$ or for fuel centerline temperature at or above the melting temperature.

3. The codes' ability to predict cladding strains resulting from pellet - cladding mechanical interaction has not been assessed. As currently configured the code is not expected to provide accurate predictions of power hysteresis or strain relaxation effects. Future coding modifications will concentrate on improving the cladding mechanical modeling and predictions.

4. The code has not been assessed against mixed oxide data and the model for calculating the radial power profile is not able to accurately model mixed oxide fuel. Very limited assessment has been performed for fuel rods containing gadolinia. 


\subsection{Report Outline and Relation to Other Reports}

Section 2 and Section 3 of this report deal with the modeling concepts and the code description, respectively. The new high burnup models included in either FRAPCON-3 or MATPRO-11, newly revised, are fully documented in a separate report. ${ }^{8}$ Instructions for creating an input file are discussed in Appendix A. The reader is cautioned that, although the thermal and mechanical models are described separately, they actually are highly interrelated. Section 2.2 is included to outline these interrelationships.

This report does not present an assessment of the code performance with respect to inreactor data. Critical comparisons with experimental data from well-characterized, instrumented test rods are presented in a separate report titled "FRAPCON-3 Integral Assessment." 


\subsection{General Modeling Descriptions}

\subsection{FRAPCON-3 Solution Scheme}

The FRAPCON-3 code iteratively calculates the interrelated effects of fuel and cladding temperature, rod internal gas pressure, fuel and cladding deformation, release of fission product gases, fuel swelling and densification, cladding thermal expansion and irradiation-induced growth, cladding corrosion, and crud deposition as functions of time and fuel rod specific power.

The calculated procedure is illustrated in Figure 2.1, a simplified flowchart of FRAPCON-3. (A detailed flowchart is provided in Section 3 ). The calculation begins by processing input data. Next, the initial fuel rod state is determined through a self-initialization calculation. Time is advanced according to the input-specified time-step size, a steady-state solution is performed, and the new fuel rod state is determined. The new fuel rod state provides the initial state conditions for the next time step. The calculations are cycled in this manner for the user-specified number of time steps.

The solution for each time step consists of 1) calculating the temperature of the fuel and the cladding, 2) calculating fuel and cladding deformation, and 3) calculating the fission product generation and release, void volume, and fuel rod internal gas pressure. Each of these calculations is made in a separate subcode. As is shown in Figure 2.1, the fuel rod response for each time step is determined by repeated cycling through two nested loops of iterative calculations until the fuelcladding gap temperature difference and internal gas pressure converge.

For the FRACAS-I mechanic model, ${ }^{10}$ the fuel temperature and deformation are alternately calculated in the inner loop. On the first cycle through this loop for each time step, the gap conductance is computed using the fuel-cladding gap size from the previous time step. Then the fuel rod temperature distribution is computed. This temperature distribution feeds the deformation calculation by influencing the fuel and cladding thermal expansions and the cladding stress-strain relation. An updated fuel-cladding gap size is calculated and used in the gap conductance calculation on the next cycle through the inner loop. The cyclic process through the inner loop is repeated until two successive cycles calculate essentially the same temperature distribution.

The outer loop of calculations is cycled in a manner similar to that of the inner loop, but with the amount of internal gas being determined during each iteration. The calculation alternates between the fuel rod void volume-gas pressure calculation and the fuel rod temperaturedeformation calculation. On the first cycle through the outer loop for each time step, the gas pressure from the previous time step is used. For each cycle through the outer loop, the number of gas moles is calculated and the updated gas pressure computed and fed back to the deformation and temperature calculations (the inner loop). The calculations are cycled until two successive cycles calculate essentially the same gas pressure, then a new power-time step is begun. 


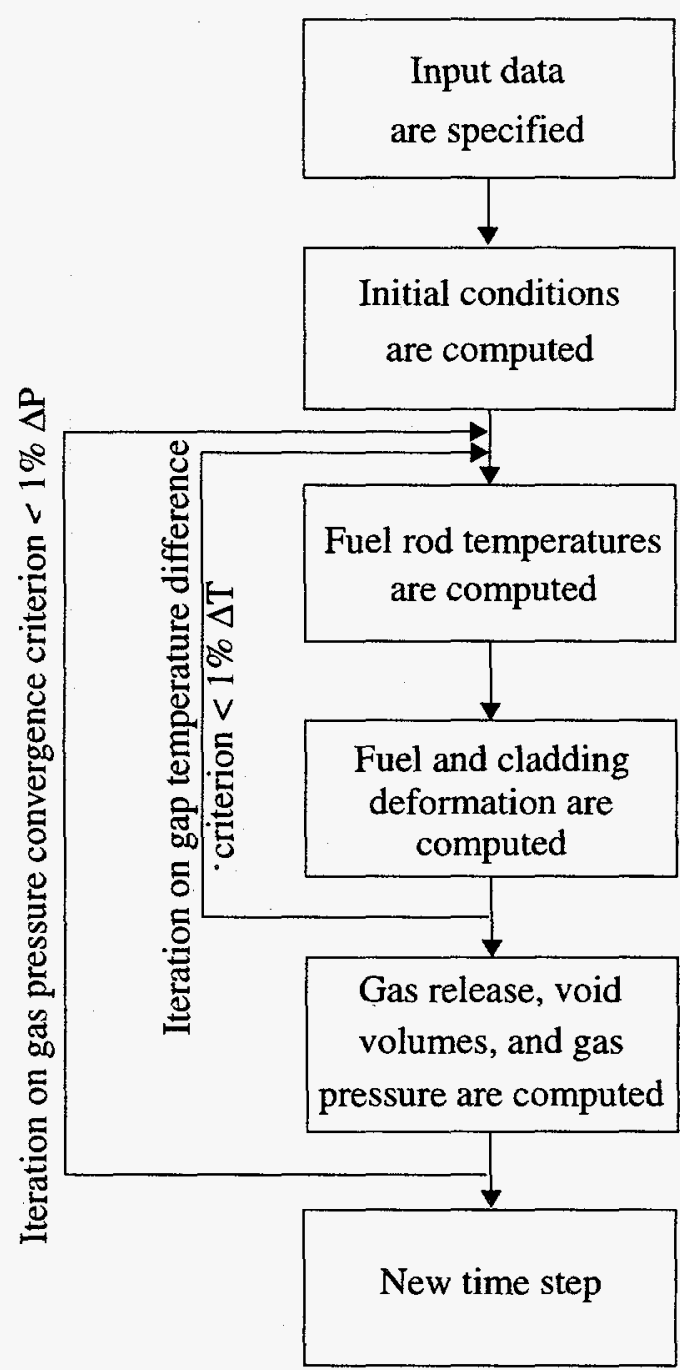

Figure 2.1 Simplified FRAPCON-3 Flow Chart

\subsection{Coupling of Thermal and Mechanical Models}

The close coupling of the thermal modeling and mechanical modeling is the result of the existence of the fuel-cladding gap. As the fuel temperature increases, the extreme stresses resulting from the large temperature gradients in the fuel cause the fuel to crack and relocate. Cracks can be both circumferential and radial, but are predominantly radial. Void space, which is originally in the fuel-cladding gap, is relocated into the fuel as fragments of fuel move outwardly into the fuel-cladding gap. 
As the fuel becomes hotter, the fuel expands, filling some of the voids within the fuel. However, asperities do not align exactly, thereby causing the fuel diameter to appear larger and the fuel to interact with the cladding at a lower power than that expected due to normal expansion (or contraction) mechanisms, including thermal expansion, swelling, and densification.

FRACAS-I allows $50 \%$ of the original fuel surface relocation to be recovered due to fuel swelling before hard contact is established between the fuel and the cladding.

The modeling of the cracked and relocated fuel, both thermally and mechanically, requires accounting for changed fuel-cladding gap size (and hence gap conductance) and the changed fuel pellet diameter as the fuel interacts with the cladding. The fuel surface relocation provides a new fuel-cladding gap size for calculating gap conductance and mechanical interactions. Also considered is the shift of voids from the fuel-cladding gap into the fuel pellet (and the resultant pressure change) and the feedback into the mechanics and thermal calculations.

FRACAS-I uses the relocated fuel-cladding gap size for the thermal calculations and makes partial use of the fuel surface relocation in the mechanics calculation, i.e., when $50 \%$ of the relocation is recovered, the code assumes the pellet to be a rigid structure, and, therefore, hard contact is assumed between the fuel and cladding.

\subsection{Fuel Rod Thermal Response}

The temperature distribution throughout the fuel and the cladding is calculated at each axial node. A simplified flowchart of the temperature distribution solution is shown in Figure 2.2. A schematic drawing of the temperature distribution at an arbitrary axial node is shown in Figure 2.3 .

The models used in the fuel rod temperature calculations assume a cylindrical fuel pellet located symmetrically within a cylindrical fuel rod surrounded by coolant. User supplied boundary conditions (coolant inlet temperature, coolant channel equivalent heated diameter, and time coolant mass flux) and the user-supplied axial linear heat generation rate are used to calculate the coolant bulk temperature, $T_{b}$, using a single channel coolant enthalpy rise model. A film temperature rise, $\Delta \mathrm{T}_{\mathrm{f}}$, is then calculated from the coolant to the surface of the fuel rod through any crud layer which may exist. The cladding inside surface temperature, $T_{\mathrm{ci}}$, is found by calculating the temperature rise across the zirconium oxide and the cladding using Fourier's Law. The temperature rise to the fuel surface is determined from an annular gap conductance model, thereby establishing the fuel surface temperatures $T_{\mathrm{fs}}$. Finally, the temperature distribution in the fuel is calculated, accounting for fuel cracking effects using the fuel surface temperature and assumed symmetry at the centerline as boundary conditions.

The models used in the temperature calculations involve a number of assumptions and limitations. The most important are 


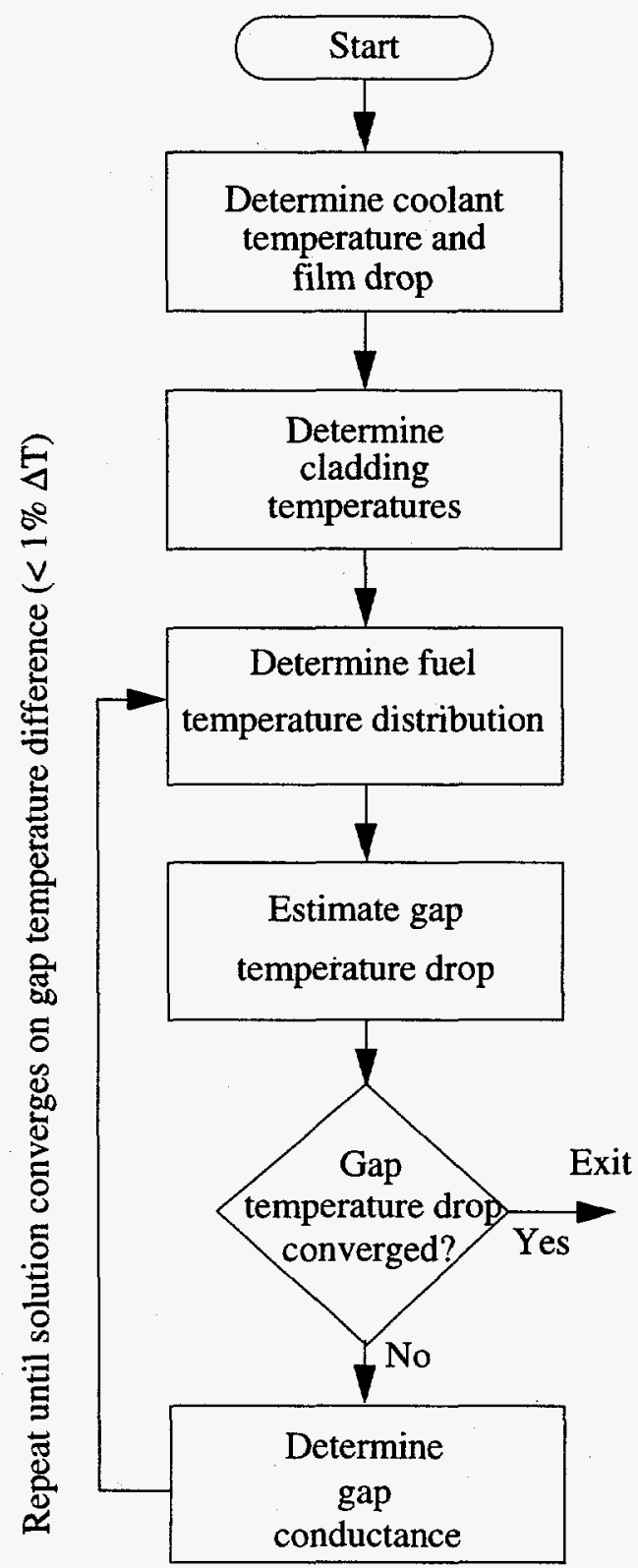

Figure 2.2 Flow Chart of the Fuel and Cladding Temperature Calculation

1. Heat conduction in the axial direction is considered negligible relative to radial heat conduction and is ignored.

2. Heat conduction in the azimuthal direction is ignored (axisymmetric analysis).

3. Constant boundary conditions are maintained during each time step. 


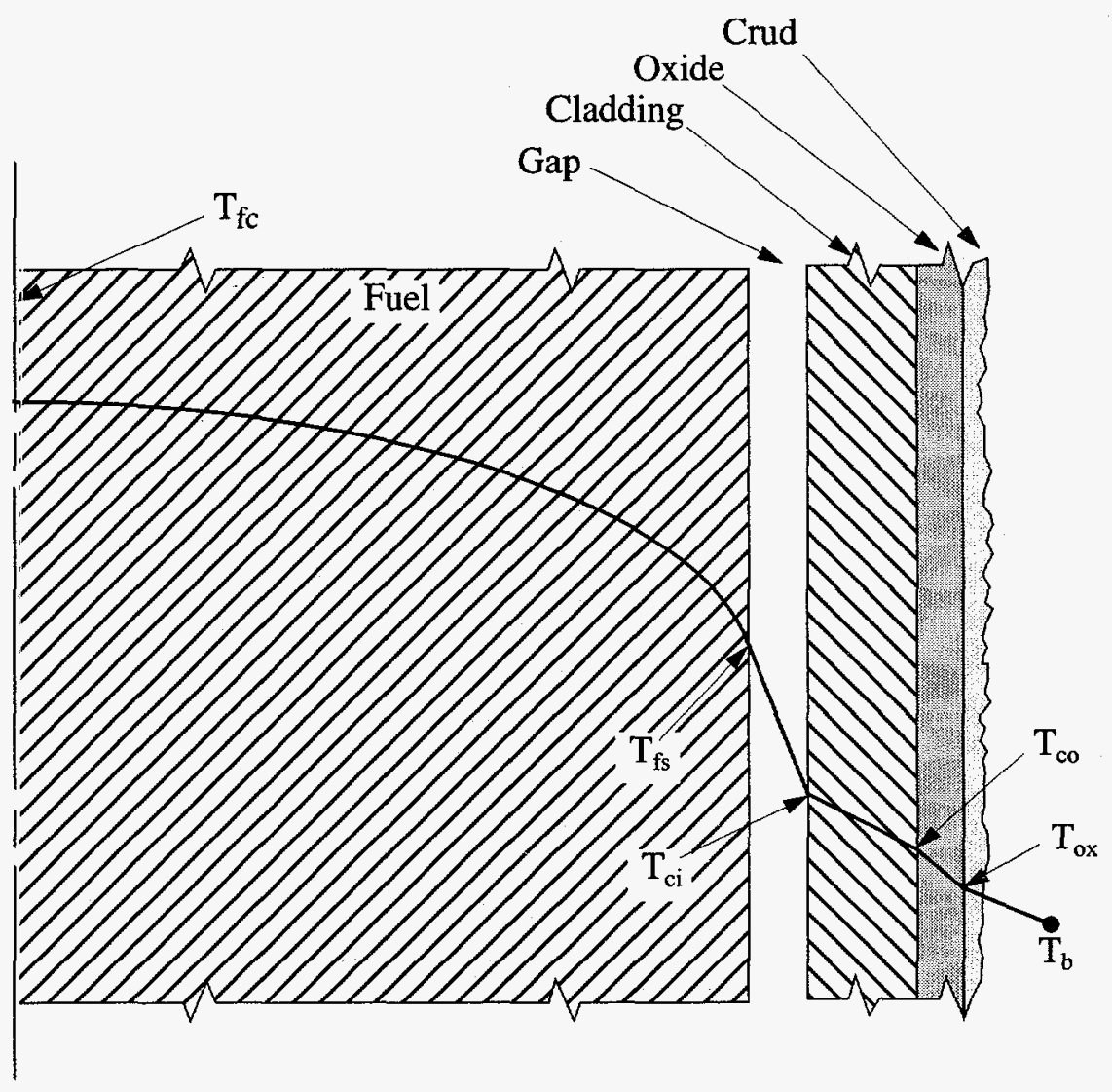

Figure 2.3 Schematic of the Fuel Rod Temperature Distribution

4. Steady-state heat flow is assumed.

5. The fuel rod is a right circular cylinder surrounded by water coolant.

\subsubsection{Coolant Conditions}

FRAPCON-3 calculates bulk coolant temperatures assuming a single, closed coolant channel according to

$$
T_{b}(z)=T_{\text {in }}+\int_{0}^{z}\left[\frac{4 q^{\prime \prime}(z)}{C_{p} G D_{e}}\right] d z
$$


where

$\begin{array}{lll}\mathrm{T}_{\mathrm{b}}(\mathrm{z}) & = & \text { bulk coolant temperature at elevation } \mathrm{z} \text { on the rod axis }(\mathrm{K}) \\ \mathrm{T}_{\text {in }} & = & \text { inlet coolant temperature }(\mathrm{K}) \\ \mathrm{q}^{\prime \prime}(\mathrm{z}) & = & \text { rod surface heat flux at elevation } \mathrm{z} \text { on the rod axis }\left(\mathrm{W} / \mathrm{m}^{2}\right) \\ \mathrm{C}_{\mathrm{p}} & = & \text { heat capacity of the coolant }(\mathrm{J} / \mathrm{kg}-\mathrm{K}) \\ \mathrm{G} & = & \text { coolant mass flux }\left(\mathrm{kg} / \mathrm{s}-\mathrm{m}^{2}\right) \\ \mathrm{D}_{\mathrm{e}} & = & \text { coolant channel heated diameter }(\mathrm{m}) .\end{array}$

Coolant heat capacity is calculated using the following relationships:

$$
\begin{aligned}
\mathrm{C}_{\mathrm{p}} & =2.4 \times 10^{5} \mathrm{~J} / \mathrm{kg} \cdot \mathrm{K} \text { for } \mathrm{T}_{\mathrm{b}}(\mathrm{z})<544 \mathrm{~K} \\
& =2.4 \times 10^{5}\left[1+2.9 \times 10^{-3}\left(1.8 \mathrm{~T}_{\mathrm{b}}(\mathrm{z})-1031\right)\right] \text { for } 544 \mathrm{~K} \leq \mathrm{T}_{\mathrm{b}}(\mathrm{z})<588 \mathrm{~K} \\
& =2.4 \times 10^{5}\left[1+2.9 \times 10^{-3}\left(1.8 \mathrm{~T}_{\mathrm{b}}(\mathrm{z})-979.4\right)\right] \text { for } \mathrm{T}_{\mathrm{b}}(\mathrm{z}) \geq 588 \mathrm{~K} .
\end{aligned}
$$

Coolant channel heated diameter is calculated from rod pitch and diameter using the following relationship:

$$
\mathrm{D}_{\mathrm{e}}=\frac{4.0\left[\left(\mathrm{P}_{\mathrm{pit}}\right)^{2}-\frac{\pi}{4}\left(\mathrm{D}_{\mathrm{o}}\right)^{2}\right]}{\pi \mathrm{D}_{\mathrm{o}}}
$$

where

$$
\begin{array}{lll}
\mathrm{P}_{\text {pit }} & = & \text { rod-to-rod pitch }(\mathrm{m}) \\
\mathrm{D}_{\mathrm{o}} & = & \text { outside cladding diameter }(\mathrm{m}) .
\end{array}
$$




\subsubsection{Fuel Rod Surface Temperature}

The cladding surface temperature at axial elevation $\mathrm{z}$ is taken as the minimum value of

$$
\begin{gathered}
\mathrm{T}_{\mathrm{w}}(\mathrm{z})=\mathrm{T}_{\mathrm{b}}(\mathrm{z})+\Delta \mathrm{T}_{\mathrm{f}}(\mathrm{z})+\Delta \mathrm{T}_{\mathrm{cr}}(\mathrm{z})+\Delta \mathrm{T}_{\mathrm{ox}}(\mathrm{z}) \\
\mathrm{T}_{\mathrm{w}}(\mathrm{z})=\mathrm{T}_{\text {sat }}+\Delta \mathrm{T}_{\mathrm{JL}}+\Delta \mathrm{T}_{\mathrm{ox}}(\mathrm{z})
\end{gathered}
$$

where

$$
\begin{array}{lll}
\mathrm{T}_{\mathrm{w}}(\mathrm{z})= & \text { rod surface temperature at elevation } \mathrm{z} \text { on the rod axis }(\mathrm{K}) \\
\left.\Delta \mathrm{T}_{\mathrm{f}} \mathrm{z}\right)= & \text { forced convection film temperature drop at elevation } \mathrm{z} \text { on the rod axis }(\mathrm{K}) \\
\Delta \mathrm{T}_{\mathrm{cr}}(\mathrm{z})= & \text { crud temperature drop at elevation } \mathrm{z} \text { on the rod axis }(\mathrm{K}) \\
\Delta \mathrm{T}_{\mathrm{ox}}(\mathrm{z})= & \text { oxide layer temperature drop at elevation } \mathrm{z} \\
\mathrm{T}_{\mathrm{sat}}= & \text { coolant saturation temperature }(\mathrm{K}) \\
\Delta \mathrm{T}_{\mathrm{JL}}= & \begin{array}{l}
\text { nucleate boiling temperature drop at elevation } \mathrm{z} \text { on the rod axis }(\mathrm{K}) \text { is } \\
\text { determined by the Jens-Lottes (JL) correlation. }
\end{array}
\end{array}
$$

The choice of the minimum value is a simple means of deciding whether heat is transferred from the cladding surface to the coolant by forced convection or nucleate boiling. It also provides a smooth numerical transition from forced convection to nucleate boiling, thereby avoiding convergence problems. For forced-convection heat transfer, the temperature drop across the coolant film layer at the rod surface is based on

$$
\Delta T_{\mathrm{f}}(\mathrm{z})=\mathrm{q}^{\prime \prime}(\mathrm{z}) / \mathrm{h}_{\mathrm{f}}
$$

where $h_{f}$ is the Dittus-Boelter ${ }^{11}$ film conductance given by

$$
h_{f}=\left(0.023 k / D_{e}\right) R_{e}^{0.8} P_{r}^{0.4}
$$


where

$$
\begin{array}{lll}
\mathrm{h}_{\mathrm{f}} & = & \text { conductance }\left(\mathrm{W} / \mathrm{m}^{2}-\mathrm{K}\right) \\
\mathrm{k} & = & \text { conductivity of the water }(\mathrm{W} / \mathrm{m}-\mathrm{K}) \\
\mathrm{D}_{\mathrm{e}} & = & \text { coolant channel heated diameter }(\mathrm{m}) \\
\mathrm{R}_{\mathrm{e}} & = & \text { Reynolds number } \\
\operatorname{Pr} & = & \text { Prandtl number. }
\end{array}
$$

The temperature drop across the crud is given by

$$
\Delta \mathrm{T}_{\mathrm{cr}}(\mathrm{z})=\mathrm{q}^{\prime \prime}(\mathrm{z}) \frac{\delta_{\mathrm{cr}}}{\mathrm{k}_{\mathrm{cr}}}
$$

where

$$
\begin{array}{lll}
\delta_{\mathrm{cr}} & =\quad \text { crud thickness }(\mathrm{m}) \\
\mathrm{k}_{\mathrm{cr}} & =\quad \text { crud thermal conductivity, } 0.8648(\mathrm{~W} / \mathrm{m}-\mathrm{k}) .
\end{array}
$$

For nucleate boiling heat transfer, the temperature drop across the coolant film layer at the rod surface is based on the Jens-Lottes ${ }^{12}$ formulation

$$
\Delta \mathrm{T}_{\mathrm{JL}}(\mathrm{z})=60\left[\mathrm{q}^{\prime \prime}(\mathrm{z}) / 10^{6}\right]^{0.25} / \mathrm{e}^{\left(\mathrm{P} / 6.2 \times 10^{6}\right)}
$$

where

$\mathrm{P} \quad=\quad$ system bulk coolant pressure $(\mathrm{Pa})$.

It is assumed that the crud does not offer any resistance to heat flow during nucleate boiling; therefore, no temperature drop due to crud is calculated. The coolant is assumed to boil through the crud blanket. 
The temperature drop across the zirconium oxide layer at elevation $\mathrm{z}$ on the rod axis is determined by

$$
\Delta \mathrm{T}_{\mathrm{ox}}(\mathrm{z})=\frac{\mathrm{q}^{\prime \prime}(\mathrm{z}) \delta_{\mathrm{ox}}(\mathrm{z})}{\mathrm{k}_{\mathrm{ox}}}
$$

where

$$
\begin{array}{ll}
\Delta \mathrm{T}_{\mathrm{ox}}(\mathrm{z})= & \text { oxide temperature drop at elevation } \mathrm{z} \text { on the rod axis }(\mathrm{K}) \\
\delta_{\mathrm{ox}}(\mathrm{z})= & \text { oxide thickness at elevation } \mathrm{z} \text { on the rod axis }(\mathrm{m}) \\
\mathrm{k}_{\mathrm{ox}}= & \text { oxide thermal conductivity }(\mathrm{W} / \mathrm{m}-\mathrm{K}) .
\end{array}
$$

\subsubsection{Cladding Temperature Drop}

The cladding temperature drop for each axial location is calculated according to the following expression for steady-state heat transfer through a cylinder with uniform thermal conductivity:

$$
\Delta \mathrm{T}_{\mathrm{c}}=\mathrm{q}^{\prime \prime}(\mathrm{z}) \mathrm{r}_{\mathrm{o}} \ln \left(\mathrm{r}_{\mathrm{o}} / \mathrm{r}_{\mathrm{i}}\right) / \mathrm{k}_{\mathrm{c}}
$$

where

$$
\begin{array}{lll}
\Delta \mathrm{T}_{\mathrm{c}} & = & \text { cladding temperature drop }(\mathrm{K}) \\
\mathrm{r}_{\mathrm{o}} & = & \text { cladding outside radius }(\mathrm{m}) \\
\mathrm{r}_{\mathrm{i}} & = & \text { cladding inside radius }(\mathrm{m}) \\
\mathrm{k}_{\mathrm{c}} & = & \begin{array}{l}
\text { temperature and material dependent thermal conductivity of the } \\
\text { cladding }(\mathrm{W} / \mathrm{m}-\mathrm{K}) .
\end{array}
\end{array}
$$

\subsubsection{Fuel-Cladding Gap Temperature Drop}

The fuel cladding gap temperature drop is calculated using the fuel rod surface heat flux at elevation $\mathrm{z}$ and the fuel-cladding gap conductance. The fuel-cladding gap conductance is the sum of three components: the conductance due to radiation, the conduction through the gas, and the 
conduction through regions of solid-solid contact. The equations and models for each of these components are presented in the following sections.

$$
\Delta \mathrm{T}_{\mathrm{gap}}=\frac{\mathrm{q}^{\prime \prime}(\mathrm{z})}{\mathrm{h}}
$$

where

$$
\begin{aligned}
& h=h_{r}+h_{\text {gas }}+h_{\text {solid }} \\
& \dot{q}^{\prime \prime}(\mathrm{z})=\quad \text { rod surface heat flux at elevation } \mathrm{z} \text { on the rod axis }\left(\mathrm{W} / \mathrm{m}^{2}\right) \\
& \mathrm{h}_{\mathrm{r}} \quad=\quad \text { conductance due to radiation }\left(\mathrm{W} / \mathrm{m}^{2}-\mathrm{K}\right) \\
& \mathrm{h}_{\text {gas }}=\quad \text { conductance of the gas gap }\left(\mathrm{W} / \mathrm{m}^{2}-\mathrm{K}\right) \\
& \mathrm{h}_{\text {solid }}=\quad \text { conductance due to fuel-cladding contact }\left(\mathrm{W} / \mathrm{m}^{2}-\mathrm{K}\right)
\end{aligned}
$$

2.3.4.1 Radiation Heat Transfer. The net radiant heat transfer of heat from the fuel to the cladding is the infinite-cylinder, gray body form as derived by Kreith ${ }^{13}$ and others:

$$
\text { Net surface heat flux (S.H.F.) }=\sigma F\left[\mathrm{~T}_{\mathrm{fs}}^{4}-\mathrm{T}_{\mathrm{ci}}^{4}\right]
$$

where

$$
\begin{array}{lll}
\mathrm{F} & = & 1 /\left[1 / \mathrm{e}_{\mathrm{f}}+\left(\mathrm{r}_{\mathrm{fs}} / \mathrm{r}_{\mathrm{ci}}\right)\left(1-1 / \mathrm{e}_{\mathrm{c}}\right)\right] \\
\sigma & = & \text { Stefan-Boltzman constant } \\
& = & 5.6697 \times 10^{-8}\left(\mathrm{~W} / \mathrm{m}^{2}-\mathrm{K}^{4}\right) \\
\mathrm{e}_{\mathrm{f}} & = & \text { fuel emissivity } \\
\mathrm{e}_{\mathrm{c}} & = & \text { cladding emissivity } \\
\mathrm{T}_{\mathrm{ci}} & = & \text { fuel surface temperature }(\mathrm{K})
\end{array}
$$




$$
\begin{array}{lll}
\mathrm{T}_{\mathrm{fs}} & = & \text { cladding inner surface temperature }(\mathrm{K}) \\
\mathrm{r}_{\mathrm{fs}} & = & \text { fuel outer surface radius }(\mathrm{m}) \\
\mathrm{r}_{\mathrm{ci}} & = & \text { cladding inner surface radius }(\mathrm{m}) .
\end{array}
$$

The conductance due to radiation, $\mathrm{h}_{\mathrm{r}}\left(\mathrm{W} / \mathrm{m}^{2}-\mathrm{K}\right)$, is defined by

$$
\mathrm{h}_{\mathrm{r}}\left(\mathrm{T}_{\mathrm{fs}}-\mathrm{T}_{\mathrm{ci}}\right)=\mathrm{S} . \mathrm{H} . \mathrm{F}
$$

Combining Equations (2-13) and (2-14) and dividing by $\left(\mathrm{T}_{\mathrm{fs}}-\mathrm{T}_{\mathrm{ci}}\right)$ gives

$$
h_{r}=\sigma F\left[T_{f s}^{2}+T_{c i}^{2}\right]\left[T_{f s}+T_{c i}\right]
$$

2.3.4.2 Conduction Through the Interfacial Gas. The form of the conductance due to conductive heat transfer through the gas in the fuel-cladding gap, $\mathrm{h}_{\mathrm{gas}}\left(\mathrm{W} / \mathrm{m}^{2}-\mathrm{K}\right)$, is that universally applied to small annular gaps:

$$
\mathbf{h}_{\mathrm{gas}}=\frac{\mathbf{k}_{\mathrm{gas}}}{\Delta \mathrm{x}}
$$

where

$$
\begin{array}{r}
\mathrm{k}_{\mathrm{gas}}=\quad \text { gas thermal conductivity }(\mathrm{W} / \mathrm{m}-\mathrm{K}) \\
\Delta \mathrm{x} \quad \Rightarrow \quad \text { total effective gap width }(\mathrm{m}) . \\
\Delta \mathrm{x}=\mathrm{d}_{\text {eff }}+1.8\left(\mathrm{~g}_{\mathrm{f}}+\mathrm{g}_{\mathrm{c}}\right)-\mathrm{b}+\mathrm{d}
\end{array}
$$

where

$$
\begin{aligned}
\mathrm{d} & =\quad \text { value from FRACAS for open fuel-cladding gap size }(\mathrm{m}) \\
\mathrm{d}_{\mathrm{eff}} & =\quad \exp (-0.00125 \mathrm{P})\left(\mathrm{R}_{\mathrm{f}}+\mathrm{R}_{\mathrm{c}}\right) \text { for closed fuel--cladding gaps }(\mathrm{m}), \\
& =\left(\mathrm{R}_{\mathrm{f}}+\mathrm{R}_{\mathrm{c}}\right) \text { for open fuel-cladding gaps }(\mathrm{m})
\end{aligned}
$$




$$
\begin{aligned}
& \mathrm{P}=\quad \text { fuel-cladding interfacial pressure }\left(\mathrm{kg} / \mathrm{cm}^{2}\right) \\
& \mathrm{R}+\mathrm{R}_{\mathrm{c}}=\quad \text { cladding plus fuel surface roughness }(\mathrm{m}) \\
& \left(\mathrm{g}+\mathrm{g}_{\mathrm{c}}\right)=\quad \text { temperature jump distances at fuel and cladding surfaces, respectively } \\
& \text { (m) } \\
& \mathrm{b}=\quad \quad=\quad 1.397 \times 10^{-6}(\mathrm{~m}) \text {. }
\end{aligned}
$$

The quantity $\left(\mathrm{g}_{\mathrm{f}}+\mathrm{g}_{\mathrm{c}}\right)$ is calculated from the GAPCON $-2^{14}$ model and is

$$
\left(\mathrm{g}_{\mathrm{f}}+\mathrm{g}_{\mathrm{c}}\right)=\mathrm{A}\left[\frac{\mathrm{k}_{\mathrm{gas}}{ }^{\sqrt{\mathrm{T}_{\text {gas }}}}}{\mathrm{P}_{\mathrm{gas}}}\right]\left[\frac{1}{\sum \mathrm{a}_{\mathrm{i}} \mathrm{f}_{\mathrm{i}} / \sqrt{\mathrm{M}_{\mathrm{i}}}}\right]
$$

where

$$
\begin{array}{lll}
\mathrm{A} & = & 0.7816 \\
\mathrm{k}_{\text {gas }} & = & \text { gas conductivity }(\mathrm{W} / \mathrm{m}-\mathrm{K}) \\
\mathrm{P}_{\mathrm{gas}} & = & \text { gas pressure }(\mathrm{Pa}) \\
\mathrm{T}_{\text {gas }} & = & \text { average gas temperature }(\mathrm{K}) \\
\mathrm{a}_{\mathrm{i}} & = & \text { accommodation coefficient of } \mathrm{i} \text {-th gas component } \\
\mathrm{M}_{\mathrm{i}} & = & \text { gram-molecular weight of } \mathrm{i} \text {-th gas component }(\mathrm{k} \cdot \mathrm{moles}) \\
\mathrm{f}_{\mathrm{i}} & = & \text { mole fraction of } \mathrm{i} \text {-th gas component. }
\end{array}
$$

2.3.4.3 Conductance Through Points of Contact. The contact conductance model is a modification of the Mikic-Todreas mode ${ }^{15}$ that preserves the roughness, conductivity, and pressure dependencies while providing a best-estimate for the range of contact conductances measured by Garnier and Begej. ${ }^{16}$ The FRACAS-I model uses expressions for $h_{\text {solid }}$ that depend on both the fuel-cladding interfacial pressure and the microscopic roughness, $R$, as follows 


$$
\begin{array}{cl}
\mathrm{h}_{\text {solid }}=\frac{5.0 \mathrm{~K}_{\mathrm{m}} \mathrm{P}_{\mathrm{rel}} \mathrm{R}_{\text {mult }}}{\mathrm{RE}} & , \text { if } \mathrm{P}_{\text {rel }}>0.003 \\
=\frac{0.015 \mathrm{~K}_{\mathrm{m}}}{\mathrm{R} \mathrm{E}} & , \text { if } 0.03>\mathrm{P}_{\mathrm{rel}}>9 \mathrm{E}-6 \\
=\frac{5.0 \mathrm{~K}_{\mathrm{m}} \mathrm{P}_{\mathrm{rel}}^{0.5}}{\mathrm{RE}} & , \text { if } \mathrm{P}_{\text {rel }}<9 . \mathrm{E}-6
\end{array}
$$

where

$$
\begin{aligned}
& \mathrm{P}_{\text {rel }}=\quad \text { ratio of interfacial pressure to cladding Meyer hardness (approximately } \\
& 680 \mathrm{MPa} \text { ) } \\
& \mathrm{K}_{\mathrm{m}} \quad=\quad \text { mean conductivity }(\mathrm{W} / \mathrm{m}-\mathrm{K}) \\
& =2 \mathrm{~K}_{\mathrm{f}} \mathrm{K}_{\mathrm{c}} /\left(\mathrm{K}_{\mathrm{f}}+\mathrm{K}_{\mathrm{c}}\right) \\
& \mathrm{R}=\sqrt{\mathrm{R}_{\mathrm{f}}^{2}+\mathrm{R}_{\mathrm{c}}^{2}}(\mathrm{~m}) \\
& \mathrm{R}_{\text {mult }}=\quad 333.3 \mathrm{P}_{\text {rel }} \text {, if } \mathrm{P}_{\text {rel }} \leq 0.0087 \\
& =\quad 2.9 \quad, \text { if } \mathrm{P}_{\text {rel }}>0.0087 \\
& \mathrm{~K}_{\mathrm{c}} \quad=\quad \text { cladding thermal conductivity }(\mathrm{W} / \mathrm{m}-\mathrm{K}) \\
& \mathrm{K}_{\mathrm{f}} \quad=\quad \text { fuel thermal conductivity }(\mathrm{W} / \mathrm{m}-\mathrm{K}) \\
& \mathrm{E} \quad=\quad \exp \left[5.738-0.528 \ln \left(\mathrm{R}_{2}\right)\right] \\
& R_{2}=\quad \text { roughness of the rougher surface. }
\end{aligned}
$$

The above comes from a fit to Ross and Stoute ${ }^{17}$ data plus that by Rapier ${ }^{18}$ using the MikicTodreas model..$^{15}$

\subsubsection{Fuel Pellet Heat Conduction Model}

This section describes the steady-state fuel pellet heat conduction model. The model is developed based upon the finite difference heat conduction models used in RELAP5 and FRAPTRAN. First, an overview of the fuel pellet heat conduction model used in FRAPCON-3 is

provided. Next, the requirements for the fuel pellet heat conduction model are given. The 
development of the finite difference approach begins in Section 2.3.5.1, and subsequent sections provide specific applications of the steady-state heat conduction equation that will lead to the final form of the heat conduction model.

A schematic drawing of a representative temperature distribution at an arbitrary axial node is shown in Figure 2.3. The fuel surface temperature, $\mathrm{T}_{\mathrm{fs}}$, is used as one of the boundary conditions to feed into the new finite difference heat conduction model, which replaces the FRAPCON-2 method-of-weighted residuals model to 1) allow accurate calculation of temperatures in high burnup fuel, and 2) to provide model consistency with FRAPTRAN.

This new finite difference model must

- $\quad$ calculate the temperature profile in the fuel pellet

- $\quad$ have fine mesh capabilities at the fuel surface that will handle fuel pellets with burnup to $75 \mathrm{MWd} / \mathrm{kgU}$

- $\quad$ interface with the new PNNL high burnup models. ${ }^{8}$

2.3.5.1 The Finite Difference Approach. Finite differences will be used to calculate the temperature distribution in the fuel region. Variable mesh spacing will be used, and the spatial dependence of the internal heat source is allowed to vary over each mesh interval.

The steady-state integral form of the heat conduction equation is

$$
\iint_{S} k(T, \bar{x}) \nabla \vec{\nabla}(\bar{x}) \bullet \vec{n} d s=\iiint_{V} S(\bar{x}) d V
$$

where

$\begin{array}{lll}\mathrm{k} & = & \text { thermal conductivity }(\mathrm{W} / \mathrm{m}-\mathrm{K}) \\ \mathrm{S} & = & \text { surface of the control volume }\left(\mathrm{m}^{2}\right) \\ \overrightarrow{\mathrm{n}} & = & \text { the surface normal unit vector } \\ \mathrm{S} & = & \text { internal heat source }\left(\mathrm{W} / \mathrm{m}^{3}\right) \\ \mathrm{T} & = & \text { temperature }(\mathrm{K})\end{array}$




$$
\begin{array}{lll}
\mathrm{V} & = & \text { control volume }\left(\mathrm{m}^{3}\right) \\
\overline{\mathrm{x}} & = & \text { the space coordinates }(\mathrm{m}) .
\end{array}
$$

The following assumptions were made to develop this heat conduction model:

- $\quad$ Fixed geometry

- $\quad$ Symmetrical geometry

- Negligible heat conduction in the axial direction

- Negligible heat conduction in the azimuthal direction

- Steady-state

- Mesh point averaged thermal conductivity (discussed in the following sections).

Two boundary conditions are needed to calculate the temperature profile in the fuel. The boundary conditions are the symmetry condition, $\left.\frac{\partial \mathrm{T}}{\partial \overline{\mathrm{x}}}\right|_{\overline{\mathrm{x}}=0}=0$, at the center of the fuel pellet and a prescribed temperature at the surface of the fuel.

2.3.5.2 Mesh Point Layout. Figure 2.4 illustrates the placement of mesh points at which temperatures are to be calculated. The mesh point spacing is positive in the radial direction. The first mesh point is placed at the fuel centerline or at the inner annular surface of the fuel. Variable mesh spacing is used to determine the placement of interior mesh points. The mesh placement is consistent with the new radial power and burnup distribution model, TUBRNP, developed at the Institute for Transuranium Elements, Karlsruhe, ${ }^{19}$ incorporated in FRAPCON-3. The last mesh point is placed on the surface of the fuel.

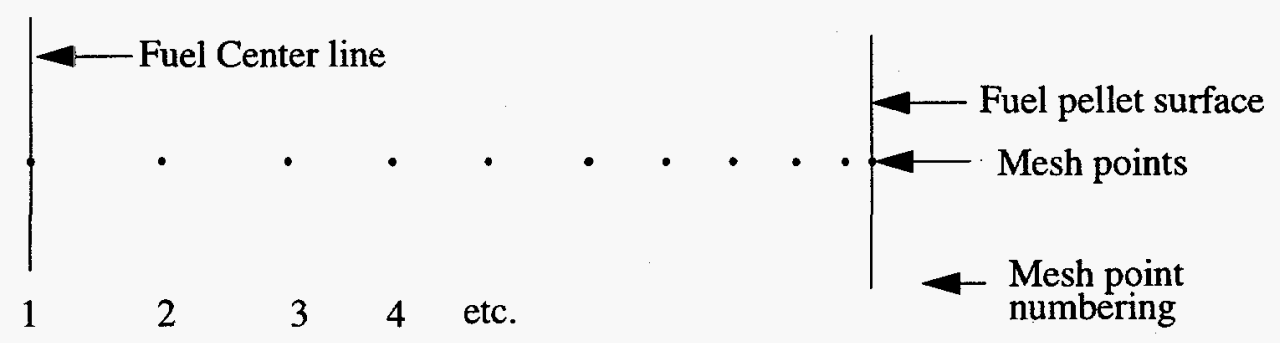

Figure 2.4 Mesh Point Layout 
Figure 2.5 represents three typical mesh points. The subscripts are space indexes indicating the mesh point number; and 1 and $r$ (if present) designate quantities to the left and right, respectively, of the mesh point. The $\delta$ 's indicate mesh point spacing. Between mesh points, the thermal conductivity, $\mathrm{k}$, and the source term, $\mathrm{S}$, are assumed spatially constant; but $\mathrm{k}_{\mathrm{lm}}$ is not necessarily equal to $\mathrm{k}_{\mathrm{rm}}$ and similarly for $\mathrm{S}$.

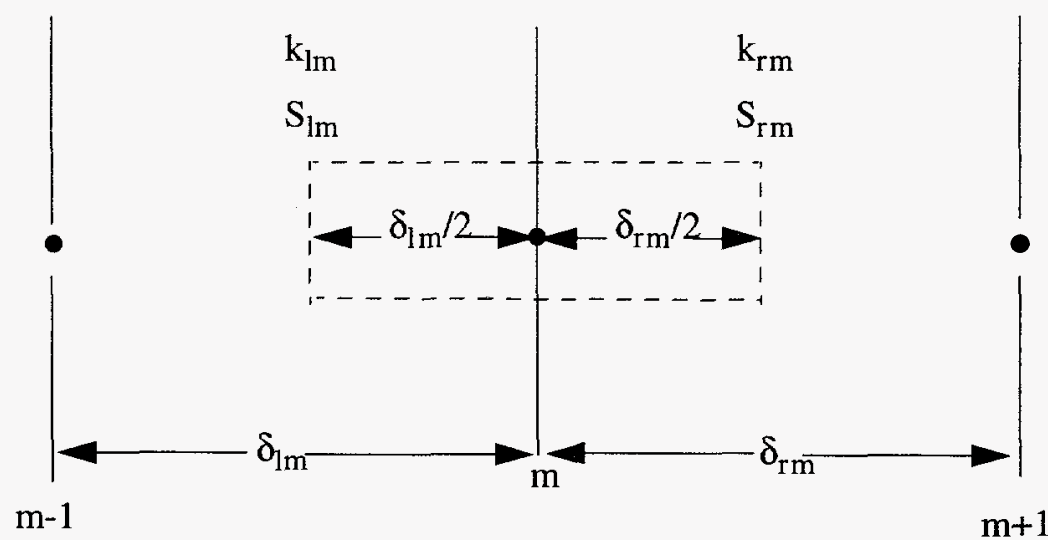

Figure 2.5 Typical Mesh Points

To obtain the spatial-difference approximation for the $\mathrm{m}$-th interior mesh point, a form of Equation (2-20) applicable to radial heat conduction in cylindrical coordinates is applied to the volume and surfaces indicated by the dashed line shown in Figure 2.5. To obtain the spatial difference approximation at the boundaries, Equation 2-20 is applied to the volumes and interior surfaces indicated by the dashed lines shown in Figure 2.6.

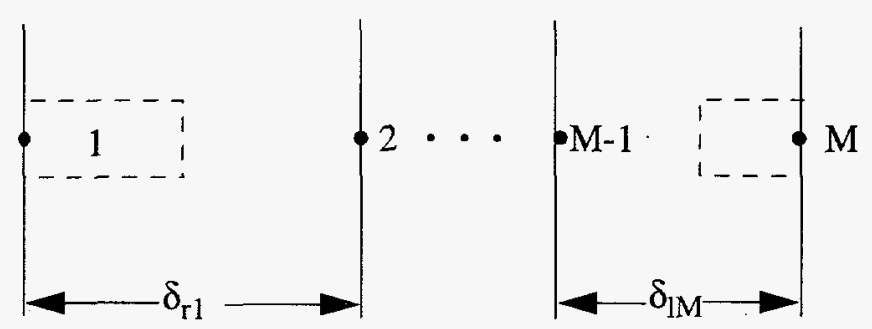

Figure 2.6 Boundary Mesh Points

The spatial finite-difference approximations use approximate expressions for the space and volume factors and simple differences for the gradient terms. To condense the expressions defining the numerical approximations, the following quantities are defined. 


$$
\begin{gathered}
\delta_{\mathrm{lm}}^{\mathrm{v}}=2 \pi \frac{\delta_{\mathrm{lm}}}{2}\left(\mathrm{x}_{\mathrm{m}}-\frac{\delta_{1 \mathrm{~m}}}{4}\right), \delta_{\mathrm{rm}}^{\mathrm{v}}=2 \pi \frac{\delta_{\mathrm{rm}}}{2}\left(\mathrm{x}_{\mathrm{m}}+\frac{\delta_{\mathrm{rm}}}{4}\right), \\
\delta_{\mathrm{lm}}^{\mathrm{s}}=\frac{2 \pi}{\delta_{\mathrm{lm}}}\left(\mathrm{x}_{\mathrm{m}}-\frac{\delta_{1 \mathrm{~m}}}{2}\right), \delta_{\mathrm{rm}}^{\mathrm{s}}=\frac{2 \pi}{\delta_{\mathrm{rm}}}\left(\mathrm{x}_{\mathrm{m}}+\frac{\delta_{\mathrm{rm}}}{2}\right), \\
\delta_{\mathrm{m}}^{\mathrm{b}}=2 \pi \mathrm{x}_{\mathrm{m}} .
\end{gathered}
$$

The superscripts, v and s, refer to volume and surface-gradient weights. The $\delta_{\mathrm{m}}^{\mathrm{b}}$ is a surface weight used at exterior boundaries and in heat-transfer-rate equations.

2.3.5.3 Difference Approximation at Internal Mesh Points. The first term of Equation (220) for the surfaces of Figure 2.5 is approximated by

$$
\iint_{s} \mathrm{k}(\mathrm{T}, \overline{\mathrm{x}}) \bar{\nabla} \mathrm{T}(\overline{\mathrm{x}}) \mathrm{d} \overline{\mathrm{s}} \approx\left(\mathrm{T}_{\mathrm{m}-1}-\mathrm{T}_{\mathrm{m}}\right) \mathrm{k}_{1 \mathrm{~m}} \delta_{\mathrm{lm}}^{\mathrm{s}}+\left(\mathrm{T}_{\mathrm{m}+1}-\mathrm{T}_{\mathrm{m}}\right) \mathrm{k}_{\mathrm{rm}} \delta_{\mathrm{rm}}^{\mathrm{s}}
$$

Note that the volume in Figure 2.5 is divided into two sub-volumes by the interface line. When the surface integrals of these sub-volumes are added, the surface integrals along the common interface cancel because of the continuity of heat flow.

The source term in Equation (2-20) is represented by

$$
S(x)=P_{f} P Q(x)
$$

where

$$
\begin{array}{ll}
\mathrm{P}_{\mathrm{f}} \quad=\quad \text { the axial power factor that relates } \mathrm{P} \text { to a particular axial node } \\
\mathrm{P} \quad \text { the power function derived from the linear heat generation rate } \\
\mathrm{Q}(\mathrm{x}) \quad=\quad \text { the radial position dependent position (as determined by the TUBRNP } \\
\quad \text { model and subroutine). }
\end{array}
$$

The value of $\mathrm{Q}(\mathrm{x})$ is assumed constant over a mesh interval, but each interval can have a different value. The third term of Equation (2-20) is then approximated as 


$$
\iiint_{V} S(\bar{x}, t) d V \approx P_{f} P\left(Q_{1 m} \delta_{1 m}^{v}+Q_{r m} \delta_{r m}^{v}\right)
$$

Gathering the approximations of terms in Equation (2-20), the basic difference equation for the $\mathrm{m}$-th mesh point is

$$
\left(\mathrm{T}_{\mathrm{m}}-\mathrm{T}_{\mathrm{m}-1}\right) \mathrm{k}_{\mathrm{lm}} \delta_{\mathrm{lm}}^{\mathrm{s}}+\left(\mathrm{T}_{\mathrm{m}}-\mathrm{T}_{\mathrm{m}+1}\right) \mathrm{k}_{\mathrm{rm}} \delta_{\mathrm{rm}}^{\mathrm{s}}=\mathrm{P}_{\mathrm{f}} \mathrm{P}\left(\mathrm{Q}_{\mathrm{lm}} \delta_{\mathrm{lm}}^{\mathrm{v}}+\mathrm{Q}_{\mathrm{rm}} \delta_{\mathrm{rm}}^{\mathrm{v}}\right)
$$

Writing Equation (2-25) in abbreviated form, the difference approximation for the $\mathrm{m}$-th interior mesh point is

$$
\begin{gathered}
a_{m} T_{m-1}+b_{m} T_{m}+c_{m} T_{m+1}=d_{m} \\
a_{m}=-\left(k_{l m} \delta_{l m}^{s}\right) \\
b_{m}=-a_{m}-c_{m} \\
c_{m}=-\left(k_{r m} \delta_{r m}^{s}\right) \\
d_{m}=P_{f} P\left(Q_{1 m} \delta_{l m}^{v}+Q_{r m} \delta_{r m}^{v}\right)
\end{gathered}
$$

2.3.5.4 Difference Approximation at Boundaries. To obtain the difference approximations for the mesh points at the boundaries, Equation (2-20) is applied to the volumes of Figure 2.6. The first boundary condition evaluated is the symmetry condition, $\left.\frac{\partial T}{\partial \bar{x}}\right|_{\bar{x}=0}=0$. The symmetry condition is applied at mesh point 1 . The first term of Equation (2-20) is approximated by

$$
\iint_{s} \mathrm{k}(\mathrm{T}, \overline{\mathrm{x}}) \bar{\nabla} \mathrm{T}(\overline{\mathrm{x}}, \mathrm{t}) \bullet \mathrm{d} \overline{\mathrm{s}}=\mathrm{k}_{\mathrm{rl}}\left(\mathrm{T}_{2}-\mathrm{T}_{1}\right) \delta_{\mathrm{rl}}^{\mathrm{s}}
$$


The complete basic expression for mesh point 1 (located at the symmetry boundary) becomes

$$
\mathrm{k}_{\mathrm{r} 1}\left(\mathrm{~T}_{1}-\mathrm{T}_{2}\right) \delta_{\mathrm{r} 1}^{\mathrm{s}}=\mathrm{P}_{\mathrm{f}} \mathrm{P}(\mathrm{t}) \mathrm{Q}_{\mathrm{r} 1} \delta_{\mathrm{r} 1}^{\mathrm{v}}
$$

Thus, for the symmetry boundary

$$
\begin{gathered}
\mathrm{b}_{1} \mathrm{~T}_{1}+\mathrm{c}_{1} \mathrm{~T}_{2}=\mathrm{d}_{1} \\
\mathrm{~b}_{1}=-\mathrm{c}_{1} \\
\mathrm{c}_{1}=-\mathrm{k}_{\mathrm{r} 1} \delta_{\mathrm{r} 1}^{\mathrm{s}} \\
\mathrm{d}_{1}=\mathrm{P}_{\mathrm{f}}(\mathrm{P}) \mathrm{Q}_{\mathrm{r} 1} \delta_{\mathrm{r} 1}^{\mathrm{v}} .
\end{gathered}
$$

For the fuel surface boundary at Mesh Point M, a known fuel surface temperature is applied giving,

$$
\begin{gathered}
\mathrm{a}_{\mathrm{M}} \mathrm{T}_{\mathrm{M}-1}+\mathrm{b}_{\mathrm{M}} \mathrm{T}_{\mathrm{M}}=\mathrm{d}_{\mathrm{M}} \\
\mathrm{a}_{\mathrm{M}}=0 \\
\mathrm{~b}_{\mathrm{M}}=1 \\
\mathrm{~d}_{\mathrm{M}}=\mathrm{T}_{\mathrm{fs}} \mathrm{d}_{\mathrm{M}}=\mathrm{T}_{\mathrm{fs}} .
\end{gathered}
$$

2.3.5.5 Thermal Conductivity and Iteration Procedures. The thermal conductivity, $\mathrm{k}$, is considered a function of temperature and space.

The fuel thermal conductivity in FRAPCON-3 is based on the expression developed by Lucuta et al. ${ }^{20}$ This expression includes the term developed by Harding and Martin ${ }^{21}$ for the 
conductivity (" $\mathrm{k}_{\mathrm{o}}$ ") of unirradiated, fully dense urania, modified for urania-gadolinia or uraniaplutonia:

$$
\mathrm{k}_{\mathrm{o}}=\frac{\mathrm{CR}}{0.0375+2.165 \times 10^{-4} \mathrm{~T}+\mathrm{BGAD}}+\left[\frac{4.715 \times 10^{9}}{\mathrm{~T}^{2}}\right] \exp \left[-\frac{16361}{\mathrm{~T}}\right]
$$

where

$$
\begin{array}{lll}
\mathrm{k}_{\mathrm{o}} & = & \text { conductivity of unirradiated urania }(\mathrm{W} / \mathrm{m}-\mathrm{K}) \\
\mathrm{T} & = & \text { temperature }(\mathrm{K}) \\
\mathrm{GAD} & = & \text { gadolinia content, wt } \% \\
\mathrm{~B} & = & \text { gadolinia degradation, }=0.0150 \mathrm{~m}-\mathrm{K} / \mathrm{W} \text { per gadolinia weight } \% \\
\mathrm{CR} & =1.0 \text { for urania or urania-gadolinia } \\
& =\begin{array}{l}
\text { ratio of mixed-oxide specific heat to urania specific heat for urania- } \\
\text { plutonia. }
\end{array}
\end{array}
$$

The effect of burnup is to build dissolved and precipitated fission products into the matrix. The effect of the dissolved fission products is reflected by a burnup and temperature-dependent factor, "FD," which multiplies $\mathrm{k}_{\mathrm{o}}$ :

$$
\mathrm{FD}=\left[\frac{1.09}{\mathrm{~B}^{3.265}}+\frac{0.0643}{\sqrt{\mathrm{B}}} \sqrt{\mathrm{T}}\right] \arctan \left[\frac{1}{\frac{1.09}{\mathrm{~B}^{3.265}}+\frac{0.0643}{\sqrt{\mathrm{B}}} \sqrt{\mathrm{T}}}\right]
$$

where

$$
\begin{array}{rll}
\mathrm{B} & = & \text { burnup in atom } \%(1 \text { atom } \%=9.383 \mathrm{GWd} / \mathrm{MTU} \text { at } 200 \mathrm{MeV} / \text { fission }) \\
\mathrm{T} & = & \text { temperature }(\mathrm{K}) .
\end{array}
$$

The effect of the precipitated fission products is reflected by the factor FP given by 


$$
\mathrm{FP}=1+\left[\frac{0.019 \mathrm{~B}}{3-0.019 \mathrm{~B}}\right]\left[\frac{1}{1+\exp \left(-\frac{\mathrm{T}-1200}{100}\right)}\right]
$$

The effect of porosity is accounted for by the well known Maxwell factor, FM, given by

$$
\mathrm{FM}=\frac{1-\mathrm{p}}{1+(\mathrm{s}-1) \mathrm{p}}
$$

where

$$
\begin{array}{lll}
\mathrm{p} & = & \text { porosity fraction (as-fabricated plus swelling) } \\
\mathrm{s} & = & \text { shape factor (assumed }=1.5 \text { for spherical pores) }
\end{array}
$$

The radiation effect (applied at all times) in-reactor is given by the factor FR:

$$
\mathrm{FR}=1-\frac{0.2}{1+\exp \left(\frac{\mathrm{T}-900}{80}\right)}
$$

This factor has a significant effect at temperatures below $900 \mathrm{~K}$, but a sharply decreasing effect as temperatures increase above $900 \mathrm{~K}$. Finally then, the conductivity $\mathrm{K}$ for irradiated urania is given by

$$
\mathrm{k}=\mathrm{k}_{\mathrm{o}} \text { (FD FP FM FR) }
$$

These thermal properties are obtained for each interval by using the average of the mesh point temperatures bounding the interval

$$
\mathrm{k}_{\mathrm{l}, \mathrm{m}}=\mathrm{k}\left(\frac{\mathrm{T}_{\mathrm{m}-1}+\mathrm{T}_{\mathrm{m}}}{2}\right)=\mathrm{k}_{\mathrm{r}, \mathrm{m}-1}
$$




$$
\mathrm{k}_{\mathrm{r}, \mathrm{m}}=\mathrm{k}\left(\frac{\mathrm{T}_{\mathrm{m}}+\mathrm{T}_{\mathrm{m}+1}}{2}\right)=\mathrm{k}_{\mathrm{l}, \mathrm{m}+1}
$$

Prior to the calculation of the temperature distribution in the fuel pellet, this model uses assumed thermal conductivity values based upon an estimated temperature profile. The existing FRAPCON-3 gap conductance iteration scheme will be used to converge on temperature and thermal conductivity in the fuel. This iteration scheme is illustrated in Figure 2.2.

2.3.5.6 The Finite Difference Temperature Calculation. The difference approximation for the mesh points [Equations (2-26), (2-33), and (2-37)] lead to a tri-diagonal set of $\mathrm{M}$ simultaneous linear equations.

$$
\left[\begin{array}{cccccc}
\mathrm{b}_{1} & \mathrm{c}_{1} & & & & \\
\mathrm{a}_{2} & \mathrm{~b}_{2} & \mathrm{c}_{2} & & & \\
& \bullet & \bullet & & & \\
& & \bullet & \bullet & \bullet & \\
& & & \mathrm{a}_{\mathrm{M}-1} & \mathrm{~b}_{\mathrm{M}-1} & \mathrm{c}_{\mathrm{M}-1} \\
& & & & \mathrm{a}_{\mathrm{M}} & \mathrm{b}_{\mathrm{M}}
\end{array}\right]\left[\begin{array}{c}
\mathrm{T}_{1} \\
\mathrm{~T}_{2} \\
\bullet \\
\bullet \\
\mathrm{T}_{\mathrm{M}-1} \\
\mathrm{~T}_{\mathrm{M}}
\end{array}\right]=\left[\begin{array}{c}
\mathrm{d}_{1} \\
\mathrm{~d}_{2} \\
\bullet \\
\bullet \\
\mathrm{d}_{\mathrm{M}-1} \\
\mathrm{~d}_{\mathrm{M}}
\end{array}\right]
$$

Equations 1 and $M$ correspond to the fuel centerline and fuel surface mesh points respectively, and Equations 2 through $\mathrm{M}-1$ correspond to the interior mesh points. The coefficient matrix would normally be symmetric, but is not because of the right boundary condition that specifies the fuel surface temperature. The corresponding off-diagonal element is zero in the last row. The solution to the above equation is obtained by

$$
\begin{gathered}
E_{1}=\frac{c_{1}}{b_{1}} \text { and } F_{1}=\frac{d_{1}}{b_{1}} \\
E_{j}=\frac{c_{j}}{b_{j}-a_{j} E_{j-1}} \quad F_{j}=\frac{d_{j}-a_{j} F_{j-1}}{b_{j}-a_{j} E_{j-1}} \text { for } j=2,3, \ldots, M-1 \\
g_{M}=\frac{d_{M}-a_{M} F_{M-1}}{b_{M}-a_{M} E_{M-1}} \\
g_{j}=-E_{j} g_{j+1}+F_{j} \text { for } j=M-1, M-2, \ldots, 3,2,1
\end{gathered}
$$




$$
T_{j}=g_{j} \text { for all } j
$$

Equations (2-50) through (2-54) were derived by applying the rules for Gaussian elimination. This method of solution introduces little roundoff error, if the off-diagonal elements are negative and the diagonal is greater than the sum of the magnitudes of the off-diagonal elements. From the form of the difference equations for a fuel pellet, these conditions are satisfied for any values of the mesh point spacing, and thermal conductivity.

\subsubsection{Plenum Gas Temperature}

The plenurn gas temperature is calculated based on energy transfer between the top of the pellet stack and the plenum gas, between the coolant channel and the plenum gas, and between the spring and the plenum gas. A discussion of these contributions follows.

Natural convection from the top of the fuel stack is calculated based on heat transfer coefficients from McAdams ${ }^{22}$ for laminar or turbulent natural convection from flat plates.

The heat transfer coefficient is calculated from

$$
h_{p}=\frac{k N u}{D}
$$

where

$$
\begin{array}{lll}
\mathrm{h}_{\mathrm{p}} & = & \quad \begin{array}{l}
\text { the heat transfer coefficient from the top of the pellet stack to the plenum } \\
\text { gas }\left(\mathrm{W} / \mathrm{m}^{2}-\mathrm{K}\right)
\end{array} \\
\mathrm{Nu} & = & \text { Nusselt Number } \\
\mathrm{D} & = & \quad \text { inside diameter of the cladding of the top node }(\mathrm{m}) \\
\mathrm{k} & = & \text { conductivity of the plenum gas }(\mathrm{W} / \mathrm{m}-\mathrm{K}) .
\end{array}
$$

The Nusselt Number is calculated using

$$
\mathrm{Nu}=\mathrm{C}(\mathrm{GrPr})^{\mathrm{m}}
$$


where

$$
\begin{array}{lll}
\mathrm{Gr} & = & \text { the Grashof Number } \\
\operatorname{Pr} & = & \text { the Prandtl Number }
\end{array}
$$

and for

$\mathrm{GrPr} \leq 2.0 \times 10^{7}, \mathrm{C}=0.54$ and $\mathrm{m}=0.25$,

or

$\operatorname{GrPr}>2.0 \times 10^{7}, \mathrm{C}=0.14$ and $\mathrm{m}=0.33$

The overall effective conductivity from the coolant to the plenum is defined as the inverse of the sum of the individual heat flow resistances. The three resistances are (a) the resistance across the inside surface film, (b) the resistance across the cladding, and (c) the resistance across the outside surface film. The overall conductivity is therefore found as

$$
\mathrm{U}_{\mathrm{c}}=\frac{1.0}{\frac{2.0}{\mathrm{Dh}_{\mathrm{f}}}+\frac{\ln \left(\frac{\mathrm{D}_{\mathrm{o}}}{\mathrm{D}_{\mathrm{i}}}\right)}{\mathrm{k}_{\mathrm{clad}}}+\frac{2.0}{\mathrm{D}_{\mathrm{o}}(1.0+\alpha \Delta \mathrm{T}) \mathrm{h}_{\mathrm{DB}}}}
$$

where
$\mathrm{U}_{\mathrm{c}} \quad=$
overall effective conductivity from the coolant to the plenum gas $(\mathrm{W} / \mathrm{m}$ - K)
$\mathrm{D}=$ hot-state inside cladding diameter $(\mathrm{m})$
$\mathrm{h}_{\mathrm{f}} \quad=\quad$ cladding inside surface film coefficient $\left(\mathrm{W} / \mathrm{m}^{2}-\mathrm{K}\right)$
$\mathrm{D}_{\mathrm{o}}=\quad$ cold-state outside cladding diameter $(\mathrm{m})$
$\mathrm{D}_{\mathrm{i}} \quad=\quad$ cold-state inside cladding diameter $(\mathrm{m})$
$\mathrm{k}_{\mathrm{clad}}=$ temperature and material dependent thermal conductivity of the cladding $(\mathrm{W} / \mathrm{m}-\mathrm{K})$ 


$$
\begin{array}{lll}
\alpha \quad= & \text { coefficient of thermal expansion of the cladding }(1 / \mathrm{K}) \\
\Delta \mathrm{T}= & \begin{array}{l}
\text { temperature difference between cladding average temperature and datum } \\
\text { temperature for thermal expansion }(\mathrm{K})
\end{array} \\
\mathrm{h}_{\mathrm{DB}} \quad=\quad \text { heat transfer coefficient between the coolant and the cladding }\left(\mathrm{W} / \mathrm{m}^{2}-\mathrm{K}\right) .
\end{array}
$$

Gamma heating in the hold down spring is calculated assuming a volumetric heating rate of $3.76 \mathrm{~W} / \mathrm{m}^{3}$ for every $\mathrm{W} / \mathrm{m}^{2}$ of rod average heat flux. The expression is

$$
\mathrm{Q}_{\mathrm{sp}}=3.76 \dot{q} \mathrm{~V}_{\mathrm{s}}
$$

where

$$
\begin{array}{lll}
\mathrm{Q}_{\mathrm{sp}} & = & \text { energy generated in the spring due to gamma heating }(\mathrm{W}) \\
\dot{\mathrm{q}}^{\prime \prime} & = & \text { average heat flux of the rod }\left(\mathrm{W} / \mathrm{m}^{2}\right) \\
\mathrm{V}_{\mathrm{s}} & = & \text { volume of the spring }\left(\mathrm{m}^{3}\right) .
\end{array}
$$

The plenum temperature is approximated from

$$
T_{\text {plen }}=\frac{Q_{s p}+U_{c} \frac{V_{p}}{D^{2}} T_{B L K}+T_{p a} h_{p} \pi D^{2} / 4}{U_{c} \frac{V_{p}}{D^{2}}+\frac{h_{p} \pi D^{2}}{4}}
$$

where

$$
\begin{array}{lll}
\mathrm{T}_{\text {plen }} & = & \text { plenum temperature }(\mathrm{K}) \\
\mathrm{V}_{\mathrm{p}} & = & \text { volume of the plenum }\left(\mathrm{m}^{3}\right) \\
\mathrm{T}_{\mathrm{BLK}} & = & \text { bulk coolant temperature at the top axial node }(\mathrm{K}) \\
\mathrm{T}_{\mathrm{pa}} & = & \text { temperature associated with the insulator or top pellet }(\mathrm{K}) .
\end{array}
$$




\subsubsection{Stored Energy}

The stored energy in the fuel rod is calculated by summing the energy of each pellet ring calculated at the ring temperature. The expression for stored energy is

$$
E_{s}=\frac{\sum_{i=1}^{I} m_{i} \int_{298 K}^{T_{i}} C_{p}(T) d T}{m}
$$

where

$$
\begin{array}{lll}
\mathrm{E}_{\mathrm{s}} & = & \text { stored energy }(\mathrm{J} / \mathrm{kg}) \\
\mathrm{m}_{\mathrm{i}} & = & \text { mass of ring segment } \mathrm{i}(\mathrm{kg}) \\
\mathrm{T}_{\mathrm{i}} & = & \text { temperature of ring segment } \mathrm{i}(\mathrm{K}) \\
\mathrm{C}_{\mathrm{p}}(\mathrm{T})= & \text { specific heat evaluated at temperature } \mathrm{T}(\mathrm{J} / \mathrm{kg}-\mathrm{K}) \\
\mathrm{m} & = & \text { total mass of the axial node }(\mathrm{kg}) \\
\mathrm{I} & = & \text { number of annular rings. }
\end{array}
$$

The stored energy is calculated for each axial node.

\subsection{Fuel Rod Mechanical Response}

An accurate calculation of fuel and cladding deformation is necessary in any fuel rod response analysis because the heat transfer coefficient across the fuel-cladding gap is a function of both the effective fuel-cladding gap size and the fuel-cladding interfacial pressure. In addition, an accurate calculation of stresses in the cladding is needed to accurately calculate the onset of cladding failure (and subsequent release of fission products) can be made.

\subsubsection{The FRACAS-I Model}

The FRACAS-I model is available for the calculation of the small displacement deformation of the fuel and cladding. The simplified model, FRACAS-I, neglects the stress-induced deformation of the fuel, and is called the rigid pellet model. 
In analyzing the deformation of fuel rods, two physical situations are envisioned. The first situation occurs when the fuel and cladding are not in contact. Here the problem of a cylindrical shell (the cladding) with specified internal and external pressures and a specified cladding temperature distribution must be solved. This situation is called the "open gap" regime.

The second situation envisioned is when the fuel (considerably hotter than the cladding) has expanded so as to be in contact with the cladding. Further heating of the fuel results on "driving" the cladding outwardly. This situation is called the "closed gap" regime. Alternatively, this closed gap regime can occur due to the creep of the cladding onto the fuel due to elevated cladding temperatures and a high coolant pressure.

The preceding two regimes of fuel rod deformation are characterized by small cladding strains and by the cladding retaining its essentially cylindrical shape.

The deformation analysis in FRAPCON-3 consists of a small deformation analysis. A small deformation analysis of the stresses, strains and displacements in the fuel and cladding is performed first for the entire fuel rod. This analysis is based on the assumption that the cladding retains its cylindrical shape during deformation, and includes the effects of:

- Fuel thermal expansion, swelling, densification, and relocation.

- Cladding thermal expansion, creep, and plasticity.

- $\quad$ Fission gas and external coolant pressures.

As part of the small displacement analysis, the applicable local deformation regime (open gap, or closed gap) is determined. Finally, an analysis is performed to determine cladding stresses and strains.

In Section 2.4.1.1, the general theory of plastic analysis is outlined and the method of solution used in the FRACAS-I model is presented. This method of solution is used in the rigid pellet model. In Section 2.4.1.2, the equations for the rigid pellet model is described.

2.4.1.1 General Theory and Method of Solution. The general theory of plastic analysis and the method of solution are used in the rigid pellet model.

2.4.1.1.1 General Considerations in Elastic-Plastic Analysis--Problems involving elastic-plastic deformation and multiaxial stress states involve a number of aspects that do not require consideration in a uniaxial problem. In the following discussion, an attempt is made to briefly outline the structure of incremental plasticity, and to outline the Method of Successive Substitutions ${ }^{23}$ (also called the Method of Successive Elastic Solutions), which has been used successfully in treating multiaxial elastic-plastic problems. The method can be used for any 
problem for which a solution based on elasticity can be obtained. This method is used in the rigid pellet model.

In a problem involving only uniaxial stress, $\sigma_{1}$, the strain, $\varepsilon_{1}$, is related to the stress by an experimentally determined stress-strain curve as shown in Figure 2.7 (including the elastic strains, plastic strains, but without thermal expansion strains) so Hooke's law is taken as

$$
\varepsilon_{1}=\frac{\sigma_{1}}{\mathrm{E}}+\varepsilon_{1}^{\mathrm{P}}+\int \alpha \mathrm{dT}
$$

where $\varepsilon_{1}^{\mathrm{P}}$ is the plastic strain and $\mathrm{E}$ is the modulus of elasticity. The onset of yielding occurs at the yield stress, which can be determined directly from Figure 2.7. Given a load (stress) history, the resulting deformation can be determined in a simple manner. The increase of yield stress with work-hardening is easily computed directly from Figure 2.7.

In a problem involving multiaxial states of stress, however, the situation is not as clear. In such a problem, a method of relating the onset or plastic deformation to the results of a uniaxial test is required, and further, when plastic deformation occurs, some means is needed for determining how much plastic deformation has occurred and how that deformation is distributed among the individual components of strain. These two complications are taken into account by use of the so-called "yield function" and "flow rule," respectively.

A considerable wealth of experimental evidence exists on the onset of yielding in a multiaxial stress state. The bulk of this evidence supports the Von Mises yield criterion, which asserts that yielding occurs when the stress state is such that

$$
0.5\left[\left(\sigma_{1}-\sigma_{2}\right)^{2}+\left(\sigma_{2}-\sigma_{3}\right)^{2}+\left(\sigma_{3}-\sigma_{1}\right)^{2}\right]=\sigma_{y}^{2}
$$

where the $\sigma_{\mathrm{i}}$ values ( $\mathrm{i}=1,2$, and 3) are the principle stresses, and $\sigma_{\mathrm{y}}$ is the yield stress as determined in a uniaxial stress-strain test. The square root of the left side of this equation is referred to as the "effective stress," $\sigma_{e}$, and this effective stress is one commonly used type of yield function.

To determine how the yield stress changes with permanent deformation, the yield stress is hypothesized to be a function of the equivalent plastic strain, $\varepsilon^{P}$. An increment of equivalent plastic strain is determined at each load step, and $\varepsilon^{\mathrm{P}}$ is defined as the sum of all increments incurred: 


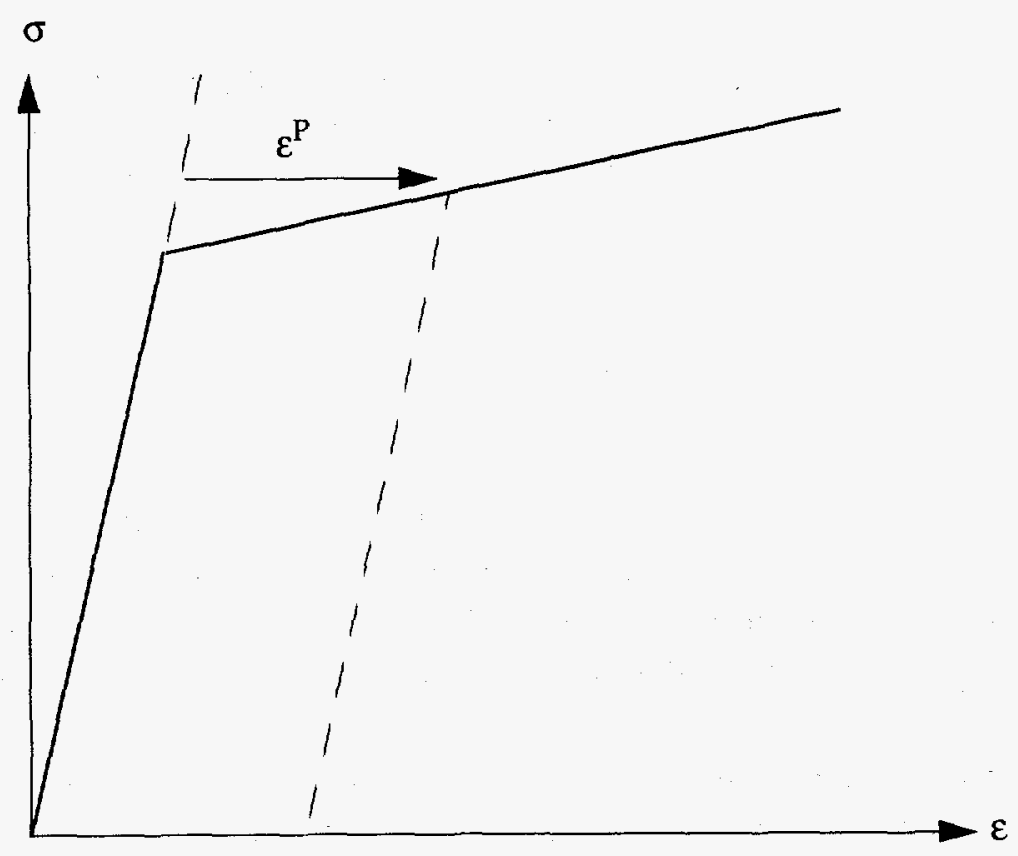

Figure 2,7 Typical Isothermal Stress-Strain Curve

$$
\varepsilon^{\mathrm{p}} \stackrel{\Delta}{=} \sum \mathrm{d} \varepsilon^{\mathrm{p}}
$$

Each increment of effective plastic strain is related to the individual plastic strain components by

$$
\mathrm{d} \varepsilon^{\mathrm{p}}=\frac{\sqrt{2}}{3}\left[\left(\mathrm{~d} \varepsilon_{1}^{\mathrm{P}}-\mathrm{d} \varepsilon_{2}^{\mathrm{P}}\right)^{2}+\left(\mathrm{d} \varepsilon_{2}^{\mathrm{P}}-\mathrm{d} \varepsilon_{3}^{\mathrm{P}}\right)^{2}+\left(\mathrm{d} \varepsilon_{3}^{\mathrm{P}}-\mathrm{d} \varepsilon_{1}^{\mathrm{P}}\right)^{2}\right]^{1 / 2}
$$

where the $d \varepsilon_{i}^{P}(i=1,2$, and 3$)$ are the plastic strain components in principle coordinates. Experimental results indicate that at pressures on the order of the yield stress, plastic deformation occurs with no change in volume, which implies that

$$
\mathrm{d} \varepsilon_{1}^{\mathrm{P}}+\mathrm{d} \varepsilon_{2}^{\mathrm{P}}+\mathrm{d} \varepsilon_{3}^{\mathrm{P}}=0
$$


Therefore, in a uniaxial test with $\sigma_{1}=\sigma, \sigma_{2}=\sigma_{3}=0$, the plastic strain increments are

$$
\mathrm{d} \varepsilon_{2}^{\mathrm{P}}=\mathrm{d} \varepsilon_{3}^{\mathrm{P}}=-1 / 2 \mathrm{~d} \varepsilon_{1}^{\mathrm{P}} .
$$

Therefore, in a uniaxial test, Equations (2-62) and (2-64) reduce to

$$
\begin{gathered}
\sigma=\sigma_{\mathrm{y}} \\
\mathrm{d} \varepsilon^{\mathrm{p}}=\mathrm{d} \varepsilon_{1}^{\mathrm{p}} .
\end{gathered}
$$

Thus, when the assumption is made that the yield stress is a function of the total effective plastic strain (called the Strain Hardening Hypothesis), the functional relationship between yield stress and plastic strain can be taken directly from a uniaxial stress-strain curve by virtue of Equations (2-67) and (2-68).

The relationship between the magnitudes of the plastic strain increments and the effective plastic strain increment is provided by the Prandtl-Reuss Flow Rule:

$$
d \varepsilon_{i}^{P}=\frac{3 d \varepsilon^{P}}{2 \sigma_{e}} S_{i} \quad i=1,2,3
$$

where the $S_{\mathrm{i}}$ values are the deviatoric stress components (in principal coordinates) defined by

$$
S_{i}=\sigma_{i}-\frac{1}{3}\left(\sigma_{1}+\sigma_{2}+\sigma_{3}\right) \quad i=1,2,3 .
$$

Equation (2-69) embodies the fundamental observation of plastic deformation; that is, plastic strain increments are proportional to the deviatoric stresses. The constant of proportionality is determined by the choice of the yield function. Direct substitution shows that Equations (2-62), (2-64), (2-69), and (2-70) are consistent with one another.

Once the plastic strain increments have been determined for a given load step, the total strains are determined from a generalized form of Hooke's law given by 


$$
\begin{aligned}
& \varepsilon_{1}=\frac{1}{\mathrm{E}}\left\{\sigma_{1}-v\left(\sigma_{2}+\sigma_{3}\right)\right\}+\varepsilon_{1}^{\mathrm{P}}+\mathrm{d} \varepsilon_{1}^{\mathrm{P}}+\int \alpha_{1} \mathrm{dT} \\
& \varepsilon_{2}=\frac{1}{\mathrm{E}}\left\{\sigma_{2}-\nu\left(\sigma_{1}+\sigma_{3}\right)\right\}+\varepsilon_{2}^{\mathrm{P}}+\mathrm{d} \varepsilon_{2}^{\mathrm{P}}+\int \alpha_{2} \mathrm{dT} \\
& \varepsilon_{3}=\frac{1}{\mathrm{E}}\left\{\sigma_{3}-v\left(\sigma_{2}+\sigma_{1}\right)\right\}+\varepsilon_{3}^{\mathrm{P}}+\mathrm{d} \varepsilon_{3}^{\mathrm{P}}+\int \alpha_{3} \mathrm{dT}
\end{aligned}
$$

in which $\varepsilon_{1}^{\mathrm{P}}, \varepsilon_{2}^{\mathrm{P}}, \varepsilon_{3}^{\mathrm{P}}$ are the total plastic strain components at the end of the previous load increment and where $E$ and $v$ are the modulus of elasticity and poisons ratio, respectively, obtained from MATPRO.

The remaining continuum field equations of equilibrium, strain displacement, and strain compatibility are unchanged. The complete set of governing equations is presented in Table 2-1, written in terms of rectangular Cartesian coordinates and employing the usual indicial notation in which a repeated Latin index implies summation. This set of equations is augmented by an experimentally determined uniaxial stress-strain relation.

Table 2-1. Summary of FRACAS-I Governing Equations

$$
\begin{gathered}
\text { Equilibrium } \\
\sigma_{\mathrm{ji}, \mathrm{j}}+\rho \mathrm{f}_{\mathrm{i}}=0 \\
\text { where } \sigma=\text { stress tensor } \\
\rho=\text { mass density } \\
\mathrm{f}_{\mathrm{i}}=\text { components of body force per unit mass } \\
\text { Stress strain } \\
\varepsilon_{\mathrm{ij}}=\frac{1+v}{\mathrm{E}} \sigma_{\mathrm{ij}}-\delta_{\mathrm{ij}}\left(\frac{v}{\mathrm{E}} \sigma_{\mathrm{kk}}-\int \alpha \mathrm{dT}\right)+\varepsilon_{\mathrm{ij}}^{\mathrm{P}}+\mathrm{d} \varepsilon_{\mathrm{ij}}^{\mathrm{P}} \\
\text { Compatibility } \\
\varepsilon_{\mathrm{ij}, \mathrm{kl}}+\varepsilon_{\mathrm{kl}, \mathrm{ij}}-\varepsilon_{\mathrm{ik}, \mathrm{jl}}-\varepsilon_{\mathrm{jl}, \mathrm{ik}}=0 \\
\text { Definitions used in plasticity } \\
\sigma_{\mathrm{e}} \triangleq \sqrt{\frac{3}{2} S_{\mathrm{ij}} \mathrm{S}_{\mathrm{ij}}} \\
S_{\mathrm{ij}} \triangleq \sigma_{\mathrm{ij}}-\frac{1}{3} \sigma_{\mathrm{kk}}
\end{gathered}
$$

Prandtl-Reuss flow rule

$$
d \varepsilon_{i j}^{P}=\frac{3}{2} \frac{d \varepsilon^{P}}{\sigma_{e}} S_{i j}
$$


The Method of Solution--When the problem under consideration is statically determinate so that stresses can be found from equilibrium conditions alone, the resulting plastic deformation can be determined directly. However, when the problem is statically indeterminate and the stresses and deformation must be found simultaneously, the full set of plasticity equations proves to be quite formidable, even in the case of simple loadings and geometries.

One numerical procedure which has been used with considerable success is the Method of Successive Substitutions. This method can be applied to any problem for which an elastic solution can be obtained, either in closed form or numerically. A full discussion of this technique, including a number of technologically useful examples, is contained in Reference 23.

Briefly, the method involves breaking the loading path up into a number of small increments. For example, in the present application, the loads are external pressure, temperature, and either internal pressure or a prescribed displacement of the inside surface of the cladding. These loads all vary during the operating history of the fuel rod. For each new increment of the loading, the solution to all the plasticity equations listed in Table 2-1 is obtained as follows.

First, an initial estimate of the plastic strain increments, $d \varepsilon_{i j}^{\mathrm{P}}$, is made. On the basis of these values, the equations of equilibrium, Hooke's Law, and strain-displacement and compatibility are solved as for any elastic problem. From the stresses so obtained, the deviatoric stresses, $\mathrm{S}_{\mathrm{ij}}$, may be computed. This "pseudo-elastic" solution represents one path in the computational scheme.

Independently, through use of the assumed $d \varepsilon_{\mathrm{ij}}^{\mathrm{p}}$ values, the increment of effective plastic strain, $d \varepsilon^{\mathrm{P}}$, may be computed. From this result and the stress-strain curve, a value of the effective stress, $\sigma_{e}$, is obtained from Equation (2-62).

Finally, a new estimate of the plastic strain increments is obtained from the Prandtl-Reuss flow rule

$$
d \varepsilon_{i j}^{P}=\frac{3}{2} \frac{d \varepsilon^{P}}{\sigma_{e}} S_{i j}
$$

and the entire process is continued until the $d \varepsilon_{i j}^{\mathrm{P}}$ converge. A schematic of the iteration scheme is shown in Figure 2.8.

The mechanism by which improved estimates of $d \varepsilon_{i j}^{p}$ are obtained results from the fact that the effective stress obtained from $\mathrm{d}^{\mathrm{P}}$ and the stress-strain curve will not be equal to the effective stress that would be obtained with the stresses from the elastic solution. The effective stresses will only agree when convergence is obtained. 


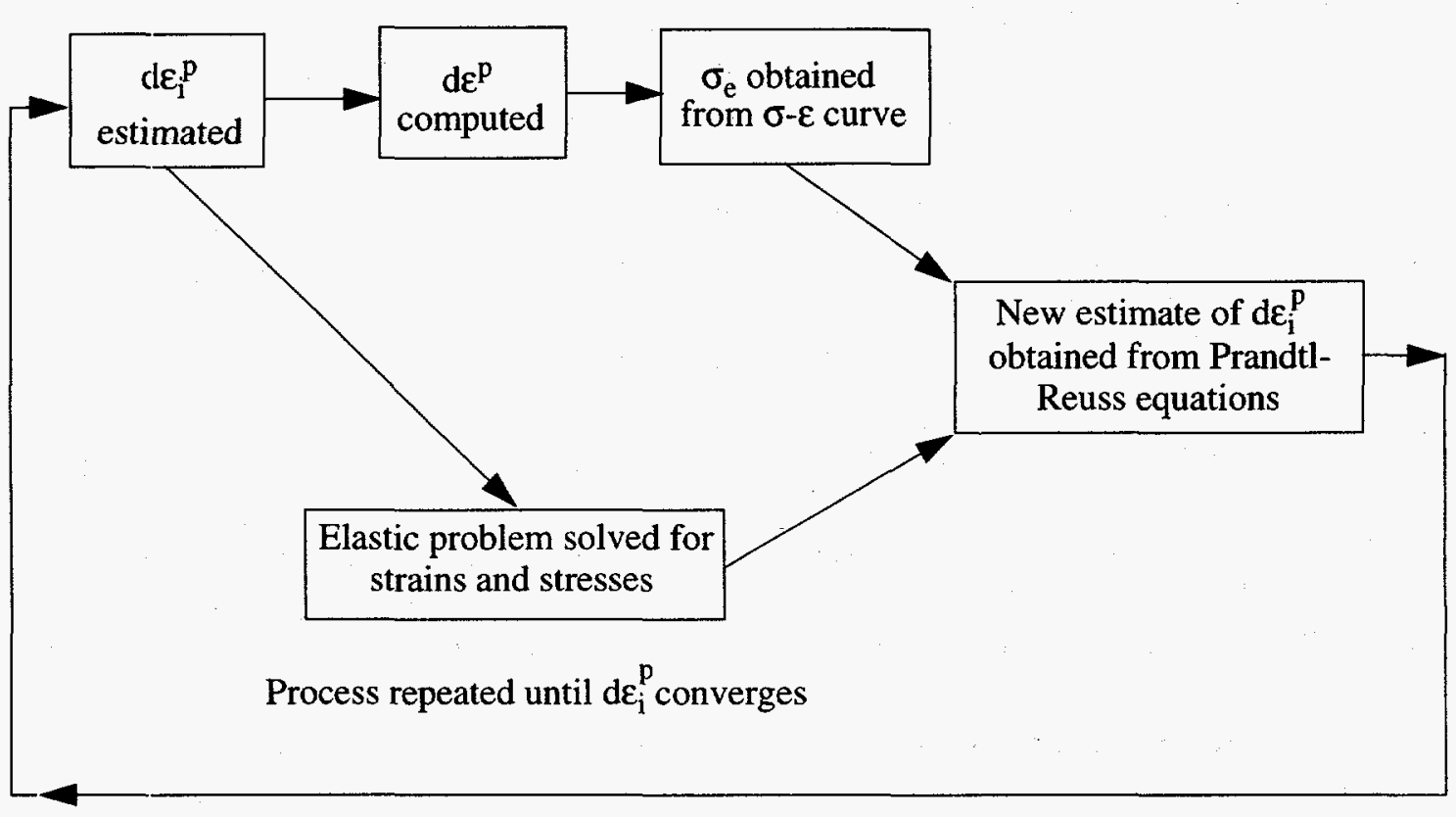

Figure 2.8 Schematic of the Method of Successive Elastic Solutions

The question of convergence is one that cannot, in general, be answered a priori. However, convergence can be shown ${ }^{23}$ to be obtained for sufficiently small load increments. Experience has shown that this technique is suitable for both steady-state and transient fuel rod analyses.

2.4.1.1.2 Extension to Creep--The method of solution described for the timeindependent plasticity calculations can also be used for time-dependent creep calculations. In this context, the term creep refers to any time-dependent constant volume permanent deformation. Creep is a stress-driven process and is usually highly dependent on temperature.

The only change required to extend the Method of Successive Elastic Solutions to allow consideration of creep is to rewrite the Prandtl-Reuss flow rule [Equation (2-69)] as 


$$
\begin{aligned}
\mathrm{d} \varepsilon_{1}^{\mathrm{c}} & =1.5 \frac{\dot{\varepsilon}^{\mathrm{c}} \Delta \mathrm{t}}{\sigma_{\mathrm{e}}} \mathrm{S}_{1}+\frac{\dot{\mathrm{V}}^{\mathrm{c}} \Delta \mathrm{t}}{9} \frac{\left(\sigma_{1}+\sigma_{2}+\sigma_{3}\right)}{\sigma_{\mathrm{m}}} \\
\mathrm{d} \varepsilon_{2}^{\mathrm{c}} & =1.5 \frac{\dot{\varepsilon}^{\mathrm{c}} \Delta \mathrm{t}}{\sigma_{\mathrm{e}}} \mathrm{S}_{2}+\frac{\dot{\mathrm{V}}^{\mathrm{c}} \Delta \mathrm{t}}{9} \frac{\left(\sigma_{1}+\sigma_{2}+\sigma_{3}\right)}{\sigma_{\mathrm{m}}} \\
\mathrm{d} \varepsilon_{3}^{\mathrm{c}} & =1.5 \frac{\dot{\varepsilon}^{\mathrm{c}} \Delta \mathrm{t}}{\sigma_{\mathrm{e}}} \mathrm{S}_{3}+\frac{\dot{\mathrm{V}}^{\mathrm{c}} \Delta \mathrm{t}}{9} \frac{\left(\sigma_{1}+\sigma_{2}+\sigma_{3}\right)}{\sigma_{\mathrm{m}}}
\end{aligned}
$$

The first term on the right hand side of each of these equations computes the constant volume creep strain, whereas the second term in each equation computes the permanent change in volume. To use this form of ti e flow rule, two additional material property correlations must be available. The first is a correlation for constant volume creep strain, $\varepsilon^{\mathfrak{c}}$ (taken in a uniaxial test), as a function of stress, time, temperature, and neutron flux; that is,

$$
\varepsilon^{\mathfrak{c}}=\mathrm{f}(\sigma, \mathrm{T}, \mathrm{t}, \dot{\mathrm{F}})
$$

where

$$
\begin{array}{lll}
\sigma & = & \text { uniaxial stress }(\mathrm{MPa}) \\
\mathrm{T} & = & \text { temperature }(\mathrm{K}) \\
\mathrm{t} & = & \text { time }(\mathrm{s}) \\
\dot{\mathrm{F}} & = & \text { neutron flux }\left(\text { neutrons } / \mathrm{m}^{2} \times \mathrm{s}\right) .
\end{array}
$$

In the FRACAS model, the strain hardening hypothesis is assumed, which implies that the strain correlation can be differentiated with respect to time and solved for creep strain rate in the form

$$
\dot{\varepsilon}^{\mathfrak{c}}=\mathrm{h}\left(\sigma, \varepsilon^{\mathfrak{c}}, \mathrm{T}, \dot{\mathrm{F}}\right)
$$

which is no longer an explicit function of time. The function " $h$ " is contained in subroutine CREPR, and is the following:

$$
\dot{\varepsilon}^{\mathrm{c}}=\{[2.0(\mathrm{a} 1 \mathrm{a} 2 \mathrm{a} 3)]\}^{2} / \varepsilon^{\mathrm{c}}
$$


where
a1 $\quad:=\quad \mathrm{k} \dot{\mathrm{F}}$
a2 $:=\quad \exp (-10000 / \mathrm{RT})$
a3 : $=\quad \sigma_{\mathrm{h}}+\mathrm{b} \exp \left(\mathrm{c} \sigma_{\mathrm{h}}\right)$

and

$\begin{array}{llll}\sigma_{\mathrm{h}} & = & & \text { hoop stress }(\mathrm{psi}) \\ \dot{\varepsilon} & = & & \text { generalized creep strain rate (in/in/s) } \\ \varepsilon^{\mathrm{c}} & = & & \text { generalized creep strain (in/in) } \\ \mathrm{R} & = & \text { universal gas constant }(\mathrm{cal} / \mathrm{mole} / \mathrm{K}) \\ \mathrm{T} & = & \text { Kelvin } \\ \mathrm{flux} & = & \mathrm{n} / \mathrm{m}^{2} / \mathrm{s} \\ \mathrm{k} & = & 5.12 \mathrm{E}^{-29} \\ \mathrm{c} & = & 4.967 \mathrm{E}^{-8} \\ \mathrm{~b} & = & 725.2 .\end{array}$

The time and stress dependencies were derived from in-reactor tubular creep rate data from Ibrahim; ${ }^{24}$ the flux dependence was based on Ross-Ross and Hunt, ${ }^{25}$ and the temperature dependence was derived from Fidleris. ${ }^{26} \mathrm{~A}$ plot of the resulting creep strain is shown as a function of time and hoop stress for representative flux and temperature values in Figure 2.9.

The second additional correlation required is a relationship between the rate of permanent volumetric strain and the applied loads; that is,

$$
\dot{\mathrm{V}}^{\mathrm{c}}=\mathrm{g}\left(\sigma_{\mathrm{m}}, \mathrm{T}, \mathrm{t}, \mathrm{V}_{\mathrm{avai1}}\right)
$$




\section{Crepr Model with Temperature $=630 \mathrm{~F}$ and Flux $=1 \mathrm{e} 18 \mathrm{n} / \mathrm{m}^{\wedge} 2 / \mathrm{s}$}

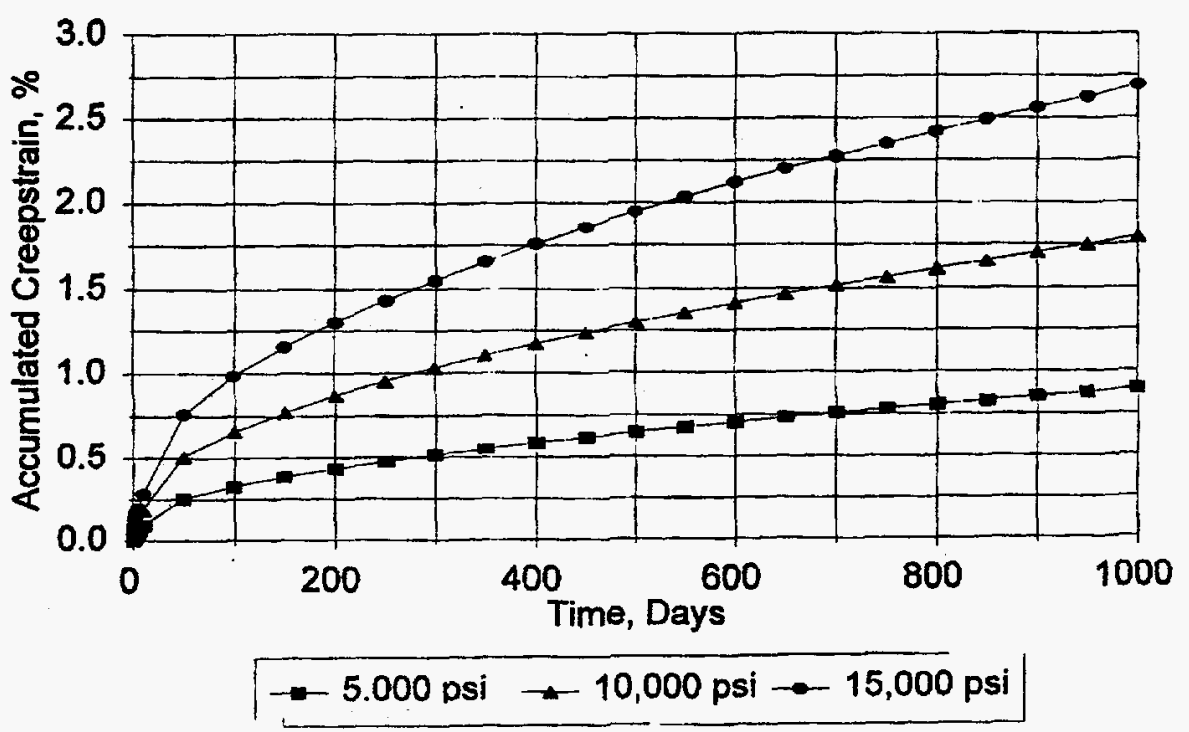

Figure 2.9 Cladding Creep Strain as a Function of Time and Hoop Stress where
$\sigma_{\mathrm{m}} \quad=\quad\left(\sigma_{1}+\sigma_{2}+\sigma_{3}\right) / 3$ the mean stress $(\mathrm{MPa})$
$\mathrm{T} \quad=\quad$ temperature $(\mathrm{K})$
$\mathrm{t} \quad$ time $(\mathrm{s})$
$\mathrm{V}_{\text {avail }}=$ measure of maximum permanent volumetric change possible. 
The permanent volumetric strain increment $\mathrm{dV}^{c}$ is related to the creep strain increments by the equation

$$
d V^{c}=d \varepsilon_{1}^{c}+d \varepsilon_{2}^{c}+d \varepsilon_{3}^{c}
$$

As previously noted, the FRACAS-I model is the only model available for analyzing the small deformation of the fuel and cladding. The model considers the fuel pellets to be essentially rigid and to deform due to thermal expansion, swelling, and densification only. Thus, in the rigid pellet model, the displacement of the fuel is calculated independently of the deformation of the cladding. This rigid pellet analysis is performed with the FRACAS-I subcode.

2.4.1.2 Rigid Pellet Cladding Deformation Model. FRACAS-I consists of a cladding deformation model and a fuel deformation model. If the fuel-cladding gap is closed, the fuel deformation model will apply a driving force to the cladding deformation model. The cladding deformation model, however, never influences the fuel deformation model.

The cladding deformation model in FRACAS-I is based on the following assumptions:

- Incremental theory of plasticity.

- $\quad$ Prandtl-Reuss flow rule.

- Isotropic work-hardening.

- Thin wall cladding (stress, strain, and temperature uniform through cladding thickness).

- If fuel and cladding are in contact, no axial slippage occurs at fuel cladding interface.

- $\quad$ Bending strains and stresses in cladding are negligible.

- $\quad$ Axisymmetric loading and deformation of cladding.

The fuel deformation model in FRACAS-I is based on the following assumptions:

Thermal expansion, swelling, and densification are the only sources for fuel deformation.

No resistance to expansion of fuel. 
- No creep deformation of fuel.

- $\quad$ Isotropic fuel properties.

The cladding and fuel deformation models in FRACAS-I are described below.

2.4.1.2.1 Cladding Deformation Model--The rigid pellet cladding deformation subcode (FRACAS-I) consists of four sets of models, each used independently of the others.

Deformation and stresses in the cladding in the open gap regime are computed using a model which considers a thin cylindrical shell with specified internal and external pressures and a prescribed uniform temperature.

Calculations for the closed gap regime are made using a model which considers a thin cylindrical shell with prescribed external pressure and a prescribed radial displacement of the cladding inside surface. The prescribed displacement is obtained from the fuel expansion models (including swelling) described later in this section. Further, since no slippage is assumed to take place when the fuel and cladding are in contact, the axial expansion of the fuel is transmitted directly to the cladding, and hence, the change in axial strain in the shell is also prescribed.

The decision whether the fuel-cladding gap is open or closed is made by considering the relative movement of the cladding inside surface and the fuel outside surface. At the completion of the FRACAS-I analysis, either a new fuel-cladding gap size or a new fuel-cladding interfacial pressure and the elastic-plastic cladding stresses and strains are obtained.

Two additional models are used to compute changes in yield stress with work-hardening, given a uniaxial stress-strain curve. This stress-strain curve is obtained from MATPRO. The first model computes the effective total strain and new effective plastic strain, given a value of effective stress and the effective plastic strain at the end of the last loading increment. The second model computes the effective stress, given an increment of plastic strain and the effective plastic strain at the end of the last loading increment. Depending on the work-hardened value of yield stress, loading can be either elastic or plastic, and unloading is constrained to occur elastically. (Isotropic work-hardening is assumed in these calculations.) These four sets of models are described below.

The decision as to whether or not the fuel is in contact with the cladding is made by comparing the radial displacement of the fuel surface with the radial displacement that would occur in the cladding due to the prescribed external (coolant) pressure and the prescribed internal (fission and fill gas) pressure. The free radial displacement of the cladding is obtained using Equation (2-71). The following expression is used to decide if fuel-cladding contact has occurred: 


$$
u_{r}^{\text {fuel }} \geq u_{r}^{\text {clad }}+\delta
$$

where

$$
\delta \quad=\quad \text { as-fabricated fuel-cladding gap size }(\mathrm{m})
$$

If Equation (2-79) is satisfied, the fuel is in contact with the cladding. The loading history enters into this decision by virtue of the permanent plastic cladding strains which are applied to the as-fabricated geometry. These plastic strains, and total effective plastic strain, $\varepsilon^{\mathrm{P}}$, are retained for use in subsequent calculations.

If the fuel and cladding displacements are such that Equation (2-79) is not satisfied, the fuelcladding gap has not closed during the current step and the solution obtained by the open gap solution is appropriate. The current value of the fuel-cladding gap size is then computed and is used in the temperature calculations. The plastic strain values may be changed in the solution if additional plastic straining has occurred.

If Equation (2-79) is satisfied, however, fuel and cladding contact has occurred during the current loading increment. At the contact interface, radial continuity requires that

$$
u_{r}^{\text {clad }}=u_{r}^{\text {fuel }}-\delta
$$

while in the axial direction the assumption is made that no slippage occurs between the fuel and the cladding. This state is referred to as "lockup".

Note that only the additional strain which occurs in the fuel after lock-up has occurred is transferred to the cladding. Thus, if $\varepsilon_{\mathrm{z}, \mathrm{o}}^{\text {clad }}$ is the axial strain in the cladding just prior to contact, and $\varepsilon_{z, 0}^{\text {tuel }}$ is the corresponding axial strain in the fuel, then the no-slippage condition in the axial direction becomes

$$
\varepsilon_{z}^{\text {clad }}-\varepsilon_{z, 0}^{\text {clad }}=\varepsilon_{z}^{\text {fuel }}-\varepsilon_{z, 0}^{\text {fuel }}
$$

The values of the "prestrains", $\varepsilon_{z, 0}^{\text {tuel }}$ and $\varepsilon_{z, 0}^{\text {clad }}$, are set equal to the values of the strains that existed in the fuel and cladding at the time of fuel-cladding gap closure and are stored and used in the cladding sequence of calculations. The values are updated at the end of any load increment during which the fuel-cladding gap is closed. 
After $u_{r}^{\text {clad }}$ and $\varepsilon_{z}^{\text {clad }}$ have been computed, they are used in a calculation which considers a thin cylindrical shell with prescribed axial strain, external pressure and prescribed radial displacement of the inside surface. After the solution is obtained, a value of the fuel-cladding interfacial pressure is computed along with new plastic strains and stresses.

The open gap modeling considers a thin cylindrical shell loaded by both internal and external pressures. Axisymmetric loading and deformation are assumed. Loading is also restricted to being uniform in the axial direction, and no bending is considered. The geometry and coordinates are shown in Figure 2.10. The displacements of the midplane of the shell are $u$ and $w$ in the radial and axial directions, respectively.
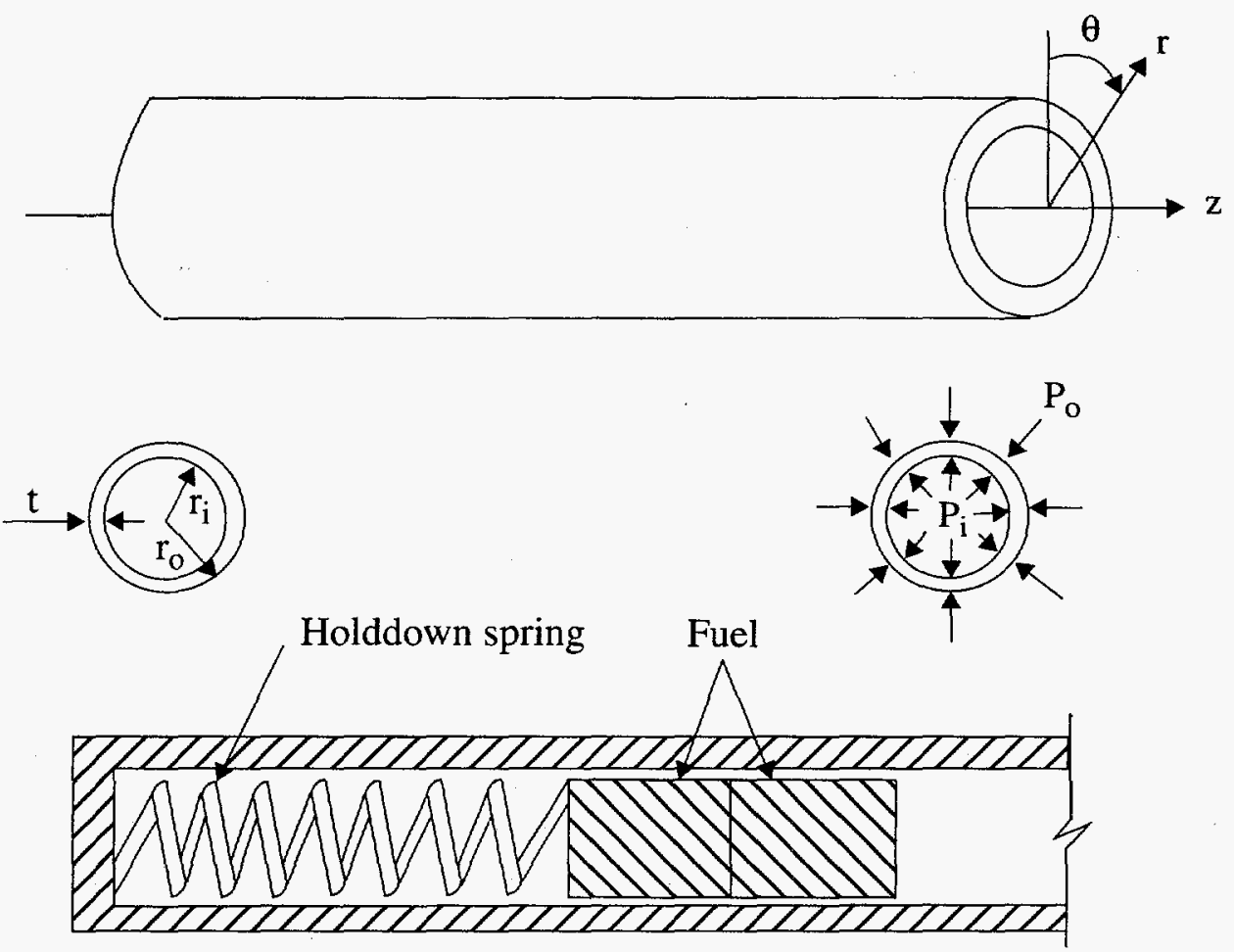

Figure 2.10 Fuel Rod Geometry and Coordinates

For this case, the equilibrium equations are identically satisfied by

$$
\begin{aligned}
& \sigma_{\theta}=\frac{r_{i} P_{i}-r_{0} P_{0}}{t} \\
& \sigma_{z}=\frac{r_{i}^{2} P_{i}-r_{0}^{2} P_{0}}{r_{0}^{2}-r_{i}^{2}}
\end{aligned}
$$


where

\begin{tabular}{|c|c|c|}
\hline$\sigma_{\theta}$ & $=$ & hoop stress $(\mathrm{MPa})$ \\
\hline$\sigma_{\mathrm{z}}$ & $=$ & axial stress $(\mathrm{MPa})$ \\
\hline$r_{i}$ & $=:$ & inside radius of cladding $(\mathrm{m})$ \\
\hline$r_{0}$ & $=$ & outside radius of cladding $(\mathrm{m})$ \\
\hline$P_{i}$ & $=:$ & fuel rod internal gas pressure (MPa) \\
\hline$P_{0}$ & $=:$ & coolant pressure $(\mathrm{MPa})$ \\
\hline $\mathrm{t}$ & $=:$ & cladding thickness $(\mathrm{m})$. \\
\hline
\end{tabular}

For membrane shell theory, the strains are related to the midplane displacements by

$$
\begin{gathered}
\varepsilon_{z}=\frac{\partial w}{\partial z} \\
\varepsilon_{\theta}=\frac{u}{\bar{r}}
\end{gathered}
$$

where $\overline{\mathbf{r}}$ is the radius of the midplane. Strain across the thickness of the shell is allowed. In shell theory, since the radial stress can be neglected, and since the hoop stress, $\sigma_{\theta}$, and axial stress, $\sigma_{z}$, are uniform across the thickness when bending is not considered, the radial strain is due only to the Poisson's effect and is uniform across the thickness. (Normally, radial strains are not considered in a shell theory, but plastic radial strains must be included when plastic deformations are considered).

The stress--strain relations are written in incremental form as

$$
\varepsilon_{\theta}=\frac{1}{E}\left\{\dot{\sigma}_{\theta}-v \sigma_{z}\right\}+\varepsilon_{\theta}^{\mathrm{P}}+\mathrm{d} \varepsilon_{\theta}^{\mathrm{P}}+\int_{\mathrm{T}_{0}}^{\mathrm{T}} \alpha_{\theta} \mathrm{dT}
$$




$$
\begin{aligned}
& \varepsilon_{z}=\frac{1}{E}\left\{\sigma_{z}-v \sigma_{\theta}\right\}+\varepsilon_{z}^{P}+d \varepsilon_{z}^{P}+\int_{T_{0}}^{T} \alpha_{z} d T \\
& \varepsilon_{r}=-\frac{v}{E}\left\{\sigma_{\theta}+\sigma_{z}\right\}+\varepsilon_{r}^{P}+d \varepsilon_{r}^{P}+\int_{T_{0}}^{T} \alpha_{r} d T
\end{aligned}
$$

where

$\begin{array}{lll}\mathrm{T}_{\mathrm{o}} & = & \text { strain-free reference temperature }(\mathrm{K}) \\ \alpha & = & \text { coefficient of thermal expansion } \\ \mathrm{T} & = & \text { current average cladding temperature }(\mathrm{K}) \\ \mathrm{E} & = & \text { modulus of elasticity } \\ \mathrm{v} & = & \text { Poisson's ratio. }\end{array}$

The terms $\varepsilon_{\theta}^{\mathrm{P}}, \varepsilon_{\mathrm{z}}^{\mathrm{P}}$ and $\varepsilon_{\mathrm{r}}^{\mathrm{P}}$ are the plastic strains at the end of the last load increment, and $\mathrm{d} \varepsilon_{\theta}^{\mathrm{P}}, \mathrm{d} \varepsilon_{\mathrm{z}}^{\mathrm{P}}$, and $\mathrm{d} \varepsilon_{\mathrm{r}}^{\mathrm{P}}$ are the additional plastic strain increments which occur due to the new load increment.

The magnitude of the additional plastic strain increments is determined by the effective stress and the Prandtl-Reuss flow rule, expresses as

$$
\begin{gathered}
\sigma_{\mathrm{e}}=\frac{1}{\sqrt{2}}\left[\left(\sigma_{\theta}-\sigma_{\mathrm{z}}\right)^{2}+\left(\sigma_{z}\right)^{2}+\left(\sigma_{\theta}\right)^{2}\right]^{1 / 2} \\
\mathrm{~d} \varepsilon_{\mathrm{i}}^{\mathrm{P}}=\frac{3}{2} \frac{\mathrm{d} \varepsilon^{\mathrm{P}}}{\sigma_{\mathrm{e}}} \mathrm{S}_{\mathrm{i}} \text { for } \mathrm{i}=\mathrm{r}, \theta, \mathrm{z} \\
\mathrm{S}_{\mathrm{i}}=\sigma_{\mathrm{i}}-\frac{1}{3}\left(\sigma_{\theta}+\sigma_{\mathrm{z}}\right) \text { for } \mathrm{i}=\mathrm{r}, \theta, \mathrm{z} .
\end{gathered}
$$


The solution of the open gap case proceeds as follows. At the end of the last load increment the plastic strain components, $\varepsilon_{\theta}^{\mathrm{P}}, \varepsilon_{z}^{\mathrm{P}}$, and $\varepsilon_{\mathrm{r}}^{\mathrm{P}}$ are known. Also the total effective plastic strain, $\varepsilon^{\mathrm{P}}$, is known.

The loading is now incremented with the prescribed values of $\mathrm{P}_{\mathrm{i}}, \mathrm{P}_{\mathrm{o}}$, and $\mathrm{T}$. The new stresses can be determined from Equations (2-82) and (2-83), and a new value of effective stress is obtained from Equation (2-89).

The increment of effective plastic strain, $\mathrm{d}^{\mathrm{P}}$, which results from the current increment of loading, can now be determined from the uniaxial stress-strain curve at the new value of $\sigma_{\mathrm{e}}$, as shown in Figure 2.11. (The new elastic loading curve depends on the value of $\varepsilon^{\mathrm{P}}$ ).

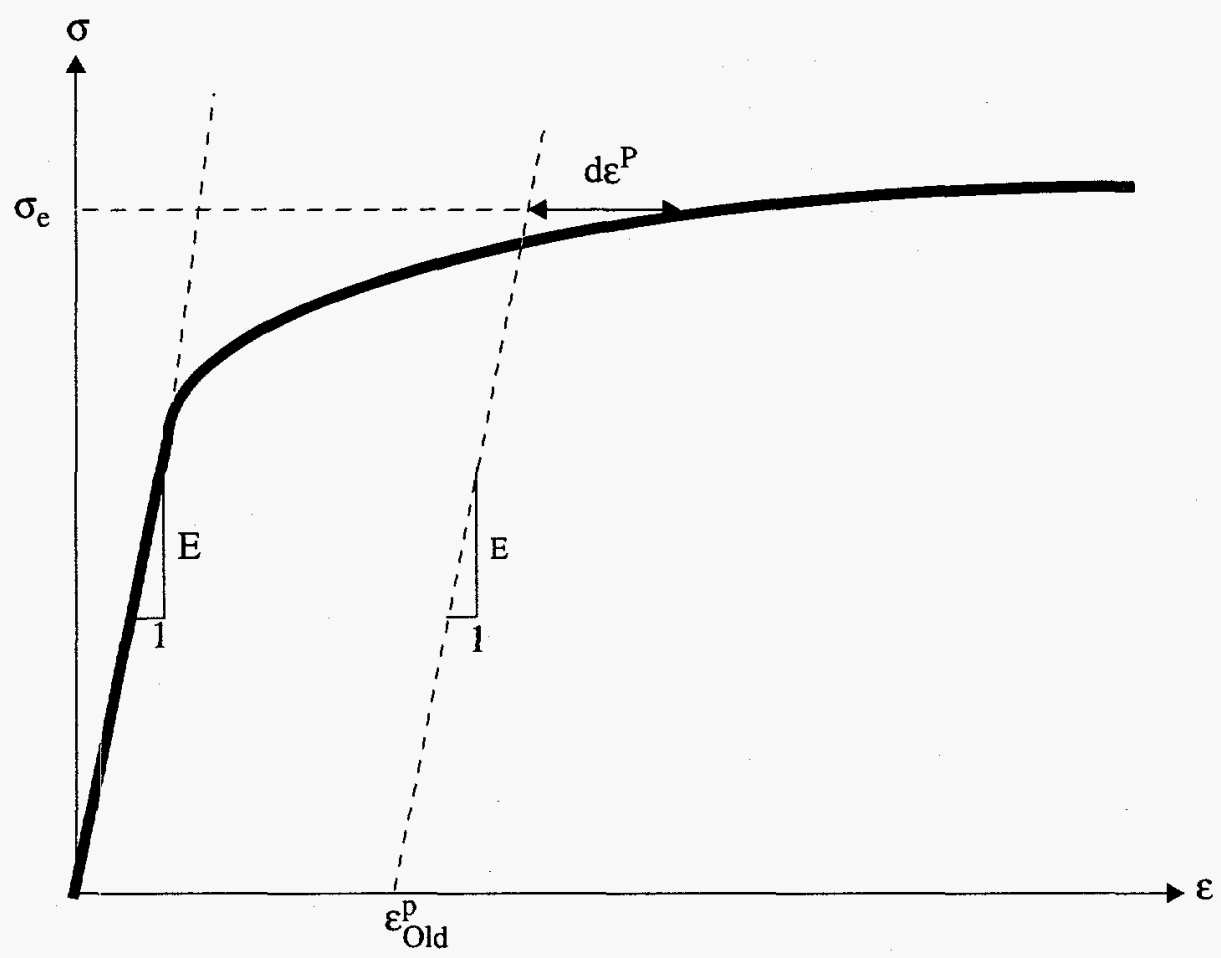

Figure 2.11 Calculation of Effective Stress $\sigma_{\mathrm{e}}$ from $\mathrm{d} \boldsymbol{\varepsilon}^{\mathrm{P}}$

Once $d \varepsilon^{\mathrm{P}}$ is determined, the individual plastic strain components are found from Equation (2-90), and the total strain components are obtained from Equations (2-86) through (2-88).

The displacement of the inside surface of the shell must be determined so that a new fuelcladding gap width can be computed. The radial displacement of the inside surface is given by 


$$
u\left(r_{i}\right)=\tilde{r} \varepsilon_{\theta}-\frac{t}{2} \varepsilon_{r}
$$

where the first term is the radial displacement of the midplane [from Equation (2-85)] and $\varepsilon_{\mathrm{r}}$ is the uniform strain across the cladding thickness, $t$.

The cladding thickness is computed by the equation

$$
t=\left(1+\varepsilon_{r}\right) t_{o}
$$

where

$\mathrm{t}_{\mathrm{o}} \quad=\quad$ as-fabricated, unstressed thickness.

The final step performed is to add the plastic strain increments to the previous plastic strain values; that is,

$$
\begin{aligned}
& \left(\varepsilon_{\theta}^{\mathrm{P}}\right)_{\text {new }}=\left(\varepsilon_{\theta}^{\mathrm{P}}\right)_{\text {old }}+\mathrm{d} \varepsilon_{\theta}^{\mathrm{P}} \\
& \left(\varepsilon_{z}^{\mathrm{P}}\right)_{\text {new }}=\left(\varepsilon_{\mathrm{z}}^{\mathrm{P}}\right)_{\text {old }}+\mathrm{d} \varepsilon_{\mathrm{z}}^{\mathrm{P}} \\
& \left(\varepsilon_{\mathrm{r}}^{\mathrm{P}}\right)_{\text {new }}=\left(\varepsilon_{\mathrm{r}}^{\mathrm{P}}\right)_{\text {old }}+\mathrm{d} \varepsilon_{\mathrm{r}}^{\mathrm{P}} \\
& \left(\varepsilon^{\mathrm{P}}\right)_{\text {new }}=\left(\varepsilon^{\mathrm{P}}\right)_{\text {old }}+\mathrm{d} \varepsilon^{\mathrm{P}}
\end{aligned}
$$

These values are used for the next load increment.

Thus all the stresses and strains can be computed directly, since in this case the stresses are determinate. In the case of the driven cladding displacement, the stresses depend on the displacement, and such a straightforward solution is not possible.

The closed gap modeling considers the problem of a cylindrical shell for which the radial displacement of the inside surface and axial strain are prescribed. Here the stresses cannot be computed directly since the pressure at the inside surface (the fuel-cladding interfacial pressure) must be determined as part of the solution. 
As in the open gap modeling, the displacement at the inside surface is given by

$$
u\left(r_{i}\right)=u-\frac{t}{2} \varepsilon_{r}
$$

where $u$ is the radial displacement of the midplane. From Equation (2-86), $u=r \varepsilon_{\theta}$ and

$$
u\left(r_{i}\right)=\bar{r} \varepsilon_{\theta}-\frac{t}{2} \varepsilon_{r} .
$$

Thus, prescribing the displacement of the inside surface of the shell is equivalent to a constraining relation between $\varepsilon_{\theta}$ and $\varepsilon_{\mathrm{i}}$. As before, Hooke's law is taken in the form

$$
\begin{aligned}
& \varepsilon_{\theta}=\frac{1}{E}\left(\sigma_{\theta}-v \sigma_{z}\right)+\varepsilon_{\theta}^{\mathrm{p}}+d \varepsilon_{\theta}^{\mathrm{P}}+\int_{\mathrm{T}_{0}}^{\mathrm{T}} \alpha_{\theta} \mathrm{dT} \\
& \varepsilon_{\mathrm{z}}=\frac{1}{\mathrm{E}}\left(\sigma_{\mathrm{z}}-v \sigma_{\theta}\right)+\varepsilon_{z}^{\mathrm{P}}+\mathrm{d} \varepsilon_{z}^{\mathrm{P}}+\int_{\mathrm{T}_{\mathrm{o}}}^{\mathrm{T}} \alpha_{\mathrm{z}} \mathrm{dT} \\
& \varepsilon_{\mathrm{r}}=-\frac{v}{\mathrm{E}}\left(\sigma_{\theta}-\sigma_{z}\right)+\varepsilon_{\mathrm{r}}^{\mathrm{P}}+\mathrm{d} \varepsilon_{\mathrm{r}}^{\mathrm{P}}+\int_{\mathrm{T}_{0}}^{\mathrm{T}} \alpha_{\mathrm{r}} \mathrm{dT} .
\end{aligned}
$$

Use of Equations (2-96) and (2-99) in Equation (2-97) results in a relation between the stresses $\sigma_{\theta}$ and $\sigma_{i}$, and the prescribed displacement $\mathrm{u}\left(\mathrm{r}_{\mathrm{i}}\right)$ :

$$
\frac{u\left(r_{i}\right)}{\dot{\mathrm{r}}}+\frac{1}{2} \frac{t}{2 \check{r}}\left\{\varepsilon_{\mathrm{r}}^{\mathrm{P}}+\mathrm{d} \varepsilon_{\mathrm{r}}^{\mathrm{P}}+\int_{\mathrm{T}_{0}}^{\mathrm{T}} \alpha \mathrm{dT}\right\}-\left\{\varepsilon_{\theta}^{\mathrm{P}}+\mathrm{d} \varepsilon_{\theta}^{\mathrm{P}}+\int_{\mathrm{T}_{0}}^{\mathrm{T}} \alpha \mathrm{dT}\right\}=\frac{1}{\mathrm{E}}\left[\left(1+\frac{v t}{2 \dot{\mathrm{r}}}\right) \sigma_{\theta}+v\left(\frac{1 \mathrm{t}}{2 \dot{\mathrm{r}}}-1\right) \sigma_{2}\right] .
$$

Equations (2-98) and (2-100) are now a pair of simultaneous algebraic equations for the stresses $\sigma_{\theta}$ and $\sigma_{z}$, which may be written as 


$$
\left[\begin{array}{ll}
\mathrm{A}_{11} & \mathrm{~A}_{12} \\
\mathrm{~A}_{21} & \mathrm{~A}_{22}
\end{array}\right]\left[\begin{array}{l}
\sigma_{\theta} \\
\sigma_{\mathrm{z}}
\end{array}\right]=\left[\begin{array}{l}
\mathrm{B}_{1} \\
\mathrm{~B}_{2}
\end{array}\right]
$$

where

$$
\begin{array}{lll}
\mathrm{A}_{11} & = & 1+\frac{v}{2} \frac{\mathrm{t}}{\overline{\mathrm{r}}} \\
\mathrm{A}_{12} & = & v\left(\frac{1}{2} \frac{\mathrm{t}^{-1}}{\mathrm{r}}\right) \\
\mathrm{A}_{21} & = & -v \\
\mathrm{~A}_{22} & = & \\
& = & \left(\mathrm{E} \frac{\mathrm{u}\left(\mathrm{r}_{1}\right)}{\overline{\mathrm{r}}}+\frac{\mathrm{E}}{2} \frac{\mathrm{t}}{2 \overline{\mathrm{r}}}\left\{\varepsilon_{\mathrm{r}}^{\mathrm{P}}+\mathrm{d} \varepsilon_{\mathrm{r}}^{\mathrm{P}}+\int_{\mathrm{T}_{0}}^{\mathrm{T}} \alpha \mathrm{dT}\right\}\right) \\
\mathrm{B}_{1} & -\mathrm{E}\left\{\varepsilon_{\theta}^{\mathrm{P}}+\mathrm{d} \varepsilon_{\theta}^{\mathrm{P}}+\int_{\mathrm{T}_{0}}^{\mathrm{T}} \alpha \mathrm{dT}\right\} \\
\mathrm{B}_{2} & = & \mathrm{E}\left[\varepsilon_{\mathrm{z}}-\mathrm{E} \varepsilon_{\mathrm{z}}^{\mathrm{P}}+\mathrm{d} \varepsilon_{\mathrm{z}}^{\mathrm{P}}+\int_{\mathrm{T}_{0}}^{\mathrm{T}} \alpha \mathrm{dT}\right] .
\end{array}
$$

Then the stresses can be written explicitly as

$$
\begin{gathered}
\sigma_{\theta}=\frac{B_{1} A_{22}-B_{2} A_{12}}{A_{11} A_{22}-A_{12} A_{21}} \\
\sigma_{z}=\frac{B_{2} A_{11}-B_{1} A_{21}}{A_{11} A_{22}-A_{12} A_{21}} .
\end{gathered}
$$

These equations relate the stresses to $u\left(r_{i}\right)$ and $\varepsilon_{z}$, which are prescribed, and to $\mathrm{d} \varepsilon_{\theta}^{\mathrm{P}}, \mathrm{d} \varepsilon_{z}^{\mathrm{P}}$, and $\mathrm{d} \varepsilon_{\mathrm{r}}^{\mathrm{P}}$, which are to be determined. The remaining equations which must be satisfied are 


$$
\begin{gathered}
\sigma_{\mathrm{e}}=\frac{1}{\sqrt{2}}\left[\left(\sigma_{\theta}-\sigma_{\mathrm{z}}\right)^{2}+\left(\sigma_{\theta}\right)^{2}+\left(\sigma_{z}\right)^{2}\right]^{1 / 2} \\
\mathrm{~d} \varepsilon^{\mathrm{P}}=\frac{\sqrt{2}}{3}\left[\left(\mathrm{~d} \varepsilon_{\mathrm{r}}^{\mathrm{P}}-\mathrm{d} \varepsilon_{\theta}^{\mathrm{P}}\right)^{2}+\left(\mathrm{d} \varepsilon_{\theta}^{\mathrm{P}}-\mathrm{d} \varepsilon_{\mathrm{z}}^{\mathrm{P}}\right)^{2}+\left(\mathrm{d} \varepsilon_{\mathrm{z}}^{\mathrm{P}}-\mathrm{d} \varepsilon_{\mathrm{r}}^{\mathrm{P}}\right)^{2}\right]^{1 / 2}
\end{gathered}
$$

and the Prandtl-Reuss flow equations [defined in Equation (2-90)]

$$
\begin{gathered}
\mathrm{d} \varepsilon^{\mathrm{P}}=\frac{3}{2} \frac{\mathrm{d} \varepsilon^{\mathrm{P}}}{\sigma_{\mathrm{e}}}\left[\sigma_{\theta}-\frac{1}{3}\left(\sigma_{\theta}+\sigma_{z}\right)\right] \\
\mathrm{d} \varepsilon_{\mathrm{z}}^{\mathrm{P}}=\frac{3}{2} \frac{\mathrm{d} \varepsilon^{\mathrm{P}}}{\sigma_{\mathrm{e}}}\left[\sigma_{z}-\frac{1}{3}\left(\sigma_{\theta}+\sigma_{z}\right)\right] \\
\mathrm{d} \varepsilon_{\mathrm{r}}^{\mathrm{P}}=-\mathrm{d} \varepsilon_{\theta}^{\mathrm{P}}-\mathrm{d} \varepsilon_{\mathrm{z}}^{\mathrm{P}} .
\end{gathered}
$$

The effective stress, $\sigma_{\mathrm{e}}$, and the plastic strain increment, $\mathrm{d} \varepsilon^{\mathrm{P}}$, must of course, be related by the uniaxial stress-strain law. Equations (2-102) through (2-108) must be simultaneously satisfied for each loading increment.

As discussed in Section 2.4.1.1, a straightforward numerical solution to these equations can be obtained by means of the Method of Successive Elastic Solutions. By this method, arbitrary values are initially assumed for the increments of plastic strain, and Equations (2-102) through (2108 ) are used to obtain improved estimates of the plastic strain components. The steps performed are as follows for each increment of load:

1. Values of $d \varepsilon_{\theta}^{P}, d \varepsilon_{z}^{P}$, and $d \varepsilon_{r}^{P}$ are assumed. Then, $d \varepsilon^{P}$ is computed from Equation (2105 ). and the effective stress is obtained from the stress-strain curve at the value of $\mathrm{d} \varepsilon^{\mathrm{P}}$.

2. From Hooke's law, still using the assumed plastic strain increments and the prescribed values of $u\left(r_{i}\right)$ and $\varepsilon_{z}$, values for the stresses can be obtained from Equations (2-102) and (2-103). 
3. New values for $d \varepsilon_{\theta}^{\mathrm{P}}, \mathrm{d} \varepsilon_{2}^{\mathrm{P}}$, and $d \varepsilon_{\mathrm{r}}^{\mathrm{P}}$ are now computed from the Prandtl-Reuss relations,

$$
\mathrm{d} \varepsilon_{\mathrm{i}}^{\mathrm{P}}=\frac{3}{2} \frac{\mathrm{d} \varepsilon^{\mathrm{P}}}{\sigma_{\mathrm{e}}}\left[\sigma_{\mathrm{i}}-\frac{1}{3}\left(\sigma_{\theta}+\sigma_{\mathrm{z}}\right)\right] \mathrm{i}=\mathrm{r}, \theta, \mathrm{z}
$$

using $\sigma_{\mathrm{e}}$ as computed in step 1 , and $\sigma_{\mathrm{i}}$ as computed in step 2 .

4. The old and new values of $d \varepsilon_{\theta}^{\mathrm{P}}, \mathrm{d \varepsilon _{z }}$, and $\mathrm{d} \varepsilon_{\mathrm{r}}^{\mathrm{P}}$ are compared and the process continued until convergence is obtained.

5. Once convergence has been obtained, the fuel-cladding interfacial pressure is computed from the following equation.

$$
P_{i n t}=\frac{t \sigma_{\theta}+r_{0} P_{0}}{r_{i}}
$$

When steps 1 through 5 have been accomplished, the solution is complete, provided that the fuel-cladding interface pressure is not less than the local gas pressure.

However, due to unequal amounts of plastic straining in the hoop and axial directions upon unloading, the fuel-cladding interfacial pressure as obtained in step 5 is often less than the gas pressure even though the fuel-cladding gap has not opened. When this situation occurs, the frictional "locking" (which is assumed to constrain the cladding axial deformation to equal the fuel axial deformation) no longer exists. The axial strain and stress adjust themselves so that the fuel-cladding interfacial pressure equals the gas pressure, at which point the axial strain is again "locked." Thus, upon further unloading, the axial strain and the hoop and axial stresses continually readjust themselves to maintain the fuel-cladding interfacial pressure equal to the gas pressure until the fuel-cladding gap opens. Since the unloading occurs elastically, a solution for this portion of the fuel-cladding interaction problem can be obtained directly as discussed below.

Since the external pressure and the fuel-cladding interfacial pressure are known, the hoop stress is obtained from Equation (2-110) as

$$
\sigma_{\theta}=\frac{r_{i} P_{i n t}-r_{0} P_{0}}{t}
$$


From Equation (2-96), the following expression can be written:

$$
\varepsilon_{\theta}=\frac{\mathrm{u}_{\mathrm{r}}^{\text {fuel }}-\delta+\mathrm{t} / 2 \varepsilon_{\mathrm{r}}}{\dot{\mathrm{r}}} .
$$

Substitution of $\varepsilon_{\theta}$ and $\varepsilon_{\mathrm{r}}$, as given by Equations (2-97) and (2-99), into Equation (2-112) results in an explicit equation for $\sigma_{z}$ :

$$
\begin{gathered}
v r_{i} \sigma_{z}=(r+v t / 2) \sigma_{\theta}+r E\left(\int \alpha d T+d \varepsilon_{\theta}^{P}\right) \\
-\frac{t}{2} E\left(\int \alpha d T+d \varepsilon_{r}^{P}\right)-E u\left(r_{i}\right)
\end{gathered}
$$

in which $\sigma_{\theta}$ is known from Equation (2-111). With $\sigma_{z}$ and $\sigma_{\theta}$ known, the strains may be computed from Hooke's law, Equation (2-97) through (2-99). This set of equations are automatically invoked whenever $\mathrm{P}_{\text {int }}$ is computed to be less than the local gas pressure.

As in the open gap modeling, the last step performed is to set the plastic strain components and total effective strain equal to their new values by adding in the computed increments $\mathrm{d} \varepsilon_{\mathrm{j}}^{\mathrm{P}}$ and $\mathrm{d} \varepsilon^{\mathrm{P}}$.

The stress-strain modeling is used to relate stress and plastic strain, taking into consideration the direction of loading and the previous plastic deformation. A typical stress-strain curve is shown in Figure 2.12. This curve presents the results of a uniaxial stress-strain experiment and may be interpreted beyond initial yield as the focus of work-hardened yield stresses. The equation of the curve is provided by the MATPRO package at each temperature.

To utilize this information, the usual idealization of the mechanical behavior of metals is made. Thus, linear elastic behavior is assumed until a sharply defined yield stress is reached, after which plastic (irrecoverable) deformation occurs. Unloading from a stress state beyond the initial yield stress, $\sigma_{y}^{o}$, is assumed to occur along a straight line having the elastic modulus for its slope. When the (uniaxial) stress is removed completely, a residual plastic strain remains, and this completely determines the subsequent yield stress. That is, when the specimen is loaded again, loading will occur along line BA in Figure 2.12, and no additional deformation will occur until point $A$ is again reached. Point $A$ is the subsequent yield stress. If $\sigma=f(\varepsilon)$ is the equation of the plastic portion of the stress-strain curve (YAC), then for a given value of plastic strain, the subsequent yield stress is found by simultaneously solving the pair of equations 


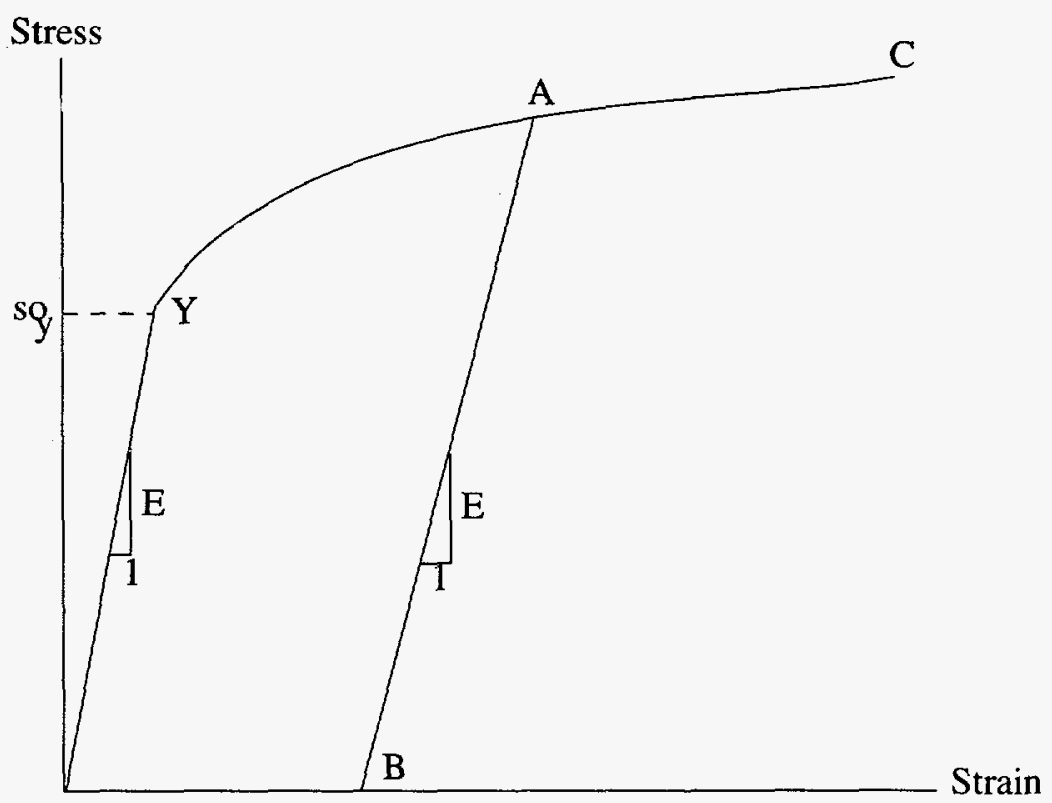

Figure 2.12 Idealized Stress-Strain Behavior

$$
\left\{\begin{array}{l}
\sigma=\mathrm{f}(\varepsilon) \\
\sigma=\mathrm{E}\left(\varepsilon-\varepsilon^{\mathrm{P}}\right)
\end{array}\right.
$$

which may be written as

$$
\sigma=f\left(\frac{\sigma}{E}+\varepsilon^{P}\right)
$$

This nonlinear equation may be solved efficiently by using an iteration scheme

$$
\sigma^{(m+1)}=f\left(\frac{\sigma^{(m)}}{E}+\varepsilon^{p}\right)=0,1,2, \ldots
$$


The initial iterate, $\sigma^{(m)}$, is arbitrary, and without loss of generality, is taken as $34.5 \mathrm{MPa}$. For any monotonically, increasing stress-plastic strain relation, the iteration scheme in Equation (2115) will converge uniformly and absolutely.

The computations of the stress-strain modeling are described below. The first computes strain as a function of plastic strain, temperature, and stress. The second computes stress as a function of plastic strain, temperature and plastic strain increments.

Values of plastic strain, $\varepsilon^{\mathrm{P}}$, temperature and stress are used as follows:

1. For a given temperature, $\sigma=\mathrm{f}(\varepsilon)$ is obtained from the MATPRO package.

2. The yield stress $\sigma_{\mathrm{y}}$ for given $\varepsilon^{\mathrm{P}}$ is obtained from Equation (2-115).

3. For a given value of stress, $\sigma$,

$$
\begin{aligned}
& \text { if } \sigma \overline{<} \sigma_{y}, \varepsilon=\frac{\sigma}{\mathrm{E}}+\varepsilon^{\mathrm{P}} \\
& \varepsilon_{\text {new }}^{\mathrm{P}}=\varepsilon_{\text {old }}^{\mathrm{P}} \\
& \text { if } \sigma>\sigma_{\mathrm{y}}, \varepsilon=\mathrm{f}(\sigma) \\
& \varepsilon_{\text {new }}^{\mathrm{P}}=\varepsilon-\sigma / \mathrm{E} \\
& \mathrm{d} \varepsilon^{P}=\varepsilon_{\text {new }}^{P}-\varepsilon_{\text {old }}^{P}
\end{aligned}
$$

where $\mathrm{E}$ is computed using the MATPRO package. follows:

Values of plastic strain, $\varepsilon^{\mathrm{P}}$, temperature, and plastic strain increment, $\mathrm{d} \varepsilon^{\mathrm{P}}$, are used as

1. For a given temperature, $\sigma=\mathrm{f}(\varepsilon)$ is obtained from the MATPRO package.

2. The yield stress $\sigma_{\mathrm{y}}$ for given $\varepsilon^{P}$ is obtained from Equation (2-115).

3. Given $d \varepsilon^{\mathrm{P}}$ (see Figure 2.13).

$$
\varepsilon_{\text {new }}^{P}=\varepsilon_{\text {old }}^{P}+d \varepsilon^{P}
$$




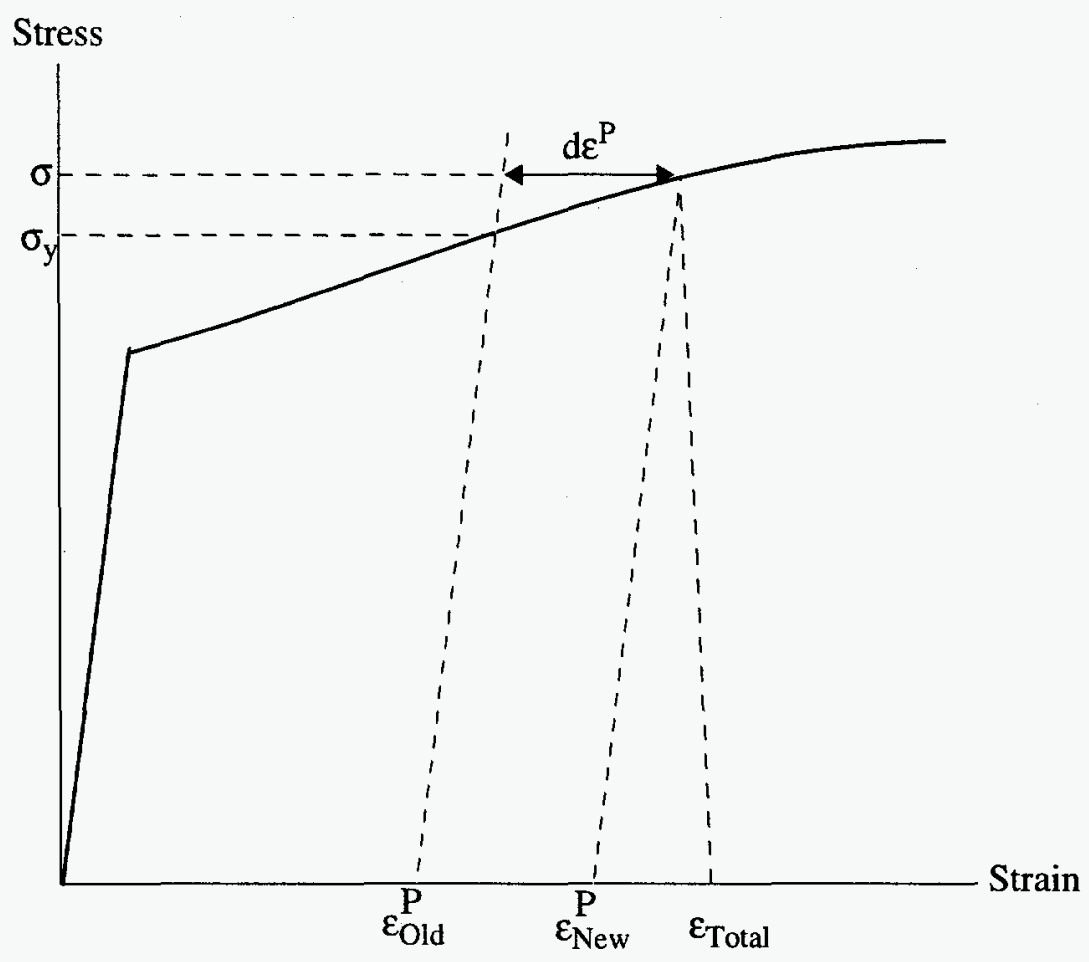

Figure 2.13 Computing STRESS

Since $d \varepsilon^{\mathrm{P}}>0$, the new value of stress and strain must lie on the plastic portion of the stressstrain curve $\sigma=\mathrm{f}(\varepsilon)$. So, $\sigma$ and $\varepsilon$ are obtained by performing a simultaneous solution, as before.

2.4.1.2.2 Rigid Pellet Fuel Deformation in FRACAS-I--This section describes the analytical models used to compute fuel deformation in FRACAS-I. Models are available to calculate length change and fuel radial displacement. Relocation is also considered in FRACAS-I, and is also discussed in this section. The effect of relocation is included in the thermal response, however, no hard contact between the fuel and cladding (and therefore no mechanical interaction) is allowed until the other fuel expansion components (swelling and thermal expansion) recover $50 \%$ of the original relocated pellet radius. Therefore, the rigid pellet for mechanical analyses, and that also controls contact conductance, includes $50 \%$ of the original relocated pellet radius as well as the other pellet expansion components.

The assumptions made with respect to fuel deformation in FRACAS-I are that no pellet deformation is induced by fuel-cladding contact stress or thermal stress and that free-ring thermal expansion applies. Each individual fuel ring is assumed to expand without restraint from any other ring, and the total expansion is the sum of the individual expansions. 
2.4.1.2.3 Radial Deformation--Radial deformation of the pellet due to thermal expansion, irradiation swelling and densification is calculated with a free-ring expansion model. The governing equation for this model is

$$
R_{H}=\sum_{i=1}^{N} \Delta r_{i}\left[1+\alpha_{T}\left(T_{i}-T_{r e f}\right)+\varepsilon_{i}^{s}+\varepsilon_{i}^{d}\right]
$$

where

$\begin{array}{lll}\mathrm{R}_{\mathrm{H}} & = & \text { hot-pellet radius (m) } \\ \alpha_{\mathrm{T}_{\mathrm{i}}} & = & \text { coefficient of thermal expansion of the } \mathrm{i} \text {-th radial temperature (1/K) } \\ \mathrm{T}_{\mathrm{i}} & = & \text { average temperature of } \mathrm{i} \text {-th radial ring }(\mathrm{K}) \\ \mathrm{T}_{\mathrm{ref}} & = & \text { reference temperature }(\mathrm{K}) \\ \Delta \mathrm{r}_{\mathrm{i}} & = & \text { width of } \mathrm{i} \text {-th radial ring (m) } \\ \mathrm{N} & = & \text { number of annular rings } \\ \varepsilon_{\mathrm{i}}^{\mathrm{s}} & = & \text { swelling strain (positive) } \\ \varepsilon_{\mathrm{i}}^{d} & = & \text { densification strain (negative). }\end{array}$

The fuel densification and swelling models are briefly discussed. The densification asymptotically approaches the (input) ultimate density change, typically over a local (nodeaverage) burnup of approximately $5 \mathrm{GWd} / \mathrm{MTU}$. Fuel swelling is considered only as the athermal swelling associated with solid fission product accumulation. It is linear with local (nodeaverage) burnup, and starts following a burnup of $6 \mathrm{GWd} / \mathrm{MTU}$ (delayed for swelling into asfabricated porosity). It then accumulates per time step at a rate equal to 0.077 volume $\%$ per GWd/MTU. This model was presented and assessed against high-burnup fuel density data in Volume 1, Section 4.0.

2.4.1.2.4 Axial Deformation--Axial deformation of the total fuel stack takes into account the thermal, densification, and swelling strains at each axial node. The calculation proceeds differently for flat-ended versus dished-pellets as described below. 
For flat-ended pellets, the volume-averaged ring axial deformation is calculated for each axial node, and these are summed to find the total stack deformation. The ring deformations account for thermal, densification, and swelling strains specific to each ring.

For dished pellets, the axial deformation of the "maximum ring" (the ring with the maximum deformed length) per node is found, and these "maximum ring" deformations are summed to find the total deformation. Typically, the "maximum ring" is the innermost ring on the dish shoulder, because the deformation of the rings within the dish do not fill the dish volume as illustrated in Figure 2.14.

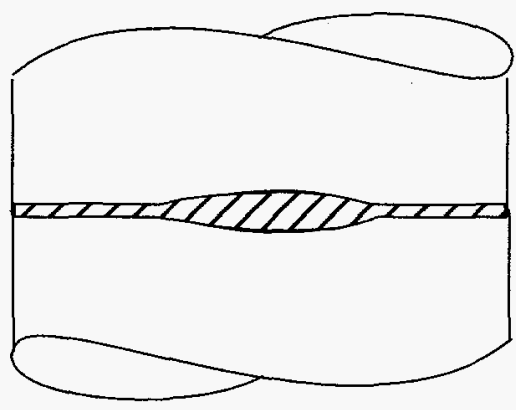

(a) Cold pellet interface

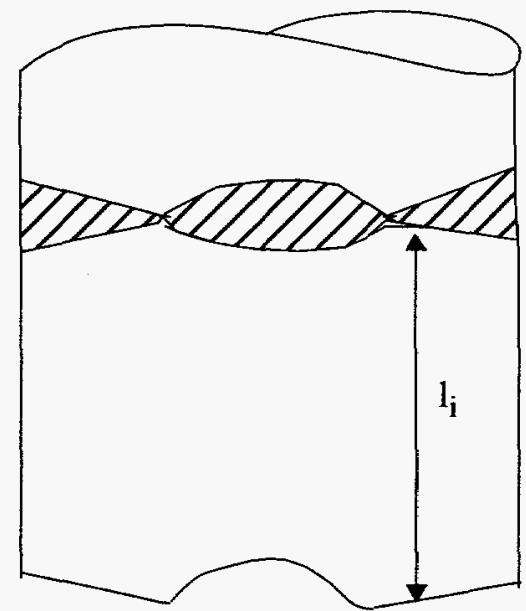

(b) Hot pellet interface

Figure 2.14 Interpellet Void Volume

2.4.1.2.5 Fuel Relocation--The best-estimate pellet relocation model developed for GT2R2, ${ }^{27}$ has been altered for use in FRAPCON in conjunction with the FRACAS-I mechanical model. The original GT2R2 relocation model was altered to provide a best estimate prediction of fuel temperatures for FRAPCON-3. This GT2R2 model is a function of LHGR and burnup that is similar to Oguma's model, but less complex in form. The gap closure due to relocation as a fraction of the as-fabricated pellet-cladding gap is given by 


$$
\begin{aligned}
\Delta \mathrm{G} / \mathrm{G} & =30+10 \mathrm{FBU} \text { for } \mathrm{LHGR}<20 \mathrm{~kW} / \mathrm{m} \\
& =28+\text { PFACTOR }+(12+\text { PFACTOR }) \text { FBU for LHGR }<40 \mathrm{~kW} / \mathrm{m} \\
& =32+18 \mathrm{FBU} \text { for LHGR }>40 \mathrm{~kW} / \mathrm{m}
\end{aligned}
$$

where

$\begin{array}{rll}\text { FBU }= & \text { BURNUP/5, for BURNUP }<5 \mathrm{GWd} / \mathrm{tU} \\ = & 1.0 \text { for BURNUP } \geq 5 \mathrm{GWd} / \mathrm{tU} \\ \text { PFACTOR:= } & \text { (LHGR }-20) 5 / 20 \\ \text { BURNUP }= & \text { fuel nodal burnup }(\mathrm{GWd} / \mathrm{tU}) \\ \text { LHGR }= & \text { nodal LHGR }(\mathrm{kW} / \mathrm{m}) .\end{array}$

A plot of this model (subroutine GTRLOC) as a function of burnup and LHGR is shown in Figure 2.15.

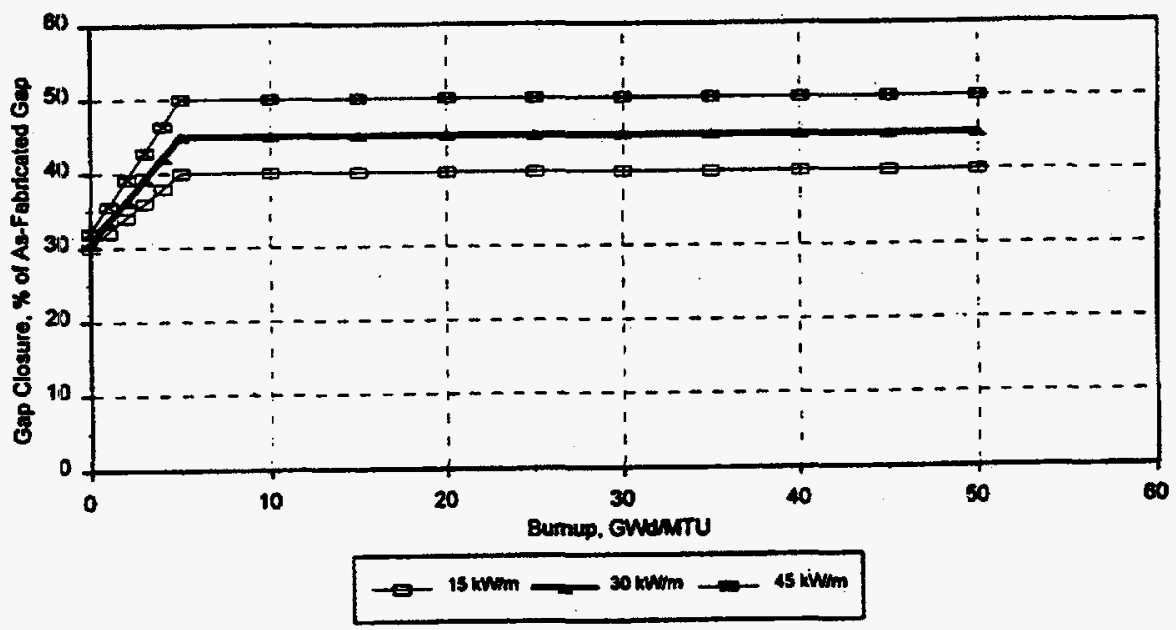

Figure 2.15 Power and Burnup Dependence of the FRAPCON-3 Relocation Model

The fuel-cladding gap size used in the thermal and internal pressure calculations include the fuel relocation, while the fuel-cladding gap size used in the structural calculations does not. 


\subsection{Fuel Rod Internal Gas Pressure Response}

After the fuel rod temperature and deformation calculations have been completed, the pressure of the gas in the fuel rod is computed. To calculate the gas pressure, the temperature and volume of the gas are required. The thermal models discussed in Section 2.3 provide the temperature of the gas in the fuel rod plenum, fuel-cladding gap, and fuel voids. The deformation models discussed in Section 2.4 provide information for computing the volume of the fuel rod plenum, fuel-cladding gap, and fuel voids.

The fuel rod internal gas pressure model is based on the following assumptions:

1. Perfect gas law holds $(\mathrm{PV}=\mathrm{NRT})$.

2. Gas pressure is constant throughout the fuel rod.

3. Gas in the fuel cracks is at the average fuel temperature.

\subsubsection{Fuel Rod Internal Gas Pressure}

Fuel rod internal gas pressure is calculated from the application of the perfect gas law to a multiple volume region. The volumes accounted for in FRAPCON-3 include the hot plenum volume, gap, annulus, crack, dish, porosity, roughness, and pellet-pellet interface volumes specific to each node. Thus the equation for rod internal pressure is

$$
P=\frac{M R}{\frac{V_{p}}{T_{p}}+\sum_{n=1}^{N}\left[\frac{V_{g}}{T_{g}}+\frac{V_{c h}}{T_{c h}}+\frac{V_{c r}}{T_{c r}}+\frac{V_{d s h}}{T_{d s h}}+\frac{V_{p o r}}{T_{p o r}}+\frac{V_{r f}}{T_{r f}}+\frac{V_{i}}{T_{i}}\right]}
$$

where the volumes $V$ are in cubic meters and the temperatures, $T$, are in Kelvin, and

$\begin{array}{lll}\mathrm{P} & = & \text { rod internal pressure, } \mathrm{Pa} \\ \mathrm{M} & = & \text { total moles of gas } \\ \mathrm{R} & = & \text { Universal gas constant, } 8.34 \mathrm{~J} / \text { mole- } \mathrm{K} \\ \mathrm{N} & = & \begin{array}{l}\text { number of axial nodes into which fuel rod is divided for numerical } \\ \text { solution }\end{array} \\ \mathrm{n} & = & \text { axial node number }\end{array}$




$$
\begin{array}{ll}
\mathrm{V}_{\mathrm{p}}, \mathrm{T}_{\mathrm{p}}= & \text { plenum volume temperature } \\
\mathrm{V}_{\mathrm{g}}, \mathrm{T}_{\mathrm{g}}=: & \text { nodal gap volumes and temperatures } \\
\mathrm{V}_{\mathrm{ch}}, \mathrm{T}_{\mathrm{ch}}= & \text { nodal central hole volumes and temperatures } \\
\mathrm{V}_{\mathrm{cr}}, \mathrm{T}_{\mathrm{cr}}=: & \text { nodal crack volumes and temperatures } \\
\mathrm{V}_{\mathrm{dsh}}, \mathrm{T}_{\mathrm{dsh}}= & \text { nodal dish volumes and temperatures } \\
\mathrm{V}_{\mathrm{por}}, \mathrm{T}_{\mathrm{por}}== & \text { nodal open-porosity volumes and temperatures } \\
\mathrm{V}_{\mathrm{rf}}, \mathrm{T}_{\mathrm{rf}}== & \text { nodal roughness volumes and temperatures } \\
\mathrm{V}_{\mathrm{i}}, \mathrm{T}_{\mathrm{i}}== & \text { nodal interface volumes and temperatures }
\end{array}
$$

Note that the temperatures assigned to the various volumes are as follows:

- The plenum temperature is dependent on the upper cladding temperature and the fuel temperature, as described in Section 2.3.6.

- The gap temperature is the average of the cladding inner and the fuel outer temperatures.

- The annulus temperature is the nodal fuel center temperature.

- The crack temperature is the average between pellet surface temperature and temperature at the restructured fuel radius.

- The open porosity temperature is the pellet volume average temperature.

- The dish temperature is the pellet volume average temperature.

- The roughness temperature is the gap temperature.

- The interface temperature is the average between the volume average temperature and the pellet surface temperature.

Note that in the FRAPCON-3 time step output, a table appears that presents the fractions of total volume represented by the plenum, gap, cracks, dishes, annulus, open porosity, roughness, and pellet-pellet interfaces, and the rod-averaged temperatures associated with these various 
volume-fractions. These are not the node-specific values that appear in the above equation, but are the results of the sum of each axial node for each volume type.

The gas pressure calculation, therefore, requires information on the gas inventory, void volumes, and the void temperatures which is provided by the following supportive models.

\subsubsection{Fission Gas Production}

Given production rates for the major diffusing gases, the burnup dependent total fission gas generated at axial elevation $\mathrm{z}$ is calculated as

$$
\mathrm{GPT}(\mathrm{z})=\frac{\mathrm{BU}(\mathrm{z}) \mathrm{VF}(\mathrm{z})}{100 \mathrm{~A}_{\mathrm{v}}}\left(\mathrm{PR}_{\text {krypton }}+\mathrm{PR}_{\text {helium }}+\mathrm{PR}_{\mathrm{xenon}}\right)
$$

where

$$
\begin{array}{lll}
\mathrm{GPT}(\mathrm{z})= & \text { total fission gas produced at } \mathrm{z} \text { (mole) } \\
\mathrm{BU}(\mathrm{z})= & \text { burnup at } \mathrm{z}(\text { fission/cc) } \\
\mathrm{VF}(\mathrm{z})= & \text { fuel volume }(\mathrm{cc}) \\
\mathrm{A}_{\mathrm{V}}= & \text { Avogadro's Number } \\
\mathrm{PR} & = & \begin{array}{l}
\text { fission gas production rate (atoms/100 fissions) for krypton, xenon, and } \\
\text { helium. }
\end{array}
\end{array}
$$

All the fission gas produced, however, is not released. A portion is trapped in the fuel and a portion is released to the fuel-cladding gap volume. Only the released portion is used to calculate the rod internal gas pressure. The gas release fraction is calculated as discussed in the following sections.

\subsubsection{Fuel Rod Gas Release}

Gas release models in FRAPCON-3 account for not only fission gas release (krypton, xenon, and helium) but also nitrogen release. The nitrogen is released from the fuel lattice where it is trapped during the fuel fabrication process. Fission gas release in FRAPCON-3 includes two model options: ANS-5.4, ${ }^{7,28}$ and the modified Forsberg and Massih model.$^{29}$ Both of these release models are based on earlier formulations by Booth ${ }^{30}$ and are discussed below. 
2.5.3.1 ANS-5.4 Gas Release Model. The ANS-5.4 fractional fission gas release is calculated as a function of time and radial fuel temperature and axial burnup. The fuel is divided into radial and axial nodes according to the proposed ANS standard. A user requirement is that the time step sizes be such that the burnup increments do not exceed $2,000 \mathrm{MWd} / \mathrm{MTU}$.

The modeling is divided into two main sections, one for release of stable isotopes and the other for release of short-lived isotopes. There are high and low temperature models for both the stable and radioactive fission products. The release is calculated using both the high and low temperature models, and the larger release value is used. Time steps should not exceed 50 days.

2.5.3.2 Modified Forsberg Massih Model. The original Forsberg/Massih ${ }^{29}$ model begins with a solution of the gas diffusion equation for constant production and properties in a spherical grain:

$$
\frac{d C}{d t}=D(t) \Delta_{r} C(r, t)+\beta(t)
$$

where

$\begin{array}{lll}\mathrm{C} & = & \text { gas concentration } \\ \beta & = & \text { gas production } \\ \Delta_{\mathrm{r}} & = & \frac{\mathrm{d}^{2}}{\mathrm{dr}^{2}}+\frac{2}{\mathrm{r}}\left(\frac{\mathrm{d}}{\mathrm{dr}}\right) \\ \mathrm{D} & = & \text { diffusion constant } \\ \mathrm{t} & = & \text { time }\end{array}$

with boundary conditions

$C(r, 0)=0$

$C(a, t)=0$.

Forsberg and Massih attempt to solve the equation for the case where there is re-solution of gas on the grain surface, which changes the outer boundary condition to

$$
C(a, t)=\frac{b(t) \lambda N(t)}{2 D}
$$


where

$\begin{array}{lll}N & = & \text { surface gas concentration } \\ \lambda & = & \text { resolution layer depth } \\ \mathrm{a} & = & \text { hypothetical grain radius } \\ \mathrm{b} & = & \text { resolution rate. }\end{array}$

They make use of a three-term approximation to the integration kernel, $\mathrm{K}$, where

$$
\int_{0}^{a} 4 \pi r^{2} C(r, t) d r=\int_{0}^{\tau} K\left(\tau-\tau_{0}\right) \beta_{e}\left(\tau_{0}\right) d \tau_{0}
$$

and

$$
\begin{aligned}
& \beta_{\mathrm{e}}=\frac{\beta}{\mathrm{D}} \\
& \tau=\mathrm{Dt}
\end{aligned}
$$

and

$$
K=\frac{8 a^{3}}{\pi} \sum_{n=1}^{\infty} \frac{\exp \left(\frac{\left(-n^{2} \pi^{2}\right) \tau}{a^{2}}\right)}{n^{2}}
$$

2.5.3.3 Low Temperature Fission Gas Release Model at High Burnup. The modified Forsberg-Massih model $^{8}$ is used to calculate fission gas release unless the low temperature fission gas release model predicts a higher value for fission gas release. The low temperature fission gas release model is defined as

$$
\mathrm{F}=7 \times 10^{-5} \times \mathrm{BU}+\mathrm{C}
$$


where: $F \quad=$ fission gas release fraction

$\mathrm{BU}=$ local burnup in GWd/MTU

$\mathrm{C} \quad=0$; for $\mathrm{BU} \leq 40 \mathrm{GWd} / \mathrm{MTU}$

$=0.01(\mathrm{BU}-40) / 10 ;$ for $>40 \mathrm{GWd} / \mathrm{MTU}$ and $\mathrm{F} \leq 0.05$

2.5.3.3.1 Grain Boundary Accumulation and Re-Solution-The final solution for a given time step, without re-solution and with constant production rate during the step, can be written as

$$
\begin{gathered}
\Delta G_{n}=f_{n} G_{n}\left(\tau_{1}\right)+A_{n} \int_{\tau 1}^{\tau 2} \exp \left[\frac{-B_{n}}{a^{2}}\left(\tau_{2}-\tau_{0}\right)\right] q\left(\tau_{0}\right) d \tau_{0} \\
\Delta G=\sum_{n=1}^{3} \Delta G_{n}
\end{gathered}
$$

$\Delta \mathrm{G} \quad=\quad$ change in gas concentration in fuel grain

$$
\Delta G_{B}=-\Sigma f_{n} G_{n}\left(\tau_{1}\right)+\int_{\tau 1}^{\tau 2} \text { funct }\left(\tau_{2}-\tau_{0}\right) q\left(\tau_{0}\right) d \tau_{0}
$$

$\Delta \mathrm{G}_{\mathrm{B}}=\quad$ change in gas concentration on grain boundaries

$$
f_{n}=\left(\exp \frac{\left(-B_{n}\right)\left(\tau_{2}-\tau_{0}\right)}{a^{2}}\right)-1
$$

$\mathrm{f}_{\mathrm{n}} \quad=\quad$ fission gas production fraction remaining in the grain from the previous time step

where $\mathrm{q}$ is determined from 


$$
a^{2} q\left[-\sum_{n=1}^{3}\left(\frac{f_{n} A_{n}}{B_{n}}\right)+f u n c t(\Delta \tau)\right]=\beta \Delta t
$$

where

$$
\begin{array}{lll}
\text { funct }(\Delta \tau)= & \frac{6}{\sqrt{\pi}}\left[\frac{\left(\tau_{2}-\tau_{0}\right)}{\mathrm{a}^{2}}\right]^{1 / 2}-3\left[\frac{\left(\tau_{2}-\tau_{0}\right)}{\mathrm{a}^{2}}\right] & \text { if } \tau<0.1 \\
\text { funct }(\Delta \tau)= & 1-\left(\frac{6}{\pi^{2}}\right) \exp \left[-\pi^{2} \frac{\left(\tau_{2}-\tau_{0}\right)}{\mathrm{a}^{2}}\right] \quad \text { if } \tau>0.1 \\
\text { funct }(\Delta \tau)= & \int_{\tau 1}^{\tau 2} \text { funct }\left(\tau_{2}-\tau_{0}\right) \mathrm{d} \tau .
\end{array}
$$

$A_{n}$ and $B_{n}$ are constants given by Massih.

$\mathrm{K}_{2}=\frac{\mathrm{a}}{3}-\frac{\mathrm{K}}{4 \pi \mathrm{a}^{2}}$

$\mathrm{K}_{3}=\frac{3}{\mathrm{a}} \mathrm{K}_{2}$

$1+K_{3}=\sum_{n=1}^{3} A_{n} \exp -\frac{B_{n} \tau}{a^{2}}, n=1,2,3$.

In modifying the original model, we have chosen to introduce re-solution by defining the partition of the gas arriving at the boundary each time step as follows:

$$
\begin{gathered}
\Delta \text { Resolved Gas }=\frac{F}{(1+F)}\left(\Delta G_{B}\right) \\
\Delta G_{B}=\frac{\Delta G_{B}}{(1+F)}
\end{gathered}
$$

where

$$
\begin{array}{lll}
\mathrm{F} & = & \text { FITMULT }\left[1.84 \times 10^{-14} \times \mathrm{GRN} /(3 \times \mathrm{D})\right] \\
\mathrm{GRN} & =\quad \text { grain radius }(\mathrm{m})
\end{array}
$$


$\mathrm{D}=\quad$ diffusion constant $\left(\mathrm{m}^{2} / \mathrm{sec}\right)$

FITMULT $=\quad$ an adjustable multiplier and the term in brackets is the original Massih equation for the resolution rate (FITMULT $=250$ ).

It should be noted that although $\mathrm{F}$ is unitless in Massih's derivation, it does not represent the fraction of retained gas.

2.5.3.3.2 Diffusion Constant-The diffusion constant in the original Forsberg/Massih model is defined over three temperature ranges, as follows:

1. $\mathrm{D}=1.09 \times 10^{-17} \exp (-6614 / \mathrm{T}), \mathrm{T}>1650 \mathrm{~K}$

2. $\mathrm{D}=2.14 \times 10^{-13} \exp (-22884 / \mathrm{T}), 1381<\mathrm{T}<1650 \mathrm{~K}$

3. $\mathrm{D}=1.51 \times 10^{-17} \exp (-9508 / \mathrm{T}), \mathrm{T}<1381 \mathrm{~K}$

In the FRAPCON-3 subroutine, MASSIH, the mid-range diffusion constant (Number 2 above), is used, except that the activation energy term $(\mathrm{Q} / \mathrm{R})$ is $22884 \times 1.15$. If the modified constant from MASSIH is less than the low-range Massih diffusion constant (Number 3 above), the latter is used.

A burnup enhancement factor multiplies the mid-range diffusion constant (Number 2 above) and has the form $100^{(\mathrm{BURNUP}-21) / 35}$, where BURNUP $=$ burnup in $\mathrm{GWd} / \mathrm{MTU}$ with a maximum value of 20000 for this enhancement factor.

2.5.3.3.3 Gas Release--A factor of 14 is applied to the burnup-enhanced diffusion constant as a final step. The gas is accumulated at the grain boundary until a saturation concentration is achieved, at which time the grain boundary gas is released. The saturation area density of gas is given by

$$
\mathrm{N}_{s}=\left[\frac{4 \mathrm{rF}(\theta) \mathrm{V}_{\mathrm{c}}}{3 \mathrm{~K}_{\mathrm{B}} \mathrm{T} \sin ^{2}(\theta)}\right]\left(\frac{2 \gamma}{\mathrm{r}}+\mathrm{P}_{\mathrm{ext}}\right)
$$

where

$$
\begin{array}{lll}
\theta & = & \text { dihedral half-angle }=50^{\circ} \\
\mathrm{K}_{\mathrm{B}} & = & \text { Boltzman constant }
\end{array}
$$




$$
\begin{array}{lll}
\gamma & = & \text { surface tension }=0.6\left(\mathrm{~J} / \mathrm{m}^{2}\right) \\
\mathrm{V}_{\mathrm{c}} & = & \text { critical area coverage fraction }=0.25 \\
\mathrm{r} & = & \text { bubble radius }=0.5 \text { microns } \\
\mathrm{F}(\theta) & = & 1-1.5 \cos (\theta)+0.5 \cos 3(\theta) \\
\mathrm{P}_{\text {ext }} & = & \text { external pressure on bubbles }=\text { gas pressure }(\mathrm{Pa})
\end{array}
$$

The final modification to the original model was to release both the grain boundary and the re-solved gas whenever the saturation condition is achieved and the grain boundary gas is released.

To summarize, optimized parameters have been applied, based on comparisons to selected steady-state and transient data:

The activation energy $(\mathrm{Q} / \mathrm{R})=1.15 \times 22884 .=29060$ (high temperature diffusion).

The resolution parameter $=250 \times 1.84 \mathrm{E}-14=1.47 \mathrm{E}-12$.

Multiplier on the diffusion constant $=14.0$. (Applied after all other modifications).

\subsubsection{Nitrogen Release}

The release of nitrogen initially present in fuel material from fabrication occurs as a result of a diffusion transport mechanism. The model proposed by Booth ${ }^{30}$ is used, given the following assumptions:

1. The initial concentration of diffusing substance, $\mathrm{C}$, is uniform throughout a sphere of radius, a.

2. Transport of material does not occur from the external phase (gaseous nitrogen) back into the initial carrier medium.

The governing equation is

$$
r \frac{\partial C}{\partial t}=D\left(\frac{\partial^{2}}{\partial r^{2}}(C r)\right)
$$


where

$\begin{array}{lll}\mathrm{r} & = & \text { radial location }(\mathrm{m}) \\ \mathrm{C} & = & \text { concentration of diffusing substance } \\ \mathrm{t} & = & \text { time }(\mathrm{s}) \\ \mathrm{D} & = & \text { diffusion coefficient }\end{array}$

with
C
$=$
0.0 , when $\mathrm{r}=\mathrm{a}$
$\mathrm{C}=$
C, when $\mathrm{t}=0$

By applying a series solution method, the fractional release of the diffusing substance (nitrogen) can be approximated based on the value of $B$ :

$$
\mathrm{B}=\pi^{2} \mathrm{D}_{\mathrm{N}_{2}}(\mathrm{~T}) \mathrm{t}
$$

where

$$
\begin{array}{lll}
D_{N_{2}}(T) & =\text { temperature dependent diffusion coefficient for nitrogen } \\
t & =\text { time from the start of diffusion }(\mathrm{s}) .
\end{array}
$$

Then, when $B>1$, the fraction of nitrogen released as of time, $t$, equals

$$
F_{N_{2}}=1-6 \exp \left(-B / \pi^{2}\right)
$$

and, when $\mathrm{B} \leq 1$,

$$
\mathrm{F}_{\mathrm{N}_{2}}=6\left[\mathrm{D}_{\mathrm{N}_{2}}(\mathrm{~T}) \mathrm{t} / \pi\right]^{0.5}-3 \mathrm{D}_{\mathrm{N}_{2}}(\mathrm{~T}) \mathrm{t}
$$


From the experimental data of Ferrari ${ }^{31,32}$

$$
D_{N_{2}}(t)=\left(1 \times 10^{-12}\right) \exp (G)
$$

where

$$
\mathrm{G}=20202.0\left(\frac{1.0}{1673.0}-\frac{1.0}{\mathrm{~T}}\right)
$$

\subsubsection{Fuel Rod Void Volumes}

Void volumes computed by FRAPCON-3 include the pellet dishing, the fuel-cladding gap, the crack, the plenum, the open porosity, and the roughness volume. These are calculated as indicated below.

2.5.5.1 Pellet Dish Volume. The volume between pellets is calculated and included as part of the overall volume in the internal gas pressure model. The interpellet volume is calculated at each time step based on hot-pellet geometries. Figure 2.14 shows 1) a cold-pellet interface configuration for the case where the pellets are dished and 2) an exaggerated hot-pellet interface configuration. The void volume available for internal fill gas is defined by the cross hatched areas ( $a$ and $b$ in the figure). The dish volume is that portion of the hot interpellet volume that is within the dishes, excluding the volume of any central hole.

2.5.5.2 Interface Volume. The pellet-pellet interface volume is calculated as the difference between the hot interpellet volume and the dish volume.

2.5.5.3 Fuel-Cladding Gap Volume. The fuel-cladding gap volume is calculated by considering the area between two concentric cylinders. The outer cylinder is assumed to have a diameter equal to the diameter of the cladding inside surface based on plastic deformation. The inside cylinder is assumed to have a diameter equal to the diameter of the relocated fuel pellets.

2.5.5.4 Fuel Crack Volume. As the fuel expands, extensive cracking occurs due to the high thermally-induced stresses resulting in a relocated fuel surface. The crack volume is computed as

$$
\mathrm{V}_{\mathrm{c}}=\mathrm{V}_{\mathrm{g}}-\mathrm{V}_{\mathrm{eg}}-\mathrm{V}_{\mathrm{TX}}
$$


where

$$
\begin{array}{ll}
\mathrm{V}_{\mathrm{c}} \quad=\quad \begin{array}{l}
\text { fuel crack volume per unit length }\left(\mathrm{m}^{2}\right) \\
\mathrm{V}_{\mathrm{eg}}
\end{array} \quad \begin{array}{l}
\text { fuel volume per unit length defined by expanded radial nodes, including } \\
\text { the thermal expansion, swelling, and densification }\left(\mathrm{m}^{2}\right)
\end{array} \\
\mathrm{V}_{\mathrm{TX}} \quad: \quad \quad \begin{array}{l}
\text { the computed fuel-cladding gap volume per unit length based on the } \\
\text { relocated fuel surface }\left(\mathrm{m}^{2}\right)
\end{array} \\
\mathrm{V}_{\mathrm{g}} \quad=\quad \text { the volume per unit length within the thermally expanded cladding }\left(\mathrm{m}^{2}\right) .
\end{array}
$$

2.5.5.5 Plenum Volume. The plenum volume is calculated from geometry considerations of the thermally expanded cladding and the thermal expansion, densification, and swelling of the fuel. The volume of the hold-down spring is considered.

2.5.5.6 Open Porosity Volume. A portion of the initial fabrication porosity is open to free gas flow, which is given by the expressions

$$
\begin{gathered}
\mathrm{V}_{\text {por }}=0.0 \quad \text { when } \mathrm{G}_{\text {den }} \geq 94.0 \\
\mathrm{~V}_{\text {por }}=1.97 \times 10^{-8}\left(94.0-\mathrm{G}_{\text {den }}\right) \quad \text { when } 91.25<\mathrm{G}_{\text {den }}<94.0 \\
\mathrm{~V}_{\text {por }}=2.77 \times 10^{-4}-3.818 \mathrm{G}_{\text {den }} \\
-1.43 \times 10^{-8} \mathrm{G}_{\text {den }}^{2}+2.497 \times 10^{-10} \mathrm{G}_{\text {den }}^{3} \text { when } \mathrm{G}_{\text {den }}<91.25
\end{gathered}
$$

where

$$
\begin{array}{lll}
\mathrm{V}_{\text {por }} & = & \text { porosity volume per unit length }\left(\mathrm{m}^{2}\right) \\
\mathrm{G}_{\text {den }} & = & \text { DEN }-1.25 \\
\mathrm{DEN} & = & \text { fuel density (percent of theoretical density). }
\end{array}
$$


2.5.5.7 Roughness Volume. The roughness of the surface of the fuel and cladding results in a small void volume accounted for by

$$
\mathrm{V}_{\text {rough }}=\frac{5.27 \times 10^{-5} \pi \mathrm{D}_{\mathrm{p}}}{\mathrm{V}_{\mathrm{f}}}
$$

where

$$
\begin{array}{lll}
\mathrm{V}_{\text {rough }} & = & \text { roughness volume per unit length }\left(\mathrm{m}^{2}\right) \\
\mathrm{D}_{\mathrm{P}} & = & \text { initial pellet diameter }(\mathrm{m}) \\
\mathrm{V}_{\mathrm{f}} & = & \text { geometric fuel volume per unit length }\left(\mathrm{m}^{2}\right) .
\end{array}
$$

The gas pressure response resulting from the above models feeds back into the mechanical and temperature response models in the iteration scheme.

2.5.5.8 Central Hole Volume. The central hole volume is calculated by considering the area of the central hole (if present), the length of the axial node, and the length of the central hole.

\subsection{Waterside Corrosion and Hydrogen Pickup}

The cladding waterside corrosion and hydrogen pickup models have been altered from those in FRAPCON-2, as described below.

\subsubsection{PWR and BWR Waterside Corrosion Models}

The corrosion models for PWR and BWR conditions are taken from the ESCORE code documentation. They are described and assessed against in-reactor data in Volume 1 of this report (Section 8.0). In brief, a cubic rate law for corrosion-layer thickness as a function of time is applied until a transition thickness of 2.0 microns is attained:

$$
(\mathrm{ds}) /(\mathrm{dt})=\left(\mathrm{A} / \mathrm{s}^{2}\right) \exp \left\{\left(-\mathrm{Q}_{1}\right) /\left(\mathrm{RT}_{1}\right)\right\}
$$


Thereafter, a flux-dependent linear rate law is applied, with the rate constant being an Arrhenius function of oxide-metal interface temperature:

$$
(\mathrm{ds}) /(\mathrm{dt})=\left\{\mathrm{C}_{0}+\mathrm{U}(\mathrm{M} \Phi)^{\mathrm{P}}\right\} \exp \left\{\left(-\mathrm{Q}_{2}\right) /\left(\mathrm{RT}_{1}\right)\right\}
$$

In the above, for the PWR condition,

$$
\begin{array}{ll}
\mathrm{ds} / \mathrm{dt} & =\text { Oxidation rate }(\mathrm{m} / \text { day }) \\
\mathrm{T}_{1} & ==\text { metal-oxide interface temperature, } \mathrm{K} \\
\Phi & =\text { fast neutron flux }(\mathrm{E}>1 \mathrm{MeV}), \mathrm{n} / \mathrm{cm}^{2} / \mathrm{s} \\
\mathrm{A} & =6.3 \times 10^{9} \mathrm{~m}^{3} / \text { day } \\
\mathrm{Q}_{1} & =32,289 \mathrm{cals} / \mathrm{mol} \\
\mathrm{C}_{0} & =8.04 \times 10^{7} \mathrm{~m} / \text { day } \\
\mathrm{M} & =1.91 \times 10^{-15} \mathrm{~cm}^{2}-\mathrm{sec} / \mathrm{n} \\
\mathrm{P} & =0.24 \\
\mathrm{Q}_{2} & =27,354 \mathrm{cals} / \mathrm{mol} \\
\mathrm{U} & =2.38 \times 10^{8} \mathrm{~m} / \text { day } \\
\mathrm{R} & =1.98 \mathrm{cals} / \mathrm{mol} / \% \mathrm{~K}
\end{array}
$$

To achieve numerical stability, the rate equation is integrated across each time step and applied to calculated corrosion layer increments per time step, which are accumulated to calculate cumulative layer thickness as a function of axial position (axial node) along the rod. The parameters for the linear rate law are different for BWR versus PWR conditions.

\subsubsection{Hydrogen Pickup Fraction}

The fraction of the hydrogen liberated by the metal-water corrosion reaction that is absorbed locally by the cladding is called the pickup fraction. As discussed in Volume 1 (Section 8.0), this fraction is set at 0.15 in FRAPCON-3, based on data from nominal-to-high burnup PWR rods. 


\subsection{General Code Description}

\subsection{Code Structure and Solution Routine}

FRAPCON-3 is a large and complex code that contains over 200 subroutines. This section discusses the code structure, solution scheme, and the major subroutines involved in the solution scheme.

\subsubsection{Code Structure}

The FRAPCON-3 subroutines have been grouped in packages, not all of which need to be compiled for every run. These packages are listed in Table 3.1. Note that every execution requires the FRPCON package and the MATPRO package; the former contains the driver routine, the setup routines, and the thermal models. Using only these two packages restricts one to the FRACAS-I mechanical modeling option.

Table 3.1. Major FRAPCON-3 Packages

\begin{tabular}{|l|l|}
\hline \multicolumn{1}{|c|}{ Package } & \multicolumn{1}{c|}{ Description } \\
\hline FRPCON & $\begin{array}{l}\text { The main section of the code, including all of the thermal models; also } \\
\text { includes the FRACAS-I mechanics model. }\end{array}$ \\
\hline FRACAS-I & Contains the subroutines comprising the FRACAS-I mechanics model. \\
\hline MATPRO & The MATPRO material properties package. \\
\hline
\end{tabular}

\subsubsection{Solution Scheme}

Figure 3.1 shows a flowchart of FRAPCON-3 beginning with case setup, following through the convergence loops, and ending with output. Each major section of this sequence will be discussed, together with the subroutines involved. To aid this discussion, Figure 3.2 presents an abbreviated outline of the main subprogram, FRPCON, arranged in the same order as the flowchart. Major subroutines appear in the figure as do the major FORTRAN loops.

The first portion of the flowchart has to do with case setup and initialization. This includes reading the input data, the dynamic dimensioning procedure, initializing variables, and an initial problem description output. The subroutines listed in Table 3.2 are involved in the setup and initialization. 

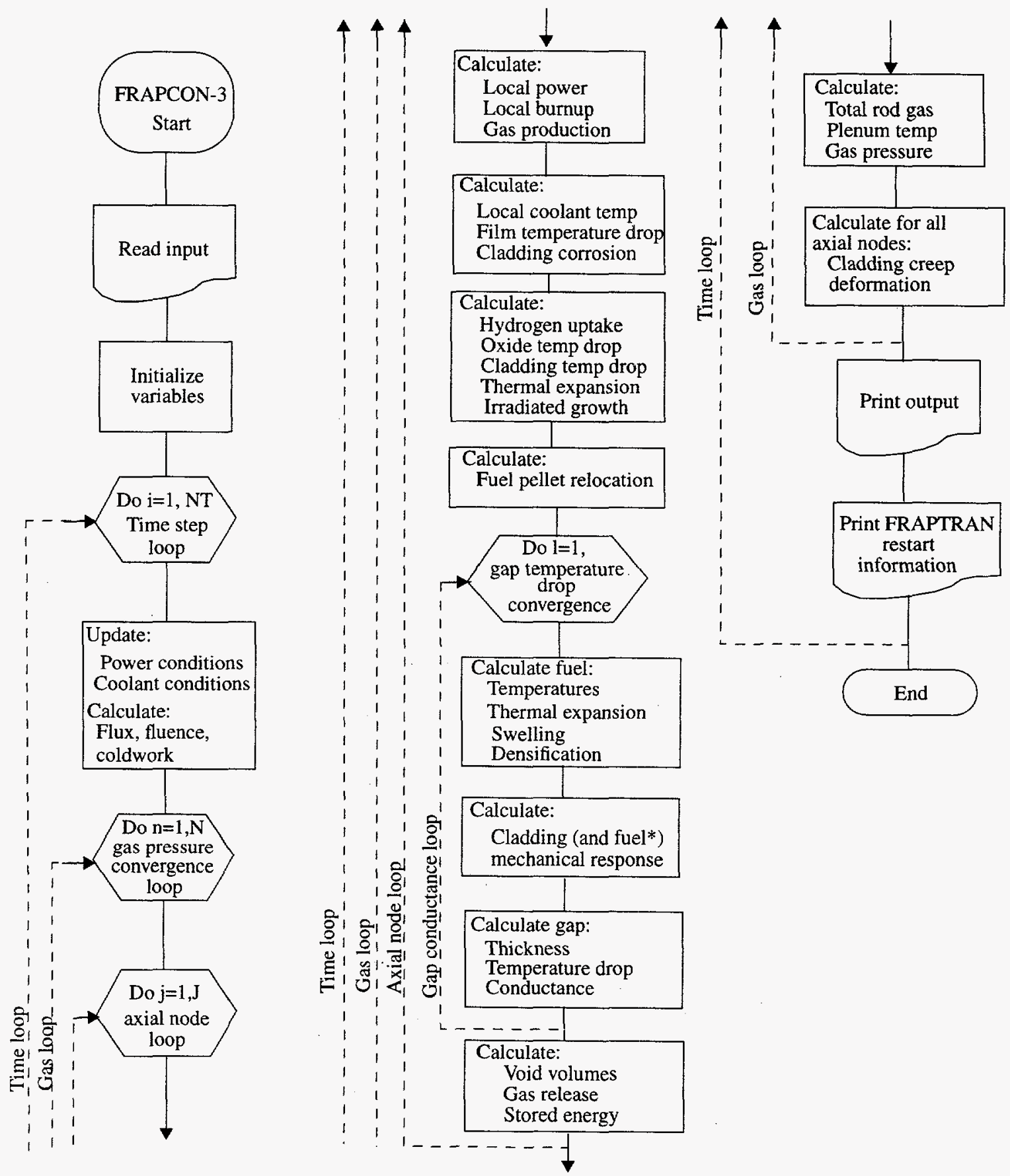

Figure 3.1. FRAPCON-3 Flow Chart 


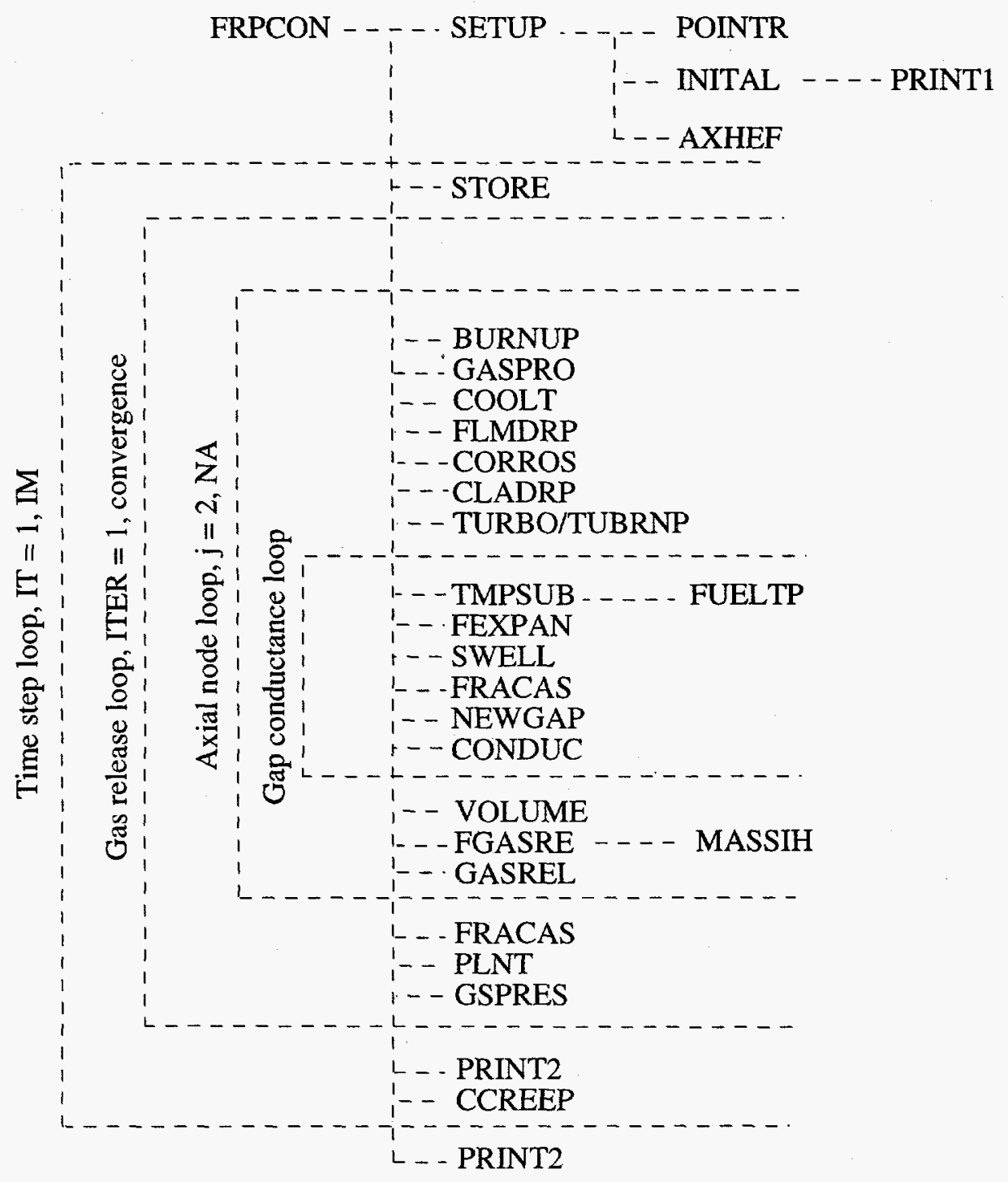

Figure 3.2. Calling Sequence for FRAPCON-3 Subroutines 
Table 3.2. Initialization Subroutines

\begin{tabular}{|l|l|}
\hline Subroutine & \multicolumn{1}{|c|}{ Description } \\
\hline SETUP & Reads the data input pertaining to the problem size requirements. \\
\hline POINTR & Performs the dynamic dimensioning procedure. \\
\hline INITAL & Reads the remaining problem description input and initializes the variables. \\
\hline PRINT1 & $\begin{array}{l}\text { Generates the output, reflecting the initial conditions and specifications of the } \\
\text { fuel rod, and lists the proposed power history. }\end{array}$ \\
\hline AXHEF & $\begin{array}{l}\text { Calculates the axial power profile as it affects the axial regions of the fuel rod } \\
\text { and also any varying axial power profile changes. }\end{array}$ \\
\hline
\end{tabular}

Next, the code enters the first of four major loops in the FORTRAN coding, the time-step loop. The time-step loop encompasses virtually all of the remainder of the FRAPCON-3 code. In each execution of the time-step loop, the code solves for the thermal and mechanical equilibrium of the fuel rod at a new point along the rod power versus time history input by the user. Those subroutines, which are executed only once per time step, are listed in Table 3.3.

Table 3.3. Subroutines in the Time Step Loop

\begin{tabular}{|l|l|}
\hline Subroutine & \multicolumn{1}{|c|}{ Description } \\
\hline STORE & Stores variable values as necessary to account for history dependency. \\
\hline PRINT2 & $\begin{array}{l}\text { Generates output for the code that presents converged values for all of the } \\
\text { axial nodes for both thermal and mechanical solutions. }\end{array}$ \\
\hline CCREEP & $\begin{array}{l}\text { The cladding creep portion of the FRACAS-I mechanics model (the } \\
\text { subroutine calls FCMI, which in turn calls CLADF that calls CREPR where } \\
\text { the creep rate model is located). }\end{array}$ \\
\hline
\end{tabular}


Three additional loops exist in the code. The next loop encountered within the time-step loop is the gas-release loop. This loop is cycled until the value for calculated rod internal gas pressure (dependent on temperature, volume, and fission gas release) converges. Subroutines called from within this loop are listed in Table 3.4 .

Table 3.4. Subroutines in the Gas-Release Loop

\begin{tabular}{|l|l|}
\hline Subroutine & \multicolumn{1}{c|}{ Description } \\
\hline FRACAS & $\begin{array}{l}\text { The FRACAS-I fuel-cladding mechanical response model is controlled by this } \\
\text { subroutine. This loop calculates the time-independent permanent deformation. }\end{array}$ \\
\hline PLNT & Calculates the current plenum gas temperature and volume. \\
\hline GSPRES & Calculates the rod internal gas pressure. \\
\hline
\end{tabular}

The next inner loop in the coding is the axial node loop. For every pass through the gas release loop, the axial node loop sequences through each of the axial regions defined by the input. The subroutines controlled by this loop are listed in Table 3.5 .

Table 3.5. Subroutines in the Axial-Node Loop

\begin{tabular}{|l|l|}
\hline \multicolumn{1}{|c|}{ Subroutine } & \multicolumn{1}{c|}{ Description } \\
\hline BURNUP & Calculates the local fuel burnup. \\
\hline GASPRO & Calculates the fission gas production. \\
\hline COOLT & Calculates the coolant temperature. \\
\hline FLMDRP & Calculates the temperature drop from the cladding surface to the coolant. \\
\hline CORROS & Calculates the corrosion on the cladding surface. \\
\hline CLADRP & $\begin{array}{l}\text { Calculates the temperature drop from the cladding inside surface to the } \\
\text { cladding outside surface. }\end{array}$ \\
\hline TUBRNP & Calculates the radial power and burnup distribution. \\
\hline
\end{tabular}


The innermost loop is the gap conductance loop. This loop iterates on each axial node until thermal equilibrium in the radial direction is achieved. Thermal equilibrium is signified by a converged value for the calculated temperature drop from the fuel outer surface to the cladding inner surface. The subroutines listed in Table 3.6 comprise the gap conductance loop.

Table 3.6. Subroutines in the Gap Conductance Loop

\begin{tabular}{|l|l|}
\hline \multicolumn{1}{|c|}{ Subroutine } & \multicolumn{1}{c|}{ Description } \\
\hline TMPSUB & Calculates the radial temperature distribution through the fuel. \\
\hline FUELTP & Solves the equations for the radial heat balance. \\
\hline FEXPAN & Fuel thermal expansion routine. \\
\hline SWELL & Calculates fuel swelling and fuel densification. \\
\hline FRACAS & $\begin{array}{l}\text { This subroutine calculates the new position of the cladding due to deflection } \\
\text { caused by internal gas pressure changes. }\end{array}$ \\
\hline NEWGAP & $\begin{array}{l}\text { Calculates the new fuel-cladding gap size (used with the FRACAS mechanics } \\
\text { model only). }\end{array}$ \\
\hline CONDUC & $\begin{array}{l}\text { Calculates new values for the gap conductance and the fuel-cladding gap } \\
\text { temperature drop. }\end{array}$ \\
\hline
\end{tabular}

At the completion of all the time steps, and before returning to the driver package, a final call to PRINT2 is made. This call results in the printing of a summary table for the entire power history of the rod.

\subsection{Code Results}

FRAPCON-3 generates fuel rod response information as a function of fuel rod fabrication information, boundary conditions, and power history. This information is provided to the user in the form of printed output and in the form of plots (optional). The capability also exists to supply this information for steady-state initialization of the FRAPTRAN computer code. The information provided to the transient fuel rod analysis code consists of permanent burnup effects, such as cladding creepdown, fuel swelling, fuel densification, normalized radial power and burnup profiles, and fission gas inventory. This section presents the important response parameters, the plotting package, and information on the FRAPCON link with FRAPTRAN.

\subsubsection{Fuel Rod Response}

FRAPCON-3 provides the calculated fuel rod thermal, mechanical, and pressure response data. The results are presented in three forms: an axial-region printout, a power-time step printout, and a summary-page printout. 
The axial-region printout presents local information on power, time, time step, and burnup. Also presented are rod radial-temperature distribution, coolant temperature, cladding stresses and strains (both recoverable and permanent), gap conductance, fuel-cladding interfacial pressure, and coolant film heat-transfer information.

The power-time step printout presents rod burnup, void volumes and associated temperatures, mole fractions of constituent gases and release fractions, total moles of rod gas, and rod gas pressure. Also, this printout presents stresses, strains, temperatures, and stored energy as a function of axial region.

The summary page printout presents time-dependent information about the hot axial region. This includes temperatures of the cladding, fuel-cladding gap, and fuel; fuel-cladding interfacial pressure; cladding stress and strain; fuel outside diameter; gap conductance and gas pressure; zircaloy oxide thickness; and hydrogen uptake.

\subsubsection{Plot Package}

The FRAPCON-3 plotting package is made up of subroutines that use XMGR $5^{33}$, an INEEL extension of the $\mathrm{XMGR}^{34}$ graphics package. The plot variables, labels, type (independent or dependent), index of number of values per variable, and units are shown in Table 3.7.

\subsubsection{FRAPTRAN Initialization}

FRAPCON-3 contains subroutine RESTFS, which, when the flag NTAPE is set to 1 , stores sets of history-dependent information for each power-time step. This information is stored on unit TAPE1 and is for FRAPTRAN initialization. This gives the user the ability to model the fuel rod response of a rod that experiences significant burnup before some transient excursion.

\subsection{Features of FRAPCON-3}

FRAPCON-3 has been designed with special features to aid the user. FRAPCON-3 has been dynamically dimensioned so that a minimum of core storage is required for any given fuel modeling process. Those parameters that are a function of the problem size are dimensioned to the exact size required by the axial and radial nodalization and the number of power-time steps. The user can set the core size based on the number of axial and radial nodes and the number of time steps. 
Table 3.7. FRAPCON-3 Plot File Layout

\begin{tabular}{|c|c|c|c|c|c|}
\hline Description & Label & Type & Num & $\begin{array}{l}\text { Units } \\
\text { (SI) }\end{array}$ & $\begin{array}{c}\text { Units } \\
\text { (British) }\end{array}$ \\
\hline Time at start of step & time_0 & ind & 1 & (s) & (s) \\
\hline Time at end of step & time_1 & ind & 1 & (s) & (s) \\
\hline Power & power_nn_\&_ave & ind & ir1 & $\mathrm{kW} / \mathrm{m}$ & $\mathrm{kW} / \mathrm{ft}$ \\
\hline Burnup & burnup_nn \&_ave & ind & ir1 & $\mathrm{MWd} / \mathrm{kg}$ & $\mathrm{MWd} / \mathrm{kg}$ \\
\hline Clad surface temp & clad_temp_nn & dep & irl-1 & $\mathrm{K}$ & $\mathrm{F}$ \\
\hline Fuel centerline temp & fuel_cl_temp_nn & dep & ir1-1 & $\mathrm{K}$ & $\mathrm{F}$ \\
\hline Rod gas pressure & rod_gas_press & dep & 1 & $\mathrm{~Pa}$ & psia \\
\hline Cladding hoop strain & hoop_strain_nn & dep & ir1-1 & - & - \\
\hline Fuel axial displ. & fuel_axial_disp & dep & 1 & $\mathrm{~m}$ & $\mathrm{ft}$ \\
\hline Cladding axial displ. & clad_axial_disp & dep & 1 & $\mathrm{~m}$ & $\mathrm{ft}$ \\
\hline Rod linear power & lhgr_nn & dep & ir $1-1$ & $\mathrm{~kW} / \mathrm{m}$ & $\mathrm{kW} / \mathrm{ft}$ \\
\hline Fuel surface temp & surf_temp_nn & dep & ir 1-1 & $\mathrm{K}$ & $\mathrm{F}$ \\
\hline Gap heat trans coef. & gap_htc_nn & dep & ir 1-1 & $\mathrm{W} / \mathrm{m}^{2} \times \mathrm{K}$ & $\mathrm{Btu} / \mathrm{hr}-\mathrm{ft}^{2} \times \mathrm{F}$ \\
\hline Surface ht trans coef & surf_htc_nn & dep & ir $1-1$ & $\mathrm{~W} / \mathrm{m}^{2} \times \mathrm{K}$ & Btu/hr-ft' ${ }^{2} \times F$ \\
\hline Clad average temp & ave_clad_temp_nn & dep & ir $1-1$ & $\mathrm{~K}$ & $\mathrm{~F}$ \\
\hline Zircaloy oxide thick & zro2_thk_nn & dep & ir1-1 & $\mathrm{mm}$ & in \\
\hline Helium mole frac. & he_mole_frac & dep & 1 & - & - \\
\hline Plenum temp & plenum_temp & dep & 1 & $\mathrm{~K}$ & $\mathrm{~F}$ \\
\hline Inc in rod gas cont. & rod_gas_incr & dep & 1 & $\%$ & $\%$ \\
\hline Coolant mass flux & coolant_mass_flux & dep & 1 & $\mathrm{~kg} / \mathrm{s}-\mathrm{m}^{2}$ & $\mathrm{lbm} / \mathrm{hr}-\mathrm{ft}^{2}$ \\
\hline Stored energy & st_energy_nn & dep & ir $1-1$ & $\mathrm{~J} / \mathrm{kg}$ & $\mathrm{Btu} / \mathrm{lbm}$ \\
\hline Coolant pressure & coolant_pres & dep & 1 & $\mathrm{~Pa}$ & psia \\
\hline Gap thickness & gap_thk_nn & dep & ir $1-1$ & $\mathrm{~mm}$ & in \\
\hline Coolant bulk temp & coolant_temp_nn & dep & ir 1-1 & $\mathrm{K}$ & $\mathrm{F}$ \\
\hline
\end{tabular}




\subsection{References}

1. L. J. Siefken, C. M. Allison, M. P. Bohn, and S. O. Peck, FRAP-T6: A Computer Code for the Transient Analysis of Oxide Fuel Rods, EGG-CDAP-5410, April 1981.

2. D. L. Hagrman, A. Reymann, and R. E. Mason, MATPRO-Version 11 (Revision 1): A Handbook of Materials Properties for Use in the Analysis of Light Water Reactor Fuel Rod Behavior, NUREG/CR-0497, TREE-1280, Rev. 1, February 1980.

3. G. A. Berna and M. P. Bohn, FRAPCON-1: A Computer Code for the Steady State Analysis of Oxide Fuel Rods, NUREG/CR-1463, EGG-2039, May 1981.

4. D. R. Coleman et al., FRAP-S3: A Computer Code for the Steady State Analysis of Oxide Fuel Rods - Model Assessment Report, NUREG/CR-0786, TREE-1352, R4, April 1979.

5. G. A. Berna, M. P. Bohn, W. N. Rausch, R. W. Williford, and D. D. Lanning, FRAPCON2: A Computer Code for the Calculation of Steady-State Thermal-Mechanical Behavior of Oxide Fuel Rods, NUREG/CR-1845, December 1980.

6. EG\&G Idaho, Inc., Quarterly Technical Progress Report on Water Reactor Safety Programs, July-September, 1978, Sponsored by the Nuclear Regulatory Commission's Division of Reactor Safety Research, NUREG/CR-0412, TREE-1294, October 1978, pp. 45-49.

7. American Nuclear Society (ANS), "Method for Calculating the Fractional Release of Volatile Fission Products from Oxide Fuel," ANS5.4 of the Standards Committee of the American Nuclear Society, ANSU/ANS-5.4-1982.

8. D. D. Lanning, C. E. Beyer, and C. L. Painter, Modifications to NRC Fuel Rod Material Properties and Performance Models for High Burnup Application, Volume 1, NUREG/ CR-6534, PNNL-11513, Volume 1, 1997.

9. D. D. Lanning, C. E. Beyer, G. A. Berna, and K. J. Geelhood, FRAPCON-3 Integral Assessment, Volume 3, NUREG/CR-6534, PNNL-11513, Volume 3, 1997.

10. M. P. Bohn, FRACAS: A Subcode for the Analysis of Fuel Pellet-Cladding Mechanical Interaction, TREE-NUREG-1028, April 1977.

11. F. Dittus and L. M. K. Boelter, "Heat Transfer in Automobile Radiators of the Tubular Type," University of California Publications in Engineering, 2, 13, 1930, pp. 443-461. 
12. W. H. Jens and P. A. Lottes, Analysis of Heat Transfer, Burnout, Pressure Drop, and Density Data for High-Pressure Water, ANL-4627, 1951.

13. F. Kreith, Principles of Heat Transfer, 8th Edition, Scranton: International Book Company (1964).

14. C. E. Beyer, C. R. Hann, D. D. Lanning, F. E. Panisko, and L. J. Parchen, GAPCONTHERMAL-2: A Computer Program for Calculating the Thermal Behavior of an Oxide Fuel Rod, BNWL-1898, November 1975.

15. N. Todreas and G. Jacobs, "Thermal Contact Conductance of Reactor Fuel Elements," Nuclear Science and Engineering, 50, 1973, p. 283.

16. J. E. Garnier and S. Begej, Ex-Reactor Determination of Thermal Gap and Contact Conductance Between Uranium Dioxide: Zircaloy-4 Interfaces; Stage I: Low Gas Pressure, NUREG/CR-0330, PNL-2696, 1979.

17. A. M. Ross and R. L. Stoute, Heat Transfer Coefficients Between $\mathrm{UO}_{2}$ and Zircaloy-2, CRFD-1075, AECL-1552, June 1962.

18. A. C. Rapier, T. M. Jones, and J. E. McIntosh, "The Thermal Conductance of Uranium Dioxide/Stainless Steel Interfaces," International Journal of Heat Mass Transfer, Volume 6, 1963, pp. 397-416.

19. K. Lassman, C. O'Carrol, J. VanderLaar, and C. T. Walker, "The Radial Distribution of Plutonium in High Burnup $\mathrm{UO}_{2}$ Fuels," J. Nuclear Materials, Vol. 28, 1994, pp. 223-231.

20. P. G. Lucuta, H. S. Matzke, and I. J. Hastings, "A Pragmatic Approach to Modeling Thermal Conductivity of Irradiated $\mathrm{UO}_{2}$ Fuel: Review and Recommendations," Journal of Nuclear Material, Volume 232, 1996, pp. 166-180.

21. J. H. Harding and D. G. Martin, "Recommendation for the Thermal Conductivity of $\mathrm{UO}_{2}$," Journal. of Nuclear Materials, 166, 1989, pp. 223-226.

22. W. H. McAdams, Heat Transmission, 34th Edition, New York: McGraw-Hill Book Company, Inc., 1954.

23. A. Mendelson, Plasticity: Theory and Applications, New York: The MacMillan Company, 1968. 
24. E. F. Ibrahim, "In-Reactor Tubular Creep of Zircaloy-2 at 260 to $300{ }^{\circ} \mathrm{C}$," Journal of Nuclear Materials, 46, 1973, pp. 169-182.

25. P. A. Ross-Ross and C. E. L. Hunt, "The In-Reactor Creep of Cold-Worked Zircaloy-2 and Zirconium-2.5 wt\% Niobium Pressure Tubes," Journal of Nuclear Material, 26, 1968, pp. 2-17.

26. V. Fidleris, "Summary of Experimental Results on In-Reactor Creep and Radiation Growth of Zirconium Alloys," Atomic Energy Review, 13, No. 1, 1976, pp. 51-80.

27. M. E. Cunningham and C. E. Beyer, GT2R2: An Updated Version of GAPCONTHERMAL-2, NUREG/CR-3907, PNL-5178, Pacific Northwest Laboratory, 1984.

28. W. N. Rausch and F. E. Panisko, ANS54: A Computer Subroutine for Predicting Fission Gas Release, NUREG/CR-1213, PNL-3077, August 1979.

29. K. Forsberg and A. R. Massih, "Diffusion Theory of Fission Gas Migration in Irradiated Nuclear Fuel $\mathrm{UO}_{2}$," Journal of Nuclear Materials, Vol. 135, 1985, pp. 140-148.

30. A. H. Booth, A Method of Calculating Fission Gas Diffusion from $\mathrm{UO}_{2}$ Fuel and Its Application to the X-2 Loop Test, AECL-496, CRDC-721, 1957.

31. H. M. Ferrari, "Nitrogen Release from $\mathrm{UO}_{2}$ Pellets at Elevated Temperatures," Nuclear Science and Engineering, 17, 4, December 1963.

32. H. M. Ferrari, "Diffusion of Nitrogen in Uranium Dioxide," Journal of Nuclear Materials, $12,2,1964$.

33. K. R. Jones, XMGR5 Extensions (Draft), INEL document, 1995.

34. P. J. Turner, ACE/gr User 's Manual, SDS3, 91-3, 1991-1993, Beaverton, OR 


\section{Appendix A}

Input Instructions for the FRAPCON-3 Code 


\section{Appendix A: Input Instructions for the FRAPCON-3 Code}

These three user-supplied NAMELIST variables groups, and their type, definitions, and units, are listed in Table A-1, Table A-2, and Table A-3, respectively. For those few variables that have default values, these values are also listed, in British units.

The NAMELIST input is divided into three sections: case control integers (in \$FRPCN); case design and operation descriptors (real and integer variables) located in \$FRPCON; and evaluation model options (in \$EMFPCN). The variables in the first group must be separated by commas and placed between the statement \$FRPCN and \$END. Similarly, the variables in the second and third groups must be placed between \$FRPCON and \$END and between \$EMFPCN and \$END, respectively. A case title line may precede the NAMELIST groups. An example case input is given in Table A-4 in Section below.

Table A-1. Control Integers in \$FRPCN

\begin{tabular}{|l|l|l|}
\hline \multicolumn{1}{|c|}{\begin{tabular}{c}
\multicolumn{1}{|c|}{ Dariable } \\
name
\end{tabular}} & \multicolumn{1}{|c|}{ Description } & \multicolumn{1}{|c|}{ Limitations } \\
\hline IM & Number of time steps & $\begin{array}{l}\text { Greater than 1, less } \\
\text { than } 400\end{array}$ \\
\hline NR & $\begin{array}{l}\text { Number of radial boundaries in the pellet (for temperature } \\
\text { calculations and temperature distribution output). These are } \\
\text { spaced by the code with the greater fraction in the outer } \\
\text { region to optimize definition of the heat generation radial } \\
\text { distribution. }\end{array}$ & $\begin{array}{l}\text { Greater than 1, less } \\
\text { than 30; suggested } \\
\text { number is 17 }\end{array}$ \\
\hline NGASR & $\begin{array}{l}\text { Number of equal-volume radial rings in the pellet for gas } \\
\text { release calculations. Also signals which gas release model } \\
\text { the code will use. If NGASR is 10 or less, the ANS5.4 } \\
\text { model is used; if 11 or greater, the MASSIH subroutine is } \\
\text { used. }\end{array}$ & $\begin{array}{l}\text { Greater than 1, less } \\
\text { than 50; suggested } \\
\text { number is 20 }\end{array}$ \\
\hline NA & $\begin{array}{l}\text { Number of equal-length axial regions along the rod, for } \\
\text { which calculations are performed and output. }\end{array}$ & $\begin{array}{l}\text { Greater than 1, less } \\
\text { than 20 }\end{array}$ \\
\hline NTAPE & $\begin{array}{l}\text { Write output to a file for FRAPTRAN restart. } \\
\text { ntape } \leq 0 \text { do not write } \\
\text { ntape }>0 \text { write output to file named restart }\end{array}$ & Default =0 \\
\hline
\end{tabular}


Table A-2. Case Descriptor Variables in \$FRPCON

\begin{tabular}{|c|c|c|c|}
\hline $\begin{array}{l}\text { Variable } \\
\text { name and } \\
\text { type } \\
I=\text { integer } \\
R=\text { real }\end{array}$ & Variable description & $\begin{array}{l}\text { Units: } \\
\text { British/SI }\end{array}$ & $\begin{array}{l}\text { Limitations and } \\
\text { default values }\end{array}$ \\
\hline AMFAIR (R) & $\begin{array}{l}\text { Mole fraction of air, use only if } \\
\text { IDXGAS }=6 \text {. }\end{array}$ & & Default $=0.0$ \\
\hline AMFARG (R) & $\begin{array}{l}\text { Mole fraction of argon; use only if } \\
\text { IDXGAS }=6 \text {. }\end{array}$ & & Default $=0.0$ \\
\hline AMFFG (R) & $\begin{array}{l}\text { Mole fraction of fission gas; use only if } \\
\text { IDXGAS }=6 \text { and if AMFXE and } \\
\text { AMFKRY }=0.0 \text {. }\end{array}$ & & Default $=0.0$ \\
\hline AMFHE (R) & $\begin{array}{l}\text { Mole fraction of helium; use only if } \\
\text { IDXGAS = } 6 \text {. }\end{array}$ & & $\begin{array}{l}\text { Default }=0.0(\text { note } \\
\text { default on } \\
\text { IDXGAS }=1 \\
\text { initializes pure He }\end{array}$ \\
\hline AMFH2 (R) & $\begin{array}{l}\text { Mole fraction of hydrogen; use only if } \\
\text { IDXGAS }=6 \text {. }\end{array}$ & & Default $=0.00$ \\
\hline $\mathrm{AMFH} 2 \mathrm{O}(\mathrm{R})$ & $\begin{array}{l}\text { Mole fraction of water vapor; use only if } \\
\text { IDXGAS }=6 \text {. }\end{array}$ & & Default $=0.0$ \\
\hline AMFKRY (R) & $\begin{array}{l}\text { Mole fraction of krypton; use only if } \\
\text { IDXGAS }=6 \text {. }\end{array}$ & & Default $=0.0$ \\
\hline AMFN2 (R) & $\begin{array}{l}\text { Mole fraction of nitrogen; use only if } \\
\text { IDXGAS }=6 .\end{array}$ & & Default $=0.0$ \\
\hline AMFXE (R) & $\begin{array}{l}\text { Mole fraction of xenon; use only if } \\
\text { IDXGAS }=6 \text {. }\end{array}$ & & Default $=0.0$ \\
\hline CREPHR (R) & Creep time step size. & hours/hours & Default $=100.0$ \\
\hline CATEXF (R) & $\begin{array}{l}\text { Cladding texture factor, defined as the } \\
\text { fraction of cladding cells with basal } \\
\text { poles parallel to the longitudinal axis of } \\
\text { the cladding tube. }\end{array}$ & Dimensionless & Default $=0.05$ \\
\hline CLDWKS (R) & $\begin{array}{l}\text { Cold-work of the cladding (fractional } \\
\text { reduction in cross-section area due to } \\
\text { processing). }\end{array}$ & Dimensionless & Default $=0.2$ \\
\hline
\end{tabular}


Table A-2. Case Descriptor Variables in \$FRPCON (Continued)

\begin{tabular}{|c|c|c|c|}
\hline $\begin{array}{c}\text { Variable } \\
\text { name and } \\
\text { type } \\
I=\text { integer } \\
R=\text { real }\end{array}$ & Variable description & $\begin{array}{l}\text { Units: } \\
\text { British/SI }\end{array}$ & $\begin{array}{l}\text { Limitations and } \\
\text { default values }\end{array}$ \\
\hline $\operatorname{COMP}(\mathrm{R})$ & Weight fraction of plutonia in urania & Weight fraction & Default $=0.0$ \\
\hline $\mathrm{CPL}(\mathrm{R})$ & Cold plenum length & inches/meters & \\
\hline CRDT (R) & $\begin{array}{l}\text { Initial thickness of crud layer on } \\
\text { cladding outside surface }\end{array}$ & mils/meters & Default $=0.0$ \\
\hline CRDTR (R) & $\begin{array}{l}\text { Rate of crud accumulation (used if } \\
\text { ICOR }=2 \text { ) }\end{array}$ & $\begin{array}{l}\text { mils/s } \\
\text { meters } / \mathrm{s}\end{array}$ & Default $=0.0$ \\
\hline $\mathrm{DCO}(\mathrm{R})$ & Cladding outer diameter & Inches/meters & \\
\hline $\mathrm{DEN}(\mathrm{R})$ & As-fabricated apparent fuel density & $\begin{array}{l}\text { Fraction of } \\
\text { theoretical density }\end{array}$ & $\begin{array}{l}\text { Theoretical } \\
\text { density taken as } \\
10.97 \mathrm{~g} / \mathrm{cc}\end{array}$ \\
\hline DENG (R) & Open porosity fraction for pellets & $\begin{array}{l}\text { Fraction of } \\
\text { theoretical density }\end{array}$ & Default $=0.0$ \\
\hline DISHSD (R) & $\begin{array}{l}\text { Pellet end-dish shoulder width (outer } \\
\text { radius of fuel pellet minus radius of } \\
\text { dish) }\end{array}$ & Inches/meters & \\
\hline DSPG (R) & Outer diameter of plenum spring & Inches/meters & \\
\hline DSPGW (R) & Diameter of the plenum spring wire & Inches/meters & \\
\hline $\operatorname{ENRCH}(\mathrm{R})$ & Fuel pellet ${ }^{235} \mathrm{U}$ enrichment & $\begin{array}{l}\text { Atom } \%{ }^{235} U \text { in } \\
\text { total } U\end{array}$ & \\
\hline FA (R) & $\begin{array}{l}\text { Peak-to-average power ratio for cosine- } \\
\text { type axial power distribution }(=1.0 \text {, } \\
\text { unless } I Q=1 ; \text { see description of } I Q)\end{array}$ & Dimensionless & \\
\hline FGPAV (R) & $\begin{array}{l}\text { Initial fill gas pressure (taken to be at } \\
\text { room temperature) }\end{array}$ & $\mathrm{psia} / \mathrm{Pa}$ & \\
\hline $\operatorname{FLUX}(\mathrm{J})(\mathrm{R})$ & $\begin{array}{l}\text { Conversion between fuel specific power } \\
\text { and fast neutron flux }(E>1 \mathrm{MeV}) \text {. Input } \\
\text { a value for each axial node. }\end{array}$ & $\mathrm{n} / \mathrm{m} / \mathrm{s} / \mathrm{W} / \mathrm{g}$ of fuel & $\begin{array}{l}\text { Default }= \\
0.25 \times 10^{17}\end{array}$ \\
\hline FOTMTL (R) & $\begin{array}{l}\text { Oxygen-to-metal atomic ratio in the } \\
\text { oxide fuel pellet }\end{array}$ & Dimensionless & Default $=2.0$ \\
\hline
\end{tabular}


Table A-2. Case Descriptor Variables in \$FRPCON (Continued)

\begin{tabular}{|c|c|c|c|}
\hline $\begin{array}{c}\text { Variable } \\
\text { name and } \\
\text { type } \\
I=\text { integer } \\
R=\text { real }\end{array}$ & Variable description & $\begin{array}{l}\text { Units: } \\
\text { British/SI }\end{array}$ & $\begin{array}{l}\text { Limitations and } \\
\text { default values }\end{array}$ \\
\hline GADOLN (R) & $\begin{array}{l}\text { Weight fraction of gadolinia in urania- } \\
\text { gadolinia fuel pellets }\end{array}$ & Dimensionless & Default $=0.0$ \\
\hline $\mathrm{GO}(\mathrm{IT})(\mathrm{R})$ & $\begin{array}{l}\text { Mass flux of coolant around fuel rod. } \\
\text { Input a value for each time step if } \\
\text { NSP }=1 \text {. }\end{array}$ & $\begin{array}{l}\mathrm{lb} / \mathrm{hr}-\mathrm{ft}^{2} \\
\mathrm{~kg} / \mathrm{s}-\mathrm{m}^{2}\end{array}$ & Default $=0.0$ \\
\hline HDISH (R) & $\begin{array}{l}\text { Height (depth) of pellet dish, assumed to } \\
\text { be a spherical indentation. }\end{array}$ & Inches/meters & \\
\hline $\operatorname{HPLT}(\mathrm{R})$ & Height (length) of each pellet & Inches/meters & \\
\hline ICM (I) & $\begin{array}{l}\text { Cladding type indicator: } \\
2=\text { zircaloy } 2 \\
4=\text { zircaloy } 4\end{array}$ & Dimensionless & \\
\hline ICOR (I) & $\begin{array}{l}\text { Index for crud model: } \\
0,1=\text { constant crud; } 1 \text { mil crud layer } \\
\text { assumed; } 20^{\circ} \mathrm{F} \text { maximum temperature } \\
\text { rise across this layer. } \\
2=\text { variable crud; growth rate is } \\
\text { CRDTR, starting from zero crud layer; } \\
0.5 \mathrm{Btu} / \mathrm{hr} / \mathrm{ft}-\mathrm{F} \text { is conductivity of layer. } \\
\text { To eliminate crud effect, use ICOR }=2 \\
\text { but give CRDTR a very small value. }\end{array}$ & Dimensionless & \\
\hline IDXGAS (I) & $\begin{array}{l}\text { Initial fill gas type indicator: } \\
1=\text { helium } \\
2=\text { air } \\
3=\text { nitrogen } \\
4=\text { fission gas } \\
5=\text { argon } \\
6=\text { user-specified mix using the } \\
\text { AMFXX variables AMFAIR, etc. }\end{array}$ & Dimensionless & Default $=1$ \\
\hline IMSWCH (I) & $\begin{array}{l}\text { Signal for EM models: } \\
=0 \text { No EM models } \\
=1 \text { Selected EM models, input signals } \\
\text { in } \$ E M F P C N\end{array}$ & Dimensionless & \\
\hline
\end{tabular}


Table A-2. Case Descriptor Variables in \$FRPCON (Continued)

\begin{tabular}{|c|c|c|c|}
\hline $\begin{array}{c}\text { Variable } \\
\text { name and } \\
\text { type } \\
I=\text { integelr } \\
R=\text { real }\end{array}$ & Variable description & $\begin{array}{c}\text { Units: } \\
\text { British/SI }\end{array}$ & $\begin{array}{l}\text { Limitations and } \\
\text { default values }\end{array}$ \\
\hline IPLANT (I) & $\begin{array}{l}\text { Signal for which type of reactor: } \\
-2=\text { PWR } \\
-3=\text { BWR } \\
-4=\text { HBWR }\end{array}$ & Dimensionless & \\
\hline IQ (I) & $\begin{array}{l}\text { Indicator for axial power shape; } \\
0=\text { User-input power shapes with } \\
\text { QMPY = rod-average powers and power } \\
\text { shapes defined by } Q F, . X \text {, and } F A=1.0 \\
1=\text { Chopped cosine shape, with } F A= \\
\text { peak-to-average ratio and } Q M P Y=\text { peak } \\
\text { power. }\end{array}$ & Dimensionless & \\
\hline JDLPR (I) & $\begin{array}{l}\text { Output print control: } \\
0=\text { all axial nodes } \\
1=\text { peak-power axial node }\end{array}$ & Dimensionless & \\
\hline $\mathrm{JN}(\mathrm{I})$ & $\begin{array}{l}\text { The number of } Q F, X \text { value pairs for } \\
\text { each axial power shape; required input if } \\
\text { IQ }=0 \text {. Input } i \text { the same sequence as the } \\
Q F \text { and } X \text { arrays. }\end{array}$ & Dimensionless & $\begin{array}{l}\text { Maximum number } \\
\text { of shapes is } 20\end{array}$ \\
\hline JST (I) & $\begin{array}{l}\text { The sequential number of the power } \\
\text { shape to be used for each time step. One } \\
\text { value of JST is required per time step if } \\
\text { IQ }=0 \text {. }\end{array}$ & Dimensionless & $\begin{array}{l}\text { Maximum numbe } \\
\text { of power shapes }= \\
20 . \text { Maximum } \\
\text { time steps is } 400 .\end{array}$ \\
\hline NSP (I) & $\begin{array}{l}\text { Signal for time-dependent input arrays } \\
\text { for } \mathrm{P} 2, \mathrm{TW} \text {, and } \mathrm{GO} \text { : } \\
\text { If NSP }=0 \text {, single values for these three } \\
\text { variables will be used for all time steps. } \\
\text { If NSP = } 1 \text {, a value for each variable for } \\
\text { each time step must be input. }\end{array}$ & Dimensionless & \\
\hline NUNITS (I) & $\begin{array}{l}\text { Signal for units system to be used for } \\
\text { input and output: } \\
1=\text { British units } \\
0=\text { SI units } \\
\text { Some errors may occur if NUNITS }=1 \text {. }\end{array}$ & Dimensionless & Default $=11$ \\
\hline
\end{tabular}


Table A-2. Case Descriptor Variables in \$FRPCON (Continued)

\begin{tabular}{|c|c|c|c|}
\hline $\begin{array}{c}\text { Variable } \\
\text { name and } \\
\text { type } \\
I=\text { integer } \\
R=\text { real }\end{array}$ & Variable description & $\begin{array}{l}\text { Units: } \\
\text { British/SI }\end{array}$ & $\begin{array}{l}\text { Limitations and } \\
\text { default values }\end{array}$ \\
\hline $\mathrm{P} 2$ (R) & $\begin{array}{l}\text { Coolant system pressure. Must be input } \\
\text { for each time step if } N S P=1 \text {. }\end{array}$ & $\mathrm{psia} / \mathrm{Pa}$ & \\
\hline PITCH (R) & $\begin{array}{l}\text { Center-to-center distance between rods } \\
\text { in a square array }\end{array}$ & Inches/meters & \\
\hline $\mathrm{PPMH} 2 \mathrm{O}(\mathrm{R})$ & $\begin{array}{l}\text { Parts per million by weight of moisture } \\
\text { in the as-fabricated pellets }\end{array}$ & ppm & Default $=0.0$ \\
\hline PPMN2 (R) & $\begin{array}{l}\text { Parts per million by weight of nitrogen } \\
\text { in the as-fabricated pellets }\end{array}$ & $\mathrm{ppm}$ & Default $=0.0$ \\
\hline QEND (R) & $\begin{array}{l}\text { Fraction of end-node heat that transfers } \\
\text { to the plenum gas }\end{array}$ & Dimensionless & Default $=0.3$ \\
\hline $\mathrm{QF}(\mathrm{N})(\mathrm{R})$ & $\begin{array}{l}\text { The ratio of the linear power at the } \mathrm{X}(\mathrm{N}) \\
\text { elevation to the axially-averaged value } \\
\text { for the } \mathrm{M} \text {-th power shape. The number } \\
\text { of } \mathrm{QF} \text {, } \mathrm{X} \text { pairs for th Mth power shape is } \\
\text { defined by } \mathrm{N}(\mathrm{M}) \text {. The user must define } \\
\text { the } \mathrm{QF} \text { values such that the axially- } \\
\text { averaged value of each power shape is } \\
1.0 \text {. }\end{array}$ & Dimensionless & \\
\hline QMPY(IT) (R) & $\begin{array}{l}\text { The linear heat generation rate at each } \\
\text { time step. This equals the rod-average } \\
\text { value if } I Q=0 \text { and the peak value if IQ } \\
=1 .\end{array}$ & $\mathrm{kW} / \mathrm{ft} / \mathrm{kW} / \mathrm{m}$ & Limit 400 steps \\
\hline $\mathrm{RC}(\mathrm{R})$ & The inner pellet radius & Inches/meters & \\
\hline ROUGHC (R) & $\begin{array}{l}\text { The cladding surface arithmetic mean } \\
\text { roughness, peak-to-average }\end{array}$ & Inches/meters & \\
\hline ROUGHF (R) & $\begin{array}{l}\text { The fuel pellet surface arithmetic mean } \\
\text { roughness, peak-to-average }\end{array}$ & Inches/meters & \\
\hline RSNTR (R) & $\begin{array}{l}\text { The increase in pellet density expected } \\
\text { during in-reactor operation (determined } \\
\text { from a standard re-sintering test) }\end{array}$ & $\mathrm{kg} / \mathrm{m}^{3}$ & \\
\hline SGAPF (R) & $\begin{array}{l}\text { Number of fission gas atoms formed per } \\
100 \text { fissions }\end{array}$ & Dimensionless & Default $=31.0$ \\
\hline
\end{tabular}


Table A-2. Case Descriptor Variables in \$FRPCON (Continued)

\begin{tabular}{|l|l|l|l|}
\hline $\begin{array}{c}\text { Variable } \\
\text { name and } \\
\text { type } \\
\begin{array}{c}\text { I } \text { integer } \\
\text { = real }\end{array}\end{array}$ & \multicolumn{1}{|c|}{ Variable description } & \multicolumn{1}{c|}{$\begin{array}{c}\text { Units: } \\
\text { British/SI }\end{array}$} & $\begin{array}{c}\text { Limitations and } \\
\text { default values }\end{array}$ \\
\hline SLIM (R) & Limit on swelling & Volume $\%$ & \\
\hline THKCLD (R) & Cladding wall thickness & Inches/meters & \\
\hline THKGAP (R) & $\begin{array}{l}\text { Pellet-cladding as-fabricated gap } \\
\text { thickness }\end{array}$ & Inches/meters & \\
\hline TIME(IT) (R) & $\begin{array}{l}\text { Cumulative time at the end of each time } \\
\text { step }\end{array}$ & Days & Limit 400 steps \\
\hline TSINT (R) & $\begin{array}{l}\text { Temperature at which pellets were } \\
\text { sintered }\end{array}$ & F/K & Default $=2911^{\circ} \mathrm{F}$ \\
\hline TOTL (R) & The total (active) fuel column length. & Feet/meters & \\
\hline TW(IT) (R) & $\begin{array}{l}\text { Coolant inlet temperature. Enter a value } \\
\text { for every time step if NSP }=1 .\end{array}$ & F/K & \\
\hline VS (R) & Number of turns in the plenum spring & Dimensionless & \\
\hline X(n) (R) & $\begin{array}{l}\text { The elevations in each QF, X array } \\
\text { defining a power shape. Note that the } \\
\text { first value should be } 0.0 \text { and the last } \\
\text { value must = TOTL. }\end{array}$ & feet/meters & \\
\hline
\end{tabular}

Table A-3. Evaluation Model Switches in \$EMFPCN

\begin{tabular}{|l|l|}
\hline \multicolumn{1}{|c|}{ Variable name } & \multicolumn{1}{c|}{ Variable description } \\
\hline IMPOWR & EM power requirement index: $=0$ not assumed to be required \\
\hline IMFUEL & Switch on dimensional changes: $0=$ BE changes, 1 = EM changes \\
\hline IMDENS & Switch on densification model \\
\hline IMRELO & Switch on fuel relocation model \\
\hline IMCLAD & Switch on cladding deformation; 1 = no permanent deformation \\
\hline IMGAPC & Switch on gap conductance calculation \\
\hline IM93WC & Switch on fuel thermal conductivity (not used) \\
\hline
\end{tabular}


Table A-3. Evaluation Model Switches in \$EMFPCN (Continued)

\begin{tabular}{|l|l|}
\hline \multicolumn{1}{|c|}{ Variable name } & \multicolumn{1}{c|}{ Variable description } \\
\hline IMENERG & $\begin{array}{l}\text { Switch on stored energy reference temperature: } \\
0=\text { reference }=298 \mathrm{~K} \\
1=\text { reference }=273 \mathrm{~K}\end{array}$ \\
\hline IMFGAS & Switch on fission gas release model (not used) \\
\hline
\end{tabular}

\section{Evaluation Model Option}

A set of ten EM flags is used to specify the EM options. One flag, IMSWSH, in the FRPCON NAMELIST is used to set all options on or off or to specify that some combination of the EM model options and best-estimate BE model options is to be used.

The input variables for the EMFPCN NAMELIST are given in Table A-3. They correspond to the nine EM requirements. All variables are defaulted to zero.

The EM input cards follow a \$EMFPCN card and end with a \$END card. If IMSWCH $=0$ or 1 , these cards must be omitted (see Table A-4).

Table A-4. Example Input File

\begin{tabular}{|l|}
\hline \multicolumn{1}{|c|}{ Lines in Input File } \\
\hline Standard PWR test case \\
\hline im $=7, !$ number of power steps \\
\hline$!$ Identification of units for input \\
\hline nunits $=1, !$ input units are British units \\
\hline$!$ Definition of fuel rod environment \\
\hline $\mathrm{p} 2(1)=2250.0, !$ coolant pressure (psia) \\
\hline tw $(1)=552.0, !$ inlet temperature of water $(\mathrm{F})$ \\
\hline go(1) $=2500000.0, !$ mass flow rate of coolant $\left(\mathrm{lb} / \mathrm{hr} \cdot \mathrm{ft}^{2}\right)$ \\
\hline pitch $=0.5629, !$ pitch of fuel rods (in.) \\
\hline$!$ Definition of fuel rod cladding and plenum spring \\
\hline dco $=0.422, !$ outer cladding diameter (in.) \\
\hline thkcld $=2.4 \mathrm{e}-2, !$ radial thickness of cladding (in.) \\
\hline
\end{tabular}


Table A-4. Example Input File (Continued)

\begin{tabular}{|l|}
\hline \\
\hline icm $=4, !$ cladding material indicator (zircaloy-4) \\
\hline cldwks $=0.2, !$ fractional cold work of the cladding \\
\hline catexf $=0.05$ \\
\hline fgpav $=345.0, !$ fill gas pressure (psia) \\
\hline cpl $=6.8, !$ plenum length (in.) \\
\hline dspg $=0.35, !$ coil diameter of spring in plenum (in.) \\
\hline dspgw $=0.076, !$ diameter of wire in plenum spring (in.) \\
\hline vs $=28.0, !$ total number of spring turns \\
\hline roughc $=4.5$ e-5, $!$ arithmetic mean roughness of cladding surface (in.) \\
\hline$!$ Definition of fuel in fuel rod \\
\hline thkgap $=3.75 \mathrm{e}-3, !$ radial thickness of fuel cladding gap (in.) \\
\hline totl $=12.0, !$ height of fuel pellet stack (ft.) \\
\hline den $=95.0, !$ fuel density (\%) \\
\hline enrch $=2.8, !$ fuel enrichment (weight $\%$ ) \\
\hline roughf $=8.5 \mathrm{e}-5, !$ arithmetic mean roughness of fuel surface (in.) \\
\hline dishsd $=0.043, !$ pellet radius minus dish radius (in.) \\
\hline hdish $=0.015, !$ depth of dishes at ends of fuel pellets (in.) \\
\hline hplt $=0.6, !$ height of fuel pellets (in.) \\
\hline deng $=0.75, !$ percent of closed porosity volume \\
\hline grnsiz $=5 ., !$ initial size of fuel grains (microns) \\
\hline tsing $=2911 ., !$ sintering temperature of fuel pellets (F) \\
\hline$!$ Fuel rod power \\
\hline$!$ time(i) $=$ time (days) to end of each level of power in array qmpy(i) \\
\hline time $=0.1, .2, .3, .4, .5,1,3$, \\
\hline$!$ qmpy(i) $=$ fuel rod average linear heat rating (kW/ $\mathrm{ft)} \mathrm{at} \mathrm{time(i)}$ \\
\hline qmpy $=1,2.5,4,5.5,7,7,7$, \\
\hline jn( 1$)=11, !$ number of entries in axial power versus elevation table \\
\hline
\end{tabular}


Table A-4. Example Input File (Continued)

\begin{tabular}{|l|}
\hline \multicolumn{1}{|c|}{ Lines in Input File } \\
\hline$! \mathrm{x}(\mathrm{i})=$ elevations $(\mathrm{ft}$.$) for which axial power factors in array \mathrm{qf}(\mathrm{i})$ apply \\
\hline $\mathrm{x}(1)=0.0,1.2,2.4,3.6,4.8,6.0,7.2,8.4,9.6,10.8,12.0$ \\
\hline$! \mathrm{q} f(\mathrm{i})=$ axial power factors for each elevation in array $\mathrm{x}(\mathrm{i})$ \\
\hline $\mathrm{q}(1)=.23, .64, .97,1.21,1.35,1.40,1.35,1.21, .97, .64, .23$ \\
\hline
\end{tabular}


Appendix B

List of Subroutines in FRAPCON-3 


\section{Appendix B. List of Subroutines in FRAPCON-3}

The list of subroutines in FRAPCON-3 is given in Table B-1 and Table B-2 with a brief description of the subroutine. Table B-1 lists those subroutines from the MATPRO library, and Table B-2 lists all the remaining subroutines (not found in MATPRO) in FRAPCON-3.

Table B-1. MATPRO Subroutines in FRAPCON-3

\begin{tabular}{|c|c|c|}
\hline Subroutine name & Model & Comments \\
\hline CAGROW & Cladding axial growth & $\begin{array}{l}\text { Modified-uses Franklin model for } \\
\text { PWR (Zr-4) and } 0.5^{*} \text { Franklin for } \\
\text { BWR (ZR-2). }\end{array}$ \\
\hline CANEAL & $\begin{array}{l}\text { Calculated general annealing of } \\
\text { cladding coldwork as a function of } \\
\text { temperature and fluence }\end{array}$ & $\begin{array}{l}\text { Called from top of FRPCON, } \\
\text { (before gas iteration loop) once per } \\
\text { time step--uses the axial average } \\
\text { current flux. }\end{array}$ \\
\hline CANISO & $\begin{array}{l}\text { Calculates coefficients of anisotropy } \\
\text { to be used in stress-strain } \\
\text { relationships for the cladding. }\end{array}$ & Not used. No call. \\
\hline CBRTTL & $\begin{array}{l}\text { Calculates cladding embrittlement } \\
\text { due to oxygen absorption. }\end{array}$ & Not used. No call. \\
\hline CCLAPS & $\begin{array}{l}\text { Calculates a cladding collapse } \\
\text { pressure. }\end{array}$ & Not used. No call. \\
\hline $\mathrm{CCP}$ & $\begin{array}{l}\text { Cladding specific heat at constant } \\
\text { pressure }\end{array}$ & Not used. No call. \\
\hline CCRPR & Cladding creep strain rate & Not used. Replaced by CREPR. \\
\hline CELAST & $\begin{array}{l}\text { Cladding elastic compliance } \\
\text { constants, based on orientation } \\
\text { parameters }\end{array}$ & Not used. No call. \\
\hline CELMOD & Cladding Young's modulus & \\
\hline CESIOD & $\begin{array}{l}\text { Calculates cesium and iodine } \\
\text { isotopes available in the gap }\end{array}$ & Not used. No call. \\
\hline CFATIG & $\begin{array}{l}\text { Fatigue constants and exponent for } \\
\text { low and high cycle fatigue failure }\end{array}$ & Not used. No call. \\
\hline
\end{tabular}


Table B-1. MATPRO Subroutines in FRAPCON-3 (Continued)

\begin{tabular}{|c|c|c|}
\hline Subroutine name & Model & Comments \\
\hline CHITOX & $\begin{array}{l}\text { Calculates Zr oxide and "xi" layer } \\
\text { thicknesses--this is for high } \\
\text { temperature oxidation only. }\end{array}$ & Not used. No call. \\
\hline CHUPTK & Cladding hydrogen uptake & $\begin{array}{l}\text { Modified to a pickup fraction of } \\
15 \% \text { for PWRs, based on data from } \\
\text { EPRI and DOE fuel surveillance } \\
\text { programs. }\end{array}$ \\
\hline CKMN & Strength coefficient and exponent & $\begin{array}{l}\text { Modified dependence on hydrogen } \\
\text { content and fluence based on EPRI } \\
\text { and DOE surveillance programs. } \\
\text { Temperature and coldwork } \\
\text { dependence unchanged. }\end{array}$ \\
\hline CHSP & $\begin{array}{l}\text { Addition of specific heat from } \\
\text { dissolution of hydrides }\end{array}$ & Not used. No call. \\
\hline CMHARD & $\begin{array}{l}\text { Cladding Meyer hardness as a } \\
\text { function of temperature }\end{array}$ & \\
\hline COBILD & $\begin{array}{l}\text { High-temperature oxidation--layer } \\
\text { thickness. }\end{array}$ & Not used. No call. \\
\hline CORROS & Cladding waterside corrosion & $\begin{array}{l}\text { Modified--uses the } 1987 \mathrm{EPRI} / \\
\text { ESCORE oxidation model for } \\
\text { PWRs and BWRs. }\end{array}$ \\
\hline CSHEAR & $\begin{array}{l}\text { Calculates shear modulus of } \\
\text { cladding based on type and } \\
\text { conditions. }\end{array}$ & \\
\hline CSIGMA & $\begin{array}{l}\text { True stress as a function of true } \\
\text { strain }\end{array}$ & Not used. No call. \\
\hline CSRUPT & $\begin{array}{l}\text { Fractional increase in cladding } \\
\text { diameter upon rupture }\end{array}$ & Not used. No call. \\
\hline CSTRAN & $\begin{array}{l}\text { True strain as a function of true } \\
\text { stress }\end{array}$ & Not used. No call. \\
\hline CSTRES & $\begin{array}{l}\text { Effective stress as a function of true } \\
\text { strain }\end{array}$ & Not used. No call. \\
\hline CSTRNI & $\begin{array}{l}\text { True strain as a function of initial } \\
\text { true strains and local current stresses }\end{array}$ & Not used. No call. \\
\hline CTHCON & Cladding thermal conductivity & \\
\hline
\end{tabular}


Table B-1. MATPRO Subroutines in FRAPCON-3 (Continued)

\begin{tabular}{|c|c|c|}
\hline Subroutine name & Model & Comments \\
\hline CTHEXP & $\begin{array}{l}\text { Cladding axial and diametral } \\
\text { thermal expansion }\end{array}$ & \\
\hline CIXTUR & $\begin{array}{l}\text { Calculates texture orientation } \\
\text { parameters from basal pole figure } \\
\text { data. }\end{array}$ & Not used. No call. \\
\hline ЕМССР & EM model for cladding specific heat & Not used. No call. \\
\hline EMCLEM & $\begin{array}{l}\text { EM version of cladding elastic } \\
\text { modulus }\end{array}$ & Not used. No call. \\
\hline EMCPIR & Cladding Poisson's ratio & Not used. No call. \\
\hline EMCTON & $\begin{array}{l}\text { EM version of cladding thermal } \\
\text { conductivity }\end{array}$ & Not used. No call. \\
\hline EMCTXP & $\begin{array}{l}\text { EM version of cladding thermal } \\
\text { expansion. }\end{array}$ & Not used. No call. \\
\hline EMFCP & EM version of fuel heat capacity & Not used. No call. \\
\hline EMFEOD & EM version of fuel elastic modulus & Not used. No call. \\
\hline EMFESS & EM version of fuel emissivity & Not used. No call. \\
\hline EMFPIR & EM version of fuel Poisson's ratio & Not used. No call. \\
\hline EMFTON & $\begin{array}{l}\text { EM version of fuel thermal } \\
\text { conductivity }\end{array}$ & Not used. No call. \\
\hline EMFTXP & $\begin{array}{l}\text { EM version of fuel thermal } \\
\text { expansion }\end{array}$ & Not used. No call. \\
\hline EMGTON & $\begin{array}{l}\text { EM version of gas thermal } \\
\text { conductivity }\end{array}$ & Not used. No call. \\
\hline EMSTRN & $\begin{array}{l}\text { EM version of cladding strain to } \\
\text { rupture }\end{array}$ & Not used. No call. \\
\hline FCP & Fuel specific heat & $\begin{array}{l}\text { Includes effects of plutonia and } \\
\text { effect of gadolinia added. }\end{array}$ \\
\hline FCREEP & Fuel creep strain & Not used. No call. \\
\hline FELMOD & Fuel elastic modulus & Not used. No call. \\
\hline FEMISS & Fuel emissivity & \\
\hline FFRACS & Fuel fracture stress & Not used. No call. \\
\hline
\end{tabular}


Table B-1. MATPRO Subroutines in FRAPCON-3 (Continued)

\begin{tabular}{|c|c|c|}
\hline Subroutine name & Model & Comments \\
\hline FGASRL & Fission gas release & Not used. \\
\hline FHOTPS & Fuel hot pressing & Not used. No call. \\
\hline FPOIR & Fuel Poisson's ratio & Not used. No call. \\
\hline FRESTR & Fuel restructuring & \\
\hline FSWELL & Fuel swelling & $\begin{array}{l}\text { Modified to include solid-swelling } \\
\text { only }\end{array}$ \\
\hline FTHCON & Fuel thermal conductivity & $\begin{array}{l}\text { Modified; changed to Lucuta (JNM } \\
\text { 11/96) model plus PNNL additions } \\
\text { for gadolinia effects and plutonia } \\
\text { effects. }\end{array}$ \\
\hline FTHEXP & Fuel thermal expansion & $\begin{array}{l}\text { Not modified; but checked against } \\
\text { other models. }\end{array}$ \\
\hline FUDENS & Fuel densification & \\
\hline FVAPRS & Fuel vapor pressure & Not used. No call. \\
\hline GTHCON & Gas thermal conductivity & $\begin{array}{l}\text { Includes gas mixtures. Now } \\
\text { modified to MATPRO-11, Rev. } 2 \\
\text { and unused Knudsen-range small- } \\
\text { gap correction was eliminated. }\end{array}$ \\
\hline GVISCO & Gas viscosity & \\
\hline PHYPRP & $\begin{array}{l}\text { Contains } \mathrm{UO}_{2} \text { and }(\mathrm{U}, \mathrm{Pu}) \mathrm{O}_{2} \text { and } \\
\text { zircaloy melting points and heats of } \\
\text { fusion, and the zirconium and } \\
\text { zircaloy alpha to beta phase } \\
\text { transition temperatures. }\end{array}$ & \\
\hline ZOEMIS & Zircaloy oxide emissivity & \\
\hline ZOTCON & $\begin{array}{l}\text { Zircaloy oxide layer thermal } \\
\text { conductivity }\end{array}$ & Called from FRPCON. \\
\hline
\end{tabular}


Table B-2. Alphabetical Listing of FRAPCON-3 Subroutines not from MATPRO

\begin{tabular}{|c|c|}
\hline File name & Description of subroutine or function \\
\hline ANS54 & Calculates fission gas release using ANS 5.4 standard. \\
\hline AXHEF & Calculates axial power shape factors. \\
\hline BES & Bessel functions used by radar. \\
\hline BES2 & Bessel functions used by tubrnp. \\
\hline BURNUP & Calculated burnup for node $\mathrm{j}$. \\
\hline CCREP & Coordinates the cladding creep step. Calls fcmi, which calls cladf, which calls crepr. \\
\hline CEXPAN & Calls cthexp--the cladding thermal expansion function. \\
\hline CHECK & Checks input values and writes error messages. \\
\hline CLADF & $\begin{array}{l}\text { Calculates cladding deformation of the free-standing cladding, including creep. } \\
\text { Calls cthexp, strain, and crepr. }\end{array}$ \\
\hline CLADRP & Calculates cladding $\Delta \mathrm{T}$; calls cthcon (cladding thermal conductivity function). \\
\hline CLDGRO & Calculates cladding incremental axial growth; calls cagrow. \\
\hline CLOCKX & Changes time to hh:mm:ss. \\
\hline CONDUC & Calls gaprs. Outputs gap conductance and gap temperature drop. \\
\hline COOLT & Calculated bulk coolant temperature and saturation temperature. \\
\hline COUPLE & Outputs interfacial pressure. Calls strain, stress, and creep. \\
\hline CRAP & Function that calculates effective stress as a function of creep rate strain. \\
\hline CREEP & Finds correct value of stress for given creep increment. \\
\hline CREPR & Calculates transverse cladding creep strain rate. \\
\hline DRIVER & Calls iofiles, echol, and frpcon. \\
\hline ECHOL & Writes the input echo into the output file. \\
\hline EDATE & Returns date as dd-mm-yy. \\
\hline EFFCON & Not accessible. \\
\hline EMDNS & Function to calculate densification of fuel (EM option). \\
\hline EMFTC & Function to calculate $\mathrm{UO}_{2}$ thermal conductivity (EM option). \\
\hline EMRLOC & Function to calculate relocation (EM option). \\
\hline EMSSF2 & Calculates emissivity factor for fuel-cladding gap. Calls zoemis. \\
\hline
\end{tabular}


Table B-2. Alphabetical Listing of FRAPCON-3 Subroutines not from MATPRO (Continued)

\begin{tabular}{|c|c|}
\hline File name & Description of subroutine or function \\
\hline ENERGY & Calculates fuel stored energy at volumetric average temperature. \\
\hline ERFD & Error function (called by ANS54 only). \\
\hline FCMI & Does elasto-plastic analysis. Calls cladf, gapcls, couple. \\
\hline FENTHL & Function to calculate enthalpy of fuel relative to absolute zero. \\
\hline FEXPAN & Calculates thermal expansion of the fuel. Calls fthexp. \\
\hline FGASRE & Calculates gas release. Calls either massih or ans 54 . \\
\hline FLMDRP & Calculates temperature drop across the film and the crud. \\
\hline FLUXD & Calculates flux depression coefficients. Calls voidp and radar. \\
\hline FLUXDP & Calculates flux depression (via RADAR or LASER). Not accessible. \\
\hline FORMFA & Function to calculate fuel ring averaged form factor or burnup. \\
\hline FRACAS & Calculates fuel and cladding mechanical states. Calls memset, fcmi, and fcmi2. \\
\hline FRAFORT & Not accessible. \\
\hline FRPCON & $\begin{array}{l}\text { Calls all major subcodes: setup, tapegn, caneal, store, burnup, turbo, phypro, } \\
\text { gaspro, coolt, flmdrp, corros, chuptk, cmlimit, cladrp, fluxd, cexpan, cldgro, } \\
\text { memset, tmpsub, fexan, swell, fracas, newgap, conduc, volume, gfasre, energy, } \\
\text { totgas, plnt, gspres, gasplt, ccreep, lprt, print } 2 \text {, pltout, and restfs. }\end{array}$ \\
\hline FUELTP & Calculates steady-state fuel temperatures. Calls fthcon and effcon. \\
\hline GAPCLS & $\begin{array}{l}\text { Finds the point of pellet-cladding gap closure for mechanical analysis if close to } \\
\text { closure for a given time step and axial node. }\end{array}$ \\
\hline GAPRS & Computes gap conductance. Calls emssf2, fthcon, chtcon, and gthcon. \\
\hline GAPT & Function to calculate gap thickness. Calls cladf. \\
\hline GASPLT & Outputs radioactive gas release predicted by ANS54. \\
\hline GASPRO & Computes the fission gas and helium production. \\
\hline GASREL & Removed from code. \\
\hline GSPRES & Calculates rod internal gas pressure. \\
\hline GRTLOC & Computes the radial outward relocation of the fuel pellet. \\
\hline INITIAL & Initializes program. Calls nemsset, lacinp, check, turbin, and printl. \\
\hline IOFILES & Reads input file. Calls EDATE and CLOCKX. \\
\hline
\end{tabular}


Table B-2. Alphabetical Listing of FRAPCON-3 Subroutines not from MATPRO (Continued)

\begin{tabular}{|c|c|}
\hline File name & Description of subroutine or function \\
\hline LACINP & Not used. Converts lace option input for matpro compatibility. \\
\hline LPRT & Stores average stresses and strains for use in summary printout. \\
\hline MASSIH & Fission gas release model based on Forsberg-Massih model. \\
\hline MEMSET & Fills pointer arrays (real variables). \\
\hline NEMSET & Fills pointer arrays (integer variables). \\
\hline NEWGAP & Calculates new estimate of gap temperature drop. \\
\hline PFHEAD & $\begin{array}{l}\text { Prints out program version identification at the top of every page. Calls propid and } \\
\text { edate. }\end{array}$ \\
\hline PLNT & $\begin{array}{l}\text { Calculates plenum temperature and hot plenum volume. Calls cthexp and cthcon } \\
\text { and uses the fuel axial expansion from volume. }\end{array}$ \\
\hline PLTINP & Prepares information for plotting. Calls pghead. \\
\hline PLTOUT & Stores plot data. Calls opnplt, wrtint, wrtchro, wrtinta, and wrtdbla. \\
\hline PONNTER & Sets up index pointers. Calls nemset, fr2ptr, and setpnt. \\
\hline POLATE & Function - guessing values. \\
\hline PRINT1 & Writes case setup output. Calls pghead. \\
\hline PRINT2 & Writes time-step and summary output. Calls pghead. \\
\hline PROPID & Prints out property ID numbers at top of printout pages. \\
\hline PWRDEP & Calculates radial power distribution based on LASER tables. \\
\hline RADAR & $\begin{array}{l}\text { Calculates array of relative radial power distribution as a function of burnup. Not } \\
\text { accessible. }\end{array}$ \\
\hline REPACK & Not accessible. \\
\hline RESTFS & Writes output for restart. \\
\hline SETPNT & Assigns correct pointer location ID. \\
\hline SETUP & $\begin{array}{l}\text { Reads and processes input and sets up pointers. Calls memset, nemset, pointer, } \\
\text { inital, and axhef. }\end{array}$ \\
\hline SIMQ & Solves simultaneous linear equations. \\
\hline STORE & Stores converged values of parameters. \\
\hline STRAIN & Calculates uniaxial strain. Calls cstres and cstran. \\
\hline
\end{tabular}


Table B-2. Alphabetical Listing of FRAPCON-3 Subroutines not from MATPRO (Continued)

\begin{tabular}{|l|l|}
\hline File name & \multicolumn{1}{|c|}{ Description of subroutine or function } \\
\hline STRESS & Calculates stress. Calls cstress. \\
\hline SWELL & Calculates fuel ring swelling and densification displacement. Calls fswell. \\
\hline TAPEGN & Used if FRAPCON is reading or writing to a tape. \\
\hline TERP & Function interpolates to find values. \\
\hline TMPSUB & Calculates fuel temperature distribution. Calls fueltp. \\
\hline TOTGAS & Calculates cumulative fission gas release, helium, and nitrogen for entire rod. \\
\hline TUBRNP & Calculates Pu buildup and radial power and burnup profiles as a function of burnup. \\
\hline TURBIN & Calculates initial concentrations of ${ }^{235,238} \mathrm{U}$ and ${ }^{239}, 240,241$, and $242 \mathrm{Pu}$. Calls tubrnp. \\
\hline TURBO & Calculates radial form factor used to calculate power and burnup. Calls tubrnp. \\
\hline VOIDP & Calculates a $\mathrm{H}_{2} \mathrm{O}$ void volume dependent value of "p" for radar. \\
\hline VOLUME & Calculates rod internal void volume. \\
\hline
\end{tabular}




\begin{tabular}{|c|c|}
\hline $\begin{array}{l}\text { NRC FORM } 335 \\
(2-89) \text { U.S. NUCLEAR REGULATORY COMMISSION } \\
\text { NRCM 1102, } \\
\text { 3201, 3202 } \\
\text { BIBLIOGRAPHIC DATA SHEET } \\
\text { (Şee instructions on the reverse) }\end{array}$ & $\begin{array}{l}\text { 1. REPORT NUMBER } \\
\text { (Assigned by NRC, Add Vol., Supp., Rev., } \\
\text { and Addendum Numbers, if any.) } \\
\text { NUREG/CR-6534 Vol } 2\end{array}$ \\
\hline \multirow{4}{*}{$\begin{array}{l}\text { 2. TITLE AND SUBTITLE } \\
\text { FRAPCON-3: A Computer Code for the Calculation of Steady-State, Thermal-Mechanical } \\
\text { Behavior of Oxide Fuel Rods for High Burnup }\end{array}$} & \multirow{2}{*}{$\begin{array}{c}\text { PNNL - } 11513 \\
\text { DATE REPORT PUBLISHED }\end{array}$} \\
\hline & \\
\hline & \begin{tabular}{c|c|} 
MONTH & YEAR \\
December & 1997 \\
\end{tabular} \\
\hline & $\begin{array}{l}\text { 4. FIN OR GRANT NUMBER } \\
\text { W6200 }\end{array}$ \\
\hline 5. AUTHOR(S) & 6. TYPE OF REPORT \\
\hline $\begin{array}{l}\text { G. A. BERNA (GABC) } \\
\text { C. E. BEYER (PNNL) }\end{array}$ & computer code manual \\
\hline $\begin{array}{l}\text { K. L. DAVIS (INEEL) } \\
\text { D. D. LANNING (PNNL) }\end{array}$ & $\begin{array}{l}\text { 7. PERIOD COVERED (Inclusive Dafes) } \\
1997\end{array}$ \\
\hline
\end{tabular}

8. PERFORMING ORGANIZATION - NAME AND ADDRESS (If NRC, provide Division, Office or Region, U.S. Nuclear Regulatory Commission, and mailing address; if contractor, provide name and mailing address.)

Pacific Northwest National Laboratory (PNNL) Idaho Nat'l Engr. \& Envir'l Lab. (INEEL)

Richland, Washington 99352-0999
Idaho Falls, Idaho $83415-3850$
Subcontractor:

Gary A. Berna Consulting (GABC)

Idaho Falls, Idaho 83404-6131

9. SPONSORING ORGANIZATION - NAME AND ADDRESS (If NRC, type "Same as above"; if contractor, provide NRC Division, Office or Region, U.S. Nuclear Regulatory Commission, and mailing address.)

Division of Systems Technology

Office of Nuclear Regulatory Research

U.S. Nuclear Regulatory Commission

Washington, DC 20555-0001

10. SUPPLEMENTARY NOTES

H. Scott, NRC Project Manager

11. ABSTRACT (200 words or less)

FRAPCON-3 is a FORTRAN IV computer code that calculates the steady-state response of light water reactor fuel rods during long-term burnup. The code calculates the temperature, pressure, and deformation of a fuel rod as functions of time-dependent fuel rod power and coolant boundary conditions. The phenomena modeled by the code include 1) heat conduction through the fuel and cladding, 2) cladding elastic and plastic deformation, 3) fuel-cladding mechanical interaction, 4) fission gas release, 5) fuel rod internal gas pressure, 6) heat transfer between fuel and cladding, 7) cladding oxidation, and 8) heat transfer from cladding to coolant. The code contains necessary material properties, water properties, and heat-transfer correlations. The codes' integral predictions of mechanical behavior have not been assessed against a data base, e.g., cladding strain or failure data. Therefore, it is recommended that the code not be used for analyses of cladding stress or strain. FRAPCON-3 is programmed for use on both mainframe computers and UNIX-based workstations such as DEC 5000 or SUN Sparcstation 10. It is also programmed for personal computers with FORTRAN compiler software and at least 8 to 10 megabytes of random access memory (RAM).

12. KEY WORDS/DESCRIPTORS (List words or phrases that will assist researchers in locating the report.)

Computer Code

Fission Gas Release

Cladding Creepdown

Fuel Swelling
Code Assessment

Fuel Rod Performance

High Burnup

Sample Problems
Input Instructions

Cladding Corrosion

Pellet Centerline Temperature

Gap Conductance

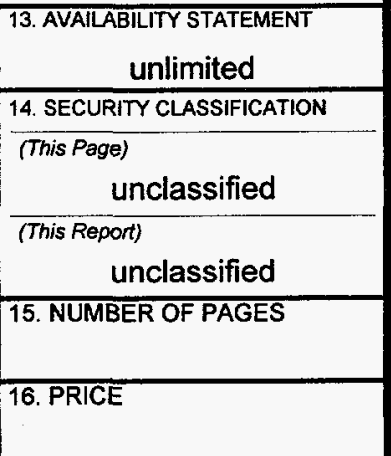

